LBL-6871 5.2 UC-97e

TID-4500-R66

DEPARTMENT OF ENERGY

\title{
Potential Electricity Impacts of a 1978 California Drought
}

January 1978

ENERGY ANALYSIS PROGRAM

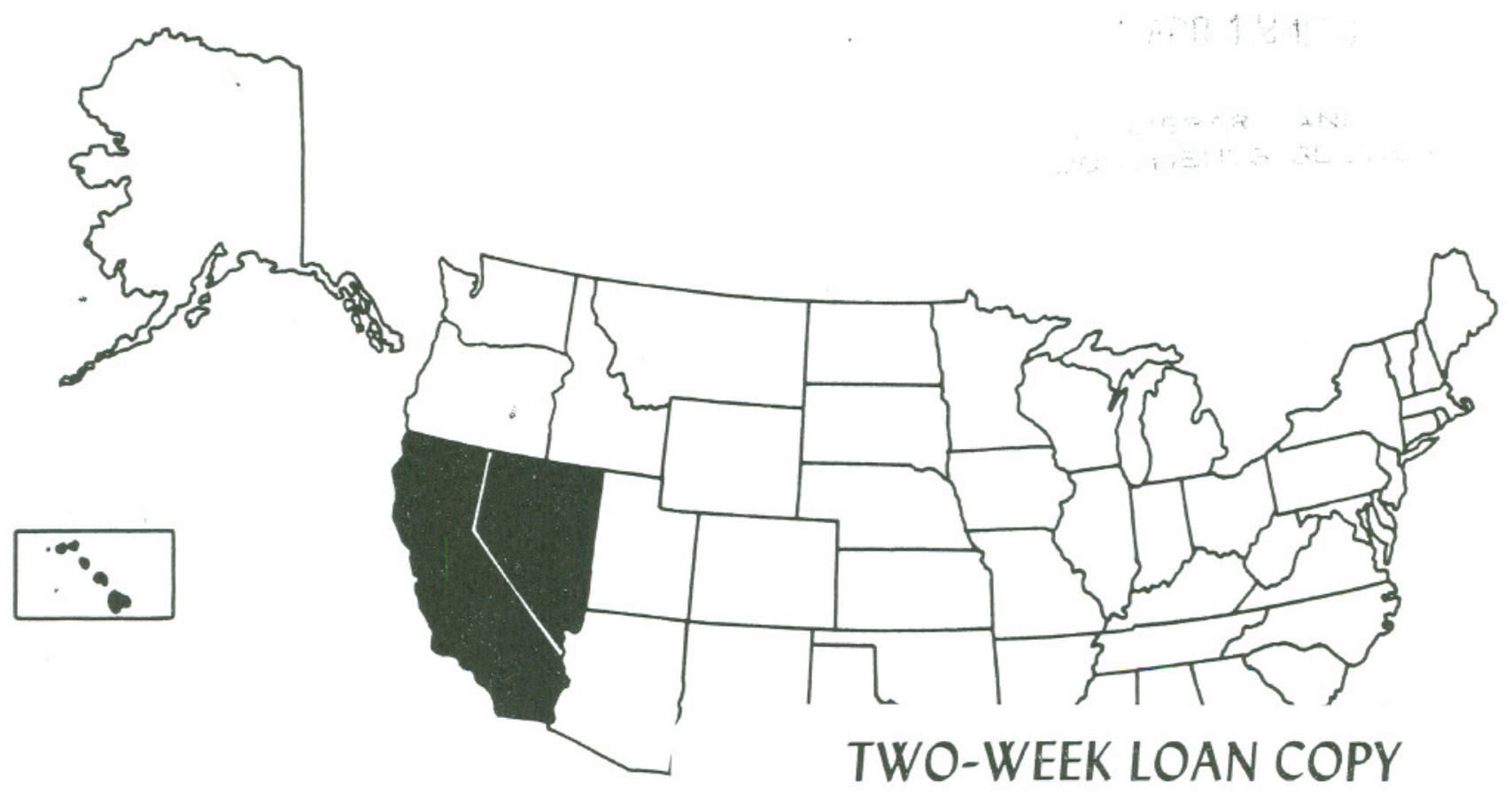

This is a Library Circulating Copy which may be borrowed for two weeks. For a personal retention copy, call Tech. Info. Dívision, Ext. 5716 
POTENTIAL ELECTRICITY IMPACTS OF A 1978 CALIFORNIA DROUGHT

Project Coordinator: Jayant Sathaye

Contributors:

Jayant Sathaye, Richard Sextro, Carl Blumstein, Henry Ruderman, Ronald Ritschard, Jim McMahon,* Dan Kirshner,* Richard Brandi, Rae Watkins, Peter Chan, Joshua Kay, Karen Tsao, and Lorraine Kelleher

January 1978

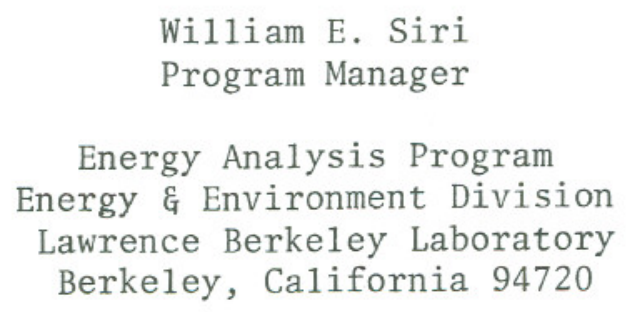

* Consultants to Lawrence Berkeley Laboratory 
ACKNOWLEDGEMENTS

We wish to thank all the individuals and organizations who provided us with data, advice and insight into the effects of the drought on California electricity supply and demand. We appreciated especially the cooperation of the California electric utility companies and government agencies who provided us with data that were crucial to the study. In particular we gratefully acknowledge the support of Paul Cho and Ray Cooper of the Department of Energy in sponsoring this study and Dennis Wong of the San Francisco Operations Office whose technical and administrative assistance was invaluable in expediting the study. We wish also to thank Bob Ham and his staff in the Emergency Planning Office of the California Energy Resources Conservation and Development Commission who helped supply utility data and whose advice was invaluable, and staff members of the Pacific Gas and Electric Company, Southern California Edison, Los Angeles Department of Water and Power, Department of Water Resources, Bonneville Power Administration, California Institute of Technology, California Air Resources Board, South Coast Air Quality Management District, California Public Utilities Commission, Emergency Drought Planning Office and several local agencies throughout the state.

Other persons from Lawrence Berkeley Laboratory who contributed to the study include Louise Millard and Sandy Sanford who helped in organizing the conference and Louis Robinson and Mary Sharp who organized the press releases and coordinated press activities at the conference.

Special thanks for secretarial and administrative assistance go to Nancy Schorn for organizing the conference and the report and to Sharran Zeleke for typing it.

Work supported by the U. S. Department of Energy. 
Table of Contents

Section

Page

List of Tables.............. . . iv

List of Figures . . . . . . . . . . . . vi

SUMMARY . . . . . . . . . . . . . . vii

E1ectricity Demand and Supply During 1977 . ix

Electricity Demand and Supp1y During 1978 . $\mathrm{x}$

Remedial Measures for Demand . . . . . . xiv

INTRODUCTION . . . . . . . . . . . . . . . . . 1

ELECTRICITY DEMAND . . . . . . . . . . . . 5

Electricity Use During 1977 . . . . . . . 5

Demand Appraisal for 1978 . . . . . . . . 13

3 ELECTRICITY SUPPLY . . . . . . . . . . . 17

Supply Assessment for 1977 . . . . . . . 17

Supply Availability for 1978 . . . . . . 18

4 IMPACTS OF SUPPLY OPTIONS . . . . . . . . . 51

Environmental Effects . . . . . . . . 51

Average Prices for Pacific Gas and Electric

Company .. . . . . . . . . . . . . 62

5

REMEDIAL MEASURES FOR DEMAND . . . . . . . 73

Conservation . . . . . . . . . . . . . . 74

Load Management . . . . . . . . . . 80

Load Shedding . . . . . . . . . . . . . 88

APPENDIX A CAPACITY AND ENERGY SUMMARY . . . . . . . . . 95

APPENDIX B FORCED OUTAGE RATES . . . . . . . . . . . . . 101

APPENDIX C CALIFORNIA AGRICULTURAL ENERGY DEMAND . . . . . 109

Introduction . . . . . . . . . . . . 109

Energy Use in Agriculture (1977) . . . . . . 112

Projected Energy Demand for Agricultural Pumping in the Central Valley (1978) . . . . . . . . 115

References . . . . . . . . . . . . . 119 
PGEE Quarterly Sales Comparisons . . . . . . . 6

Statewide Quarterly Sales Comparisons . . . . . 7

Comparison of Historical and Predicted Demand for Energy and Peak Capacity . . . . . . . . 11

PG\&్E Service Area Peak Loads and Loads Adjusted

for Temperature . . . . . . . . . . . . 12

Summary of LBL Scenarios for Energy and Peak Demand . . . . . . . . . . . . . . . 14

Month1y E1ectrical Energy Loads for PGGE for 1977 and Three Load Cases for 1978. . . . . . . 16

Reservoir Storage on October 1 . . . . . . . 21

PGE्E Area 1978 Hydroelectric Resources Assuming Average Precipitation . . . . . . . . . . 24

PGg్E Area 1978 Hydroelectric Resources Assuming 1977 Runoff . . . . . . . . . . . . . . . 26

New Generating Units Expected in 1978 . . . . . 29

Energy Supply and Demand Balances for PG\&E for 1978 Assuming Continued Drought Conditions . . . 32

Peak Load Capacity for PG\&E for the Summer of 1978 . . . . . . . . . . . . . . . 33

Statewide Supply-Demand Balances for Energy . . . 35

Statewide Capacity Balance and Reserve Margins. . 36

Summer Peak Load Order by Month for 1977 and Estimated Loads for 1978 . . . . . . . . . . 47

Statewide Loss-of-Load-Probability Results for August 1978 . . . . . . . . . . . . . . . . .

History and Outlook of Power Plant Fossil Fuel Use and Emissions in South Coast Air Quality Management District . . . . . . . . . 56

Estimated Peak Day Emissions from Power Plants in South Coast Air Quality Management District, 1978

Emission Factors for Southern California Electric Utilities . . . . . . . . . . . . . . . 
List of Tables (continued)

$\underline{\text { Table }}$

21

22

23

24

25

A-1

A-2

B-1

C-1

C-2

C -3
Tit1e

$\underline{\text { Page }}$

1978 Estimates of Variables Constant Across Scenarios . . . . . . . . . . . . . . 65

Estimated 1978 Fuel Expense . . . . . . . . 66

PG\&E Generation in 1976 by Fuel Type and Average Price . . . . . . . . . . . . 66

Dry Year 1978 PGGE Generation by Fuel Type and Average Electricity Price . . . . . . . . 69

Wet Year 1978 PG\&्षE Generation by Fue1 Type and Average Electricity Price . . . . . . . . 70

Nuclear and Geotherma1 Generation Assumptions . . 72 PGEE's Schedule No. A-17 . . . . . . . . . . 83 PGE్E's Schedule No. A-18 . . . . . . . . . . . 89

Energy Generating Capability of Major Southern California Electric Utility Companies . . . . . 9,6

Southern California Resources Available for Summer 1978 . . . . . . . . . . . . . . . . . 97

Forced Outage Rates for Individual Power Plant Units and Major Interconnecting Transmission Lines . . . . . . . . . . . . . . 103

California Precipitation . . . . . . . . . 111

Monthly Electricity Sales to Agriculture (197577) PG\&E Service Area . . . . . . . . . . . 113

Energy Use and Generation for State and Federal

Water Conveyance Projects . . . . . . . . 118 
List of Figures

$\underline{\text { Figure }}$

1

Distribution of Annual Average Daily $\mathrm{NO}_{\mathrm{x}}$ Emissions in the South Coast Air Basin, ${ }^{x}$ 1972-73, Stationary Sources . . . . . . . 54 Diablo Canyon Forced Outage Rate . . . . . . 107 Reduced Precipitation Due to the Drought by Area. 110 Electricity Sales to Agriculture. . . . . . . . 114 
POTENTIAL ELECTRICITY IMPACTS OF A 1978 CALIFORNIA DROUGHT

\author{
SUMMARY
}

California has endured a severe drought for the past two years. As a consequence surface water supplies during 1977 decreased to leve1s not experienced in the recent history of California. Hydroelectric supplies, which rely on surface runoff, also decreased to record lows raising questions regarding the adequacy of electricity supplies to meet summer peaks during 1977 and 1978. Through 1977 electricity supplies, aided by conservation of electricity by consumers, power pooling and other measures were adequate to meet demand. However, supplies were more expensive due to increased reliance on thermal generation to compensate for hydroelectric 1osses.

If the drought were to continue for another year, how would it affect electricity supply and demand in California? What would be the impact on power plant emissions and on electricity rates? And finally, what remedial measures should be considered in prudent planning? Key aspects of these questions are analyzed in this study sponsored by the U.S. Department of Energy. To analyze the impact of supply options on reliability and electricity prices, two separate models were modified and implemented. These models along with the overall methodology, although implemented primarily with data for 1978 in appropriate sections of the report, would be generally applicable for analyzing the adequacy of electricity supply during any year.

In our analysis, electricity demand and supply during 1977 are reviewed before analyzing the prospective situation during 1978. Hydroelectric supplies for 1978 are assumed at the level anticipated by the electric utility companies. These supply estimates are based on the 1977 levels of runoff. The hydroelectricity thus generated would be slightly lower than that estimated for 1977. Also on the supply side, because of the uncertainty associated with the introduction of the Diablo Canyon 1 nuclear power plant, we analyzed the supply options with and without Diablo Canyon Unit 1. The major findings of our study discussed later in detail are presented below: 
1. Statewide electricity demand during 1977 did not increase at the rate anticipated by the electric utility companies. Demand in the Pacific Gas and Electric Company (PG\&E) service area, the area most affected by the drought, actually declined from 1976 levels. The significant factors that may have contributed to reduced demand are: voltage reduction, a sharp increase in electricity rates, reduction in electricity requirements for surface water pumping, lower summer temperatures and "heightened conservation consciousness" induced by the drought.

2. In 1978, with statewide coordination of electricity resources and continued energy conservation on the part of consumers, electricity supplies would be adequate to meet projected electricity demands with sufficient reserves during the summer peak months. Supplies, at a minimum reserve margin of 12.7 percent, would be adequate without the inclusion of Diablo Canyon nuclear power plant in the PG\&E supp1y system.

3. Transfers of electricity generated from oil-fired power plants in the South Coast Air Basin to PG\&E could lead to as much as a ten percent increase in nitrogen oxide emissions from power plants in this basin during the peak summer months. The already frequent violations of air quality standards in this basin may increase because of these emissions. At the same time due to the mandated lower sulfur content of oil for 1978, sulfur oxide emissions will decrease markedly.

The difference in 1978 electricity prices between a normal versus dry weather year would be almost 20 percent for the PG\&E system. This large difference results from the increased oil and nuclear generation, which replaces inexpensive hydroelectric generation. Inclusion of Diablo Canyon nuclear result in a maximum change of less than three percent in electricity prices.

4. Although 1978 electricity supplies appear adequate, implementation of remedial measures would provide insurance against unforeseen systems failures and would result in long-term benefits. Conservation, load management and load shedding practices which could be implemented in California are therefore examined in detail. 
ELECTRICITY DEMAND AND SUPPLY DURING 1977

Statewide electrical energy sales during the first and second quarters of 1977 increased 1.6 percent and 0.9 percent over sales in the corresponding quarters of 1976. For the PG\&E service area, where hydroelectric generation capability has been most severely affected, the figures are 0.5 percent and -1.5 percent, respectively, during the same period and -1.0 percent for the entire year. Peak demand during 1977 dropped for both statewide coincident demand and for the PG\&E service area from the 1976 levels. These changes in energy sales and peak demand are well below the increases forecasted by the electric utility companies. The main factors contributing to this slower growth appear to be 1) the voltage reduction instituted by the utility companies, although this has not yet been fully implemented statewide, 2) the substantial increase in electricity prices over the past year, 3) a generally cooler summer with lower peak temperatures, 4) reduced energy requirements for water pumping, and 5) the "heightened conservation consciousness" induced in part by the drought and by public information campaigns. Adequate data were not available, however, to develop a reliable estimate of the contribution made by each of these factors.

Industrial and agricultural electricity sales between the first two quarters of 1976 and 1977 increased faster than residential and commercia1 sales both statewide and in the PG\&E service area. Second quarter 1977 commercial sales as compared with second quarter 1976 sales actually declined in both the PG\&E service area and statewide. Sales to agriculture for the first three quarters have increased from 4.34 billion $\mathrm{kWh}$ in 1976 to 4.47 billion $\mathrm{kWh}$ in 1977 in the PG\&E service area. These should be compared with sales of 3.59 billion $\mathrm{kWh}$ during a comparable period in 1975 , a "normal" water year.

Decreased water deliveries in 1977 resulted in reduced energy requirements for water pumping in both the Central Valley Project and State Water Project. In 1976 the electricity requirements for the two projects net of recovery generation were 1.2 billion $\mathrm{kWh}$ and 3.0 billion $\mathrm{kWh}$, respectively, whereas in 1977 the corresponding electricity requirements were 0.6 billion $\mathrm{kWh}$ and 1.6 billion $\mathrm{kWh}$. 
On the electricity supply side there appear to have been no major problems through 1977. In part preplanned coordination among the utilities for energy transfers from southern California and the Pacific Northwest to PG\&E allowed the utility to maintain sufficient reserves throughout the year. Except for a brief interval in early September when reserve margins for PG\&E dropped below 6 percent the utility experienced no major supply problems. Statewide, utilities had access to ample fuel supplies; in fact southern California utilities received considerably more natural gas from their suppliers than anticipated. This unexpected supply did result in increased oil storage costs for the utilities; however, the use of gas instead of oil generally decreased pollutant emissions and fuel costs.

ELECTRICITY DEMAND AND SUPPLY DURING 1978

Demand

The four major utility companies in California, Pacific Gas \& Electric, Southern California Edison (SCE), Los Angeles Department of Water and Power (LADWP), and San Diego Gas \& ELectric (SDG\&E), joint1y submitted a 1978 electricity demand and supply forecast to the California Energy $\mathrm{Re}-$ sources Conservation and Development Commission (CERCDC) in August 1977. The estimated statewide electricity demand for 1978 is 3.9 percent higher than the 1977 forecast, and coincident peak demand is up 4.7 percent over the 1977 forecast. Comparable estimates for the PG\&E service area are a 4.7 percent increase in both electricity demand and peak load over the 1977 estimates. The actual demand through July 1977 in both cases has been we11 below the 1977 forecast.

Because PGEE is the utility most severely affected by the drought, we analyzed three 1978 demand scenarios for PG\&E. The first assumed a 4.7 percent increase in electricity demand, the second assumed no growth in demand over 1977, and the third postulated a two percent decrease in demand. The growth rate in the first scenario is the same as the rate forecasted by PG\&E, whereas the two lower estimates are motivated by the declining growth recorded between 1976 and 1977. The monthly distribution of demand in each case was based on 1977 recorded and estimated demand for 
PGGE. Demand for 1978 in the other utility service areas was assumed to remain at the same level forecasted by those utilities in their submittals. From a separate analysis of agricultural energy demand, the total groundwater pumped in the Central Valley for agriculture in 1977 was estimated to be 14.7 million acre-feet. In 1978, the groundwater that will be used to make up for surface water deficits is expected to reach 17 million acre-feet. Since this water will be pumped from depths that are 5 to 10 feet lower, on the average, than those of last year, the estimated electrical demand in agriculture will increase about 11 percent over 1977 levels. The five reasons stated earlier for the low demand in 1977 compared to PGGE forecasts for 1977 provide some clues to the demand levels for 1978 in the event of a continued drought. Voltage reduction has already been introduced, and further selective reductions may be possible. The decrease in water consumption from 1977 to 1978 will be smaller than the reduction during 1977, thus producing a smaller decrease in sales than it did this year. Electricity price increases next year are likely to be less than this year since hydroelectric supplies will decrease only slightly from the already low supplies and the largest factor in these price increases has been the additional cost of oil-fired electricity generation. The actual impact on sales will depend on the price differential, the absolute price and the residual impact of the price increase persisting in 1978 .

Temperature changes primarily affect system peak loads. Milder temperatures prevailed during 1977 with most incidences of high temperatures occurring on weekends, normally a time of lower peak demand. Although the peaks were lower than anticipated this year, the high peak levels forecasted by the utilities could come about if high temperatures prevail next summer. PGGE in its forecasts projected a 4.7 percent growth in sales and in peak demand. However, the factors considered above suggest that in the event the drought continues, 1978 PG\&E sales may be less than projected by the company and may not be significantly different from sales in 1977 . 
Supp1y

Our supply scenarios are based primarily on the utility submittals to CERCDC with the changes presented in the next three paragraphs. Diablo Canyon Units 1 and 2 (1060 MWe each) are presently in the 1 icensing process. The date on which these nuclear power plants may be placed in service will be determined 1argely by the Nuclear Regulatory Commission (NRC). It now appears that August is the earliest possible startup date for Unit 1, with Unit 2 delayed until 1979. We have analyzed the supply situation with and without Diablo Canyon Unit 1.

For PG\&E, Geysers geothermal Units 12 (106 MWe) and 15 (55 MWe) have also been delayed until September and December 1978, respectively. The nuclear unit at Humboldt Bay (63 MWe), out of service since July 1976, is not expected to return during 1978. For SCE and SDGqE, the planned refueling of San Onofre (430 MWe) in July and August has been delayed past September, based on information from SCE and CERCDC.

Finally, we assume full use of both the Castaic pumped storage facility (1170 MWe) operated by LADWP and the LADWP share of the Pacific Northwest DC intertie (an additional $200 \mathrm{MWe}$ ). No changes were assumed in the 6731 MWe statewide peak hydroelectric capacity projected for a continuing drought year, which is down from the 7382 MWe projected for 1977. Favorable changes in weather would increase this figure as we11 as increase the availability of hydroelectric imports from the Pacific Northwest.

Our analysis indicates that any of these supply scenarios provide adequate electric energy and power to meet the projected demand. Our worst case assumptions yield a statewide capacity reserve margin of 12.7 percent for the peak month of August 1978, which is the same as forecasted by the utilities in their joint submittal. Under these same conditions, the excess energy generation capability drops to a minimum of 6.5 percent in July 1978, compared with the utilities' estimate of 8.3 percent.

Reliability of the coordinated electricity supply system in California and of the PG\&E supply system, measured by the loss-of-1oad probability (LOLP) index, was estimated for various supply options. Our calculations indicate that with the change in statewide resources mentioned above and without Diablo Canyon Unit 1, there is sufficient capacity to reliably meet the statewide coincident peak load predicted by the utilities, with 
the monthly LOLP a factor of three below the PG\&E risk criterion of 8.5 $x 10^{-3}$. For the PG\&E system we have estimated the amount of additional support required to meet the system load with and without Diablo Canyon Unit 1. To meet PGEE's predicted loads with a monthly LOLP of $8.5 \times 10^{-3}$, the utility would require $1300 \mathrm{MWe}$ and $1900 \mathrm{MWe}$, respectively, of outside support above and beyond the "perfect" support of $600 \mathrm{MWe}$. While this level of support is available from other utility companies, as shown in their supply forecasts, it requires significant loading of the available transmission line capacity. Interconnections between PG\&E and the Pacific Northwest, and with SCE can handle these capacities, but with greater system consequences if transmission outages occur.

Impacts

Based on these separate demand and supply scenarios average prices* for PG\&E were estimated for two meteorological cases for 1978. The first is for the amount of hydroelectric generation anticipated if the drought continues in 1978 and the second for wet year hydroelectric generation equivalent to that in the 1975 calendar year. The various demand and supply scenarios do not significantly alter the average prices. On the other hand, the dry and wet year hydroelectric generation changes the average price by 20 percent. Average electricity prices for a dry year cluster around $4.2 \phi / \mathrm{kWh}$ and for a wet year around $3.5 \phi / \mathrm{kWh}$ for these scenarios. Having Diablo Canyon in the supply system reduces the prices only slightly due to decreased expense for fuel oil and for electricity transfers, with the decrease more pronounced during a dry year. Prices also decrease slightly with an increase in sales as the returns to invested capital are distributed over a larger sales base.

In the South Coast Air Basin power plants are major contributors to sulfur oxide $\left(\mathrm{SO}_{X}\right)$ and nitrogen oxide $\left(\mathrm{NO}_{X}\right)$ emissions. The formation of sulfur oxides is directly linked to the sulfur content of fuel oil, which is mandated by law to average 0.25 percent sulfur in 1978 , down from the estimated average level of 0.32 percent in 1977. Average sulfur oxide emissions (156 tons/day) in 1978 are therefore expected to be we11 below the

* The term average price refers to average revenues at an assumed 9.2 percent rate of return. 
1977 levels (208 tons/day). Increased fuel oil use in recent years has led to a dramatic increase in $\mathrm{NO}_{X}$ emissions in power plants, up 70 percent in 1977 from 1976 levels (163 vs. 95 tons/day). During 1978 these emissions will increase another 5 to 10 percent. Any transfer of energy from the South Coast Air Basin to PG\&E will add as much as ten percent to the power plant $\mathrm{SO}_{\mathrm{X}}$ and $\mathrm{NO}_{\mathrm{X}}$ emissions during the summer peak months. Unfortunately, it is impossible at this time to determine a simple quantitative relationship between power plant emissions and air quality, which is a complex function of meteorology, topography, the interaction of pollutants and removal processes. It appears that the average meteorological conditions relevant to photochemical smog formation in this air basin were not affected by the drought in 1977 .

REMEDIAL MEASURES FOR DEMAND

In view of the supply alternatives that are available to meet a continued drought, it does not appear that measures to restrain demand are essential to avert an emergency. However, there are several reasons why any plan for dealing with electricity needs during the drought should contain measures aimed at controlling demand. First, a growth in demand significantly beyond the 4.7 percent projected by PG\&E could seriously strain the supply system. Second, the available supply alternatives are more costly, hence measures which can avert the need for some of the alternatives will reduce the financial burden that must be borne by the California economy. Third, demand control can provide insurance against unforeseen system failures or conditions such as extremely hot weather during the summer which might otherwise create excessive peak demand. Finally, measures for moderating demand srowth should be pursued because of long-term benefits. The heightened conservation consciousness of consumers during the drought should increase the receptivity to energy conservation initiatives and thus provides an opportunity to make progress toward long-term objectives.

We have examined three strategies for reducing demand: conservation, load management, and load shedding. The conservation strategy aims 
at reducing electricity consumption. The load management strategy aims at shifting electricity consumption from periods when demand for electricity is high to periods of lower demand. The load shedding strategy aims at reducing electrical loads during extreme peaks in demand or at times when equipment failures create a sudden shortage of generating capacity.

During the next year several conservation programs could be implemented. As a first step both the federal and state agencies need to place increased emphasis on an expanded public information program. A second step, which would be warranted if the situation grows more serious, would be the enforcement of CPUC Rule 14.1 especially where it affects conspicuous consumption. The last step would be mandatory reductions in electricity use by all customers. While such a program is not likely to be required, it is prudent to develop a plan for implementing such reductions. Such programs can be highly effective as evidenced in 1973 in the LADWP service area where an overall saving of more than 12 percent was achieved during the Arab oil embargo.

The only load management effort directly related to the drought so far has been the rather modest advertising campaigns by the utilities and by CERCDC. As a continuing program, however, both the CPUC and CERCDC are requiring utilities to implement time-of-use pricing. Two steps that could be taken to increase load management in the current situation are to intensify the public information campaign and to accelerate the implementation of time-of-use rates. It may also be possible to make improvements in existing time-of-use rate schedules, especially in their treatment of the energy cost adjustments.

Load shedding as the term is used here means to discontinue the operation of electricity-using equipment on short notice; it may be done either by the customer or by the utility. If the drought continues and neither the supply alternatives nor energy conservation and load management are sufficient to maintain the supply-demand balance, then load shedding will be necessary to maintain supply system operation. The first to be affected by load shedding would be those customers who were contractua11y obligated to reduce their loads when requested to do so. Efforts then would probably be made to achieve voluntary load reductions based on appeals to the public. If this were not sufficient, rotating blackouts would have to be initiated. One objective in planning for a possible continuation of 
the drought is to increase the probable response in the first two steps above so that losses associated with indiscriminant blackouts can be avoided.

During 1977 PGEE identified large customers who would be willing voluntarily to shed a combined load of $500 \mathrm{MW}$, roughly three percent of its load. One strategy that might be implemented if the drought continues is an incentive program which would encourage more customers to participate in this voluntary arrangement.

In conclusion, the analysis of electricity supply and demand highlights two themes which need to be emphasized. The first is increased statewide coordination not only among the electric utility companies, but also among government agencies and the utilities. The second is increased electricity conservation and load management practiced by consumers. In anticipation of a drought during 1977 the three major private utilities, PG\&E, SCE and SDG\&E and the municipal utility LADWP made arrangements for a smooth transfer of electricity to PG\&E on a contractual basis. These transfers helped PG\&E meet its loads without resorting to any drastic load reduction measures. Increased electricity conservation practiced by consumers whether induced by higher prices, voltage reduction, or heightened awareness of energy consumption decreased 1977 electricity use below the 1976 leve1s.

The commendable response of both the utility companies and electricity consumers to the electricity supp1y constraints experienced during 1977 should not go unobserved. The primary lesson to be learned from this response to the drought is that there is considerable potential for coordination of electricity supplies and for electricity savings through conservation in California. These two themes should be further explored by concerned agencies for their applicability during a normal year. 
SECTION 1

\section{INTRODUCTION}

During the past two years California has endured a drought whose severity is unmatched by any previous two-year period in the recorded history of the state. Reservoirs which normally supply a substantial fraction of California's water and nearly a quarter of the state's electrical energy needs reached al1-time lows in 1977. Hydroelectric generation during 1977 provided only a fraction of its normal contribution to electricity supply. The success in meeting peak demands without resorting to load shedding in 1977, even if at times the reserve margin was small, is a tribute to skillful use of thermal electric generating capacity, power pooling and voluntary conservation of electricity by consumers. However, the added use of oil and gas for thermal generation of electricity necessary to compensate for losses in hydroelectric production resulted in higher electricity rates and increased air pollutants in already impacted air sheds.

If the drought were to continue for another year, what would be the effect on California's electricity supply and demand? What would be the impact on power plant emissions and electricity rates? What remedial measures should be considered in prudent planning? This study, in cooperation with the San Francisco Operations Office and the Division of Technology Overview of the Departmentof Energy was designed to conduct an early and timely investigation of the key aspects of these questions in order to avoidlast minute crisis solutions. To analyze the impact of supply options on reliability and electricity prices, two separate models were modified and implemented. These models along with the overall methodology, although implemented primarily with data for 1978 in appropriate sections of the report, would be generally applicable for analyzing the adequacy of electricity supply during any year.

Specifically the study was designed to 1) examine the effects of the drought on electricity supply and demand during 1977, 2) anticipate the consequences of a continued drought on electricity supply and demand during 1978, 3) assess the impacts of supply options on electricity rates 
and on air pollution, 4) evaluate strategies to reduce the probability of future electricity shortages and 5) convene a conference to promote discussion of ideas to mitigate the adverse impacts of the drought.

During 1977 the drought forced electric utility companies and customers to make several changes in the electricity supply and use patterns. These changes in patterns provide some insight into the possible demand for electricity during 1978. In section 2 we first analyze the growth in different components of demand during 1977. Based on this analysis, various possible growth levels for peak loads and energy demand are projected for 1978. A detailed description of agricultural demand is presented in Appendix C.

Electricity supplies, in spite of the drought during 1977, were adequate to meet demand during the entire year. A continuation of the drought would result in further reduction of depleted hydroelectric supplies. Section 3 examines the alternative supplies available statewide to replenish the hydroelectric supplies, especially for the PG\&E service area. The adequacy of these supplies to meet the projected demands during 1978 is evaluated along with estimates of system reliability for severa1 supp1y options.

Two major impacts of the drought on electricity supply have been the increase in electricity rates and in air pollution due to the increased thermal generation of electricity. In Section 4 we focus on the impacts of various supply options for 1978 on 1) average price of electricity for the Pacific Gas \& Electric Company (PG\&E) and 2) on air pollutants in the South Coast Air Basin. Average prices were estimated on1y for PGEE, because it is the utility most affected by the drought. Air pollutants were examined in the South Coast Air Basin because additional thermal generation to supply electricity to PG\&E would increase the already high levels of air pollutants.

To match electricity demand and supply either demand or supply or both could be changed. Within the relatively short span of time before next summer, when electricity use typically peaks, it would be difficult to augment existing and planned supplies. Most of the practicable changes are therefore confined to reducing demand. In Section 5 three types of remedial measures to reduce demand are examined-conservation, load management and load shedding. 
This report makes no attempt to forecast electricity demand for 1978 . Instead we examine three demand projections based on the demand level in 1977 to bracket the probable range for 1978. On the supply side, because of the uncertainty associated with the introduction of the Diablo Canyon power plant, we analyze the supply options with and without Diablo Canyon Unit 1. Hydroelectric generation for 1978 is assumed to be at the leve1 anticipated by the utilities if the drought were to continue for another year.

Analysis of air quality impacts is limited to estimates of air pollutants and to a qualitative discussion of the impacts of air quality. Health effects of these pollutants were not examined.

Impacts of voluntary and mandatory conservation on electricity sales are difficult to quantify. Most of the discussion of conservation is therefore qualitative, although where possible estimates of reduction in sales and demand for electricity are included. On the other hand load management and load shedding are more amenable to analysis and these sections include specificmeasures and their quantitative impacts.

Ear1y in December 1977 the study team organized a conference to examine the problems and share ideas on measures that can be instituted in the short term to ensure a balance in electricity supply and demand. The conference was attended by staff members of the electric utility companies, state and federal government agencies, research institutions and public interest groups. The three panels at the conference provided a forum for the discussion of the effects of the drought on electricity demand and electricity supply and a discussion of measures to match demand and supply. The demand and supply panels provided up to date information on electricity sales and on hydroelectric and other electricity supplies available to California. The discussion on remedial measures generated new ideas for implementing some of these measures. Relevant ideas and information provided at the conference were included in appropriate sections of this report. 
SECTION 2

ELECTRICITY DEMAND

ELECTRICITY USE DURING 1977

It is instructive to review the electricity sales in California during 1977. Especially important in this respect are whether electrical energy sales increased or decreased during this time, and in which end-use sectors and areas the change occurred. We have obtained sales data by end-use billing category for the first two quarters of 1977 and quarterby-quarter for all of 1975 and 1976 from the California Energy Resources Conservation and Development Commission (CERCDC) for all electrical utilities in California. These data are summarized in Tables 1 and 2 for the PG\&E service area and statewide. Sales are compared quarter-by-quarter for 1975, 1976 and part of 1977 in Figs. 1 and 2 where the rate-of-change in sales has been plotted. One can see that there has been a general decline statewide and a sharper drop in the PG\&E service area for relative changes in sales over this time period.

Statewide electrical energy sales during the first and second quarters of 1977 increased 1.6 percent and 0.9 percent over sales in the corresponding quarters of 1976. For the PG\&E service area, where hydroelectric generation capability has been most severely affected, the figures are 0.5 percent and -1.5 percent, respectively, during the same periods. Attempting to unfold the various factors leading to the decline in the growth of sales is difficult, if not impossible quantitatively. One can, however, identify major elements or factors thought to have had an influence: 1) the voltage reduction instituted by the utility companies, although this has not yet been fully implemented statewide, 2) the substantial increase in electricity prices over the past year, 3) a generally cooler summer with lower peak temperatures, 4) reduced energy requirements for water pumping, and 5) the "heightened conservation consciousness" induced in part by the drought and by public information campaigns. These elements are discussed in more detail in the various sections of this report. 
Table 1

PGE्षE Quarterly Sales Comparisons ${ }^{a}$ (TWh)

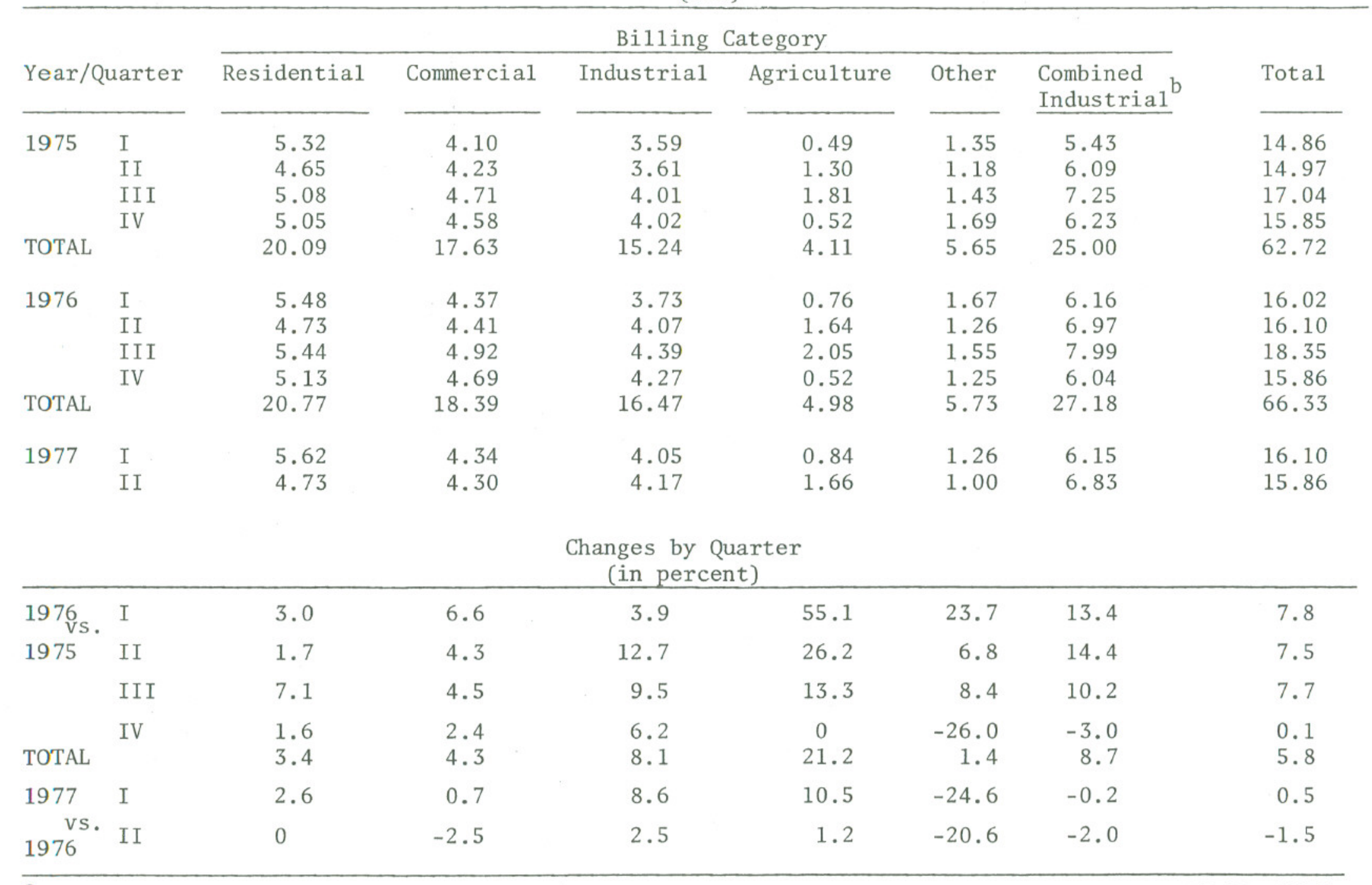

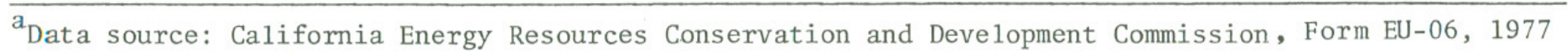

${ }^{\mathrm{b}}$ Combined Industrial $=$ industrial + agricultural + other . 
Table 2

Statewide Quarter1y Sales Comparisons ${ }^{\mathrm{a}}$ (TWh)

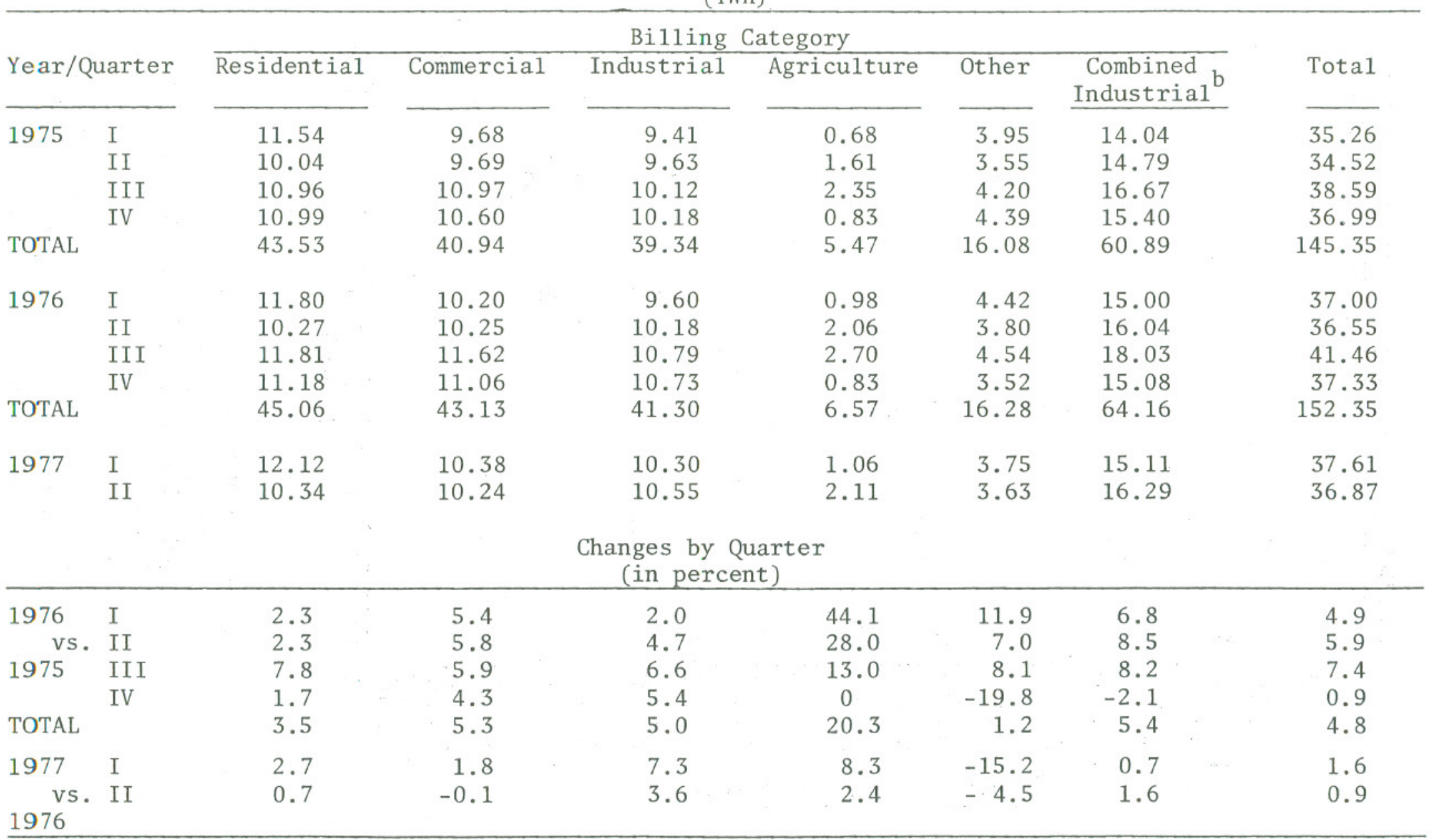

Data source: California Energy Resources Conservation and Development Commission, Form Eu-06, 1977

${ }^{b_{\text {Combined }} \text { Industrial }}$ = industrial + agricultural + other . 

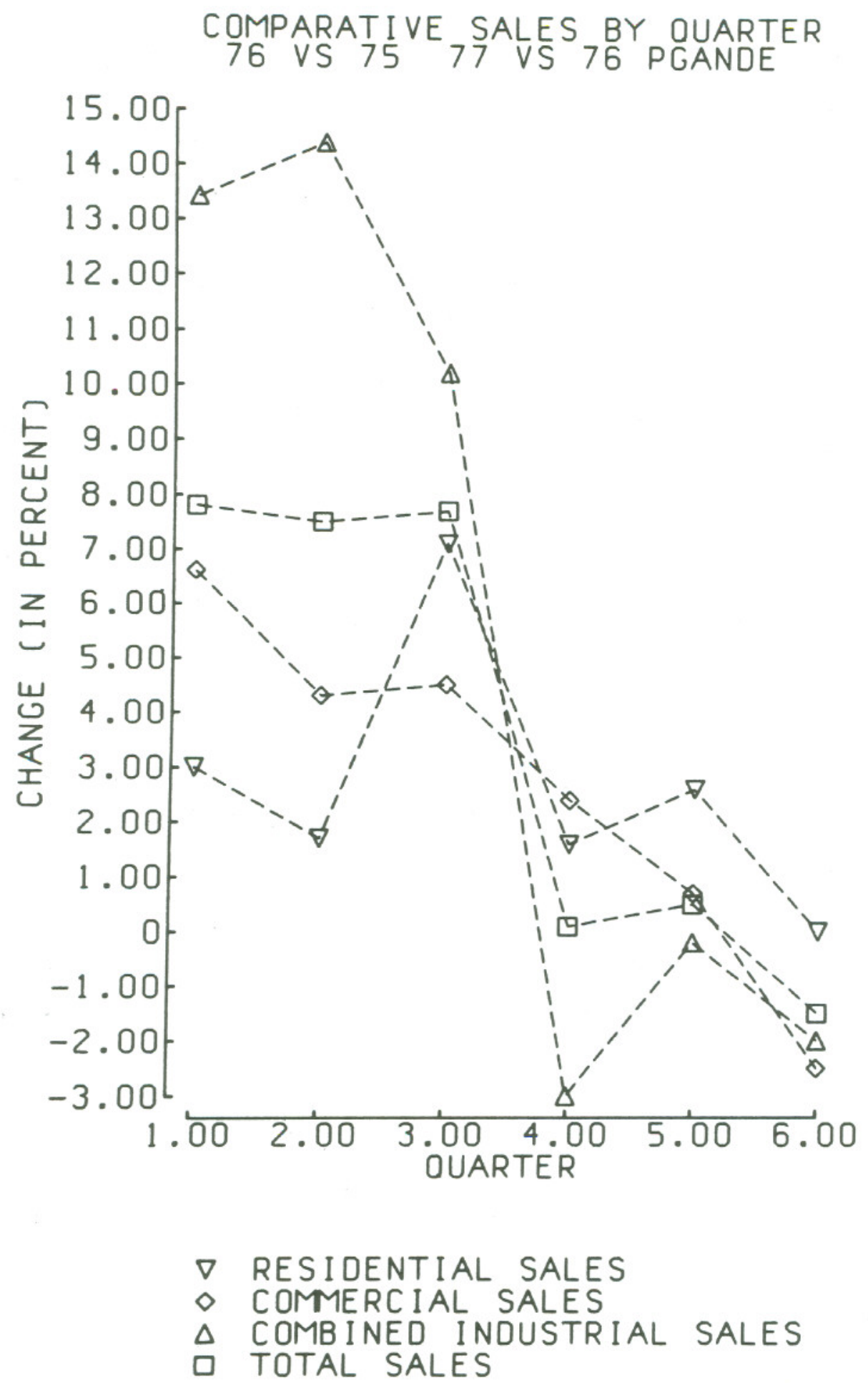

Figure 1. Quarterly Sales Comparisons. XBL 783-7458 Quarter 1 is 1976 (I) vs 1975 (I), quarter 2 is 1976 (II) vs 1975 (II), etc; quarter 5 is 1977 (I) vs 1976 (I) and quarter 6 is 1977 (II) vs 1976 (II). 

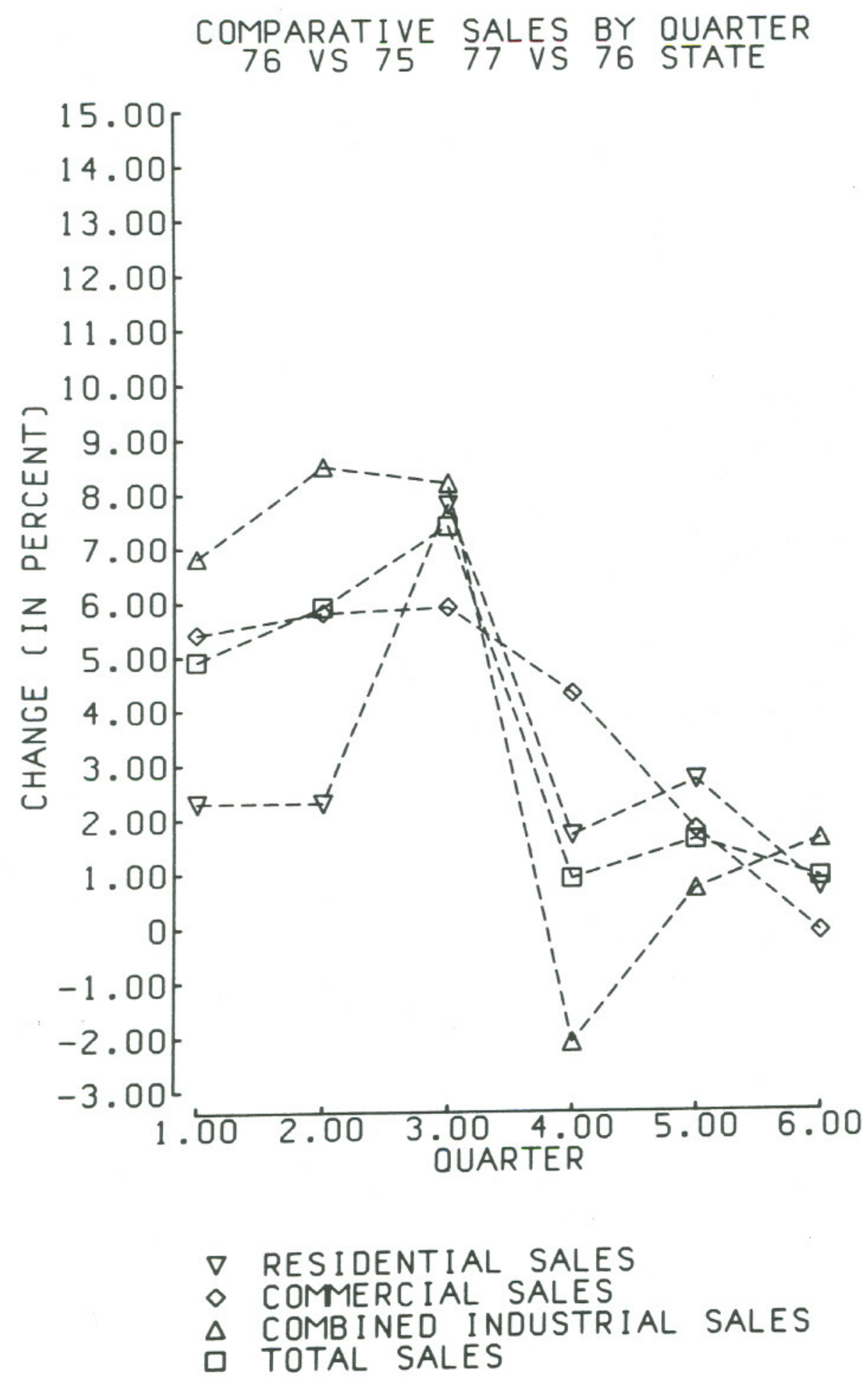

XBL $783-7459$

Figure 2. Quarterly Sales Comparison. See caption for Figure 1 for explanation. 
As indicated by the data in Tables 1 and 2, industrial and agricultural electricity sales between the first two quarters of 1976 and 1977 increased faster than residential and commercial sales, both statewide and in the PGEE service area. While agricultural loads for PG\&E have risen sharply over the past two years, the increase in 1977 was smaller than in 1976. A more detailed analysis of agricultural energy use is presented in Appendix C. Second quarter 1977 commercial sales actually declined below the second quarter 1976 levels both statewide and in the PGEE service area. Residential sales show a similar trend, though they did not drop below the level of last year. Industrial sales, however, continued to grow throughout the period although the second quarter 19771976 comparison shows the smallest increase.

Decreased water deliveries in 1977 resulted in reduced energy requirements for water pumping in both the Central Valley Project and State Water Project. In 1976 the electricity requirements for the two projects net of recovery generation were 1.8 billion $\mathrm{kWh}$ and 3.0 billion $\mathrm{kWh}$, respectively, whereas in 1977 the corresponding electricity requirements are estimated to be 0.8 billion $\mathrm{kWh}$ and 1.6 billion $\mathrm{kWh} .^{1,2}$ This decline is reflected primarily in the "other" category in Tables 1 and 2.

The overall energy load both statewide and in the PG\&E service area for the first half of 1977 did not increase to the levels forecasted earlier by the utilities. This is shown in Table 3 for the PG\&E service area, where the recorded data for 1977 are compared with forecasted leve1s.

The trends shown for aggregate statewide data and for PG\&E are somewhat characteristic of other utilities. SDGE్E and LADWP show a similar decline in growth rate in sales as PG\&E, although the rate of growth remains positive. SCE, however, shows a different pattern, with significantly higher sales in both the first and second quarter of 1977 than for the same period in 1976 .

Peak demand a1so dropped in 1977 compared with 1976 for both the statewide coincident demand, and for PG\&E. The historical trend for peak loads for PG\&E is shown in Table 4, along with temperature-adjusted loads. The 1977 peak for PG\&E was lower in part due to cooler summer temperatures; however, even the temperature-corrected peak lies below the predicted peak. These data are also compared with PG\&E and CERCDC predictions. 
Table 3

Electricity Demand by Major Utility Service Area (energy for load in $\left.10^{9} \mathrm{kWh}\right)^{\mathrm{a}}$

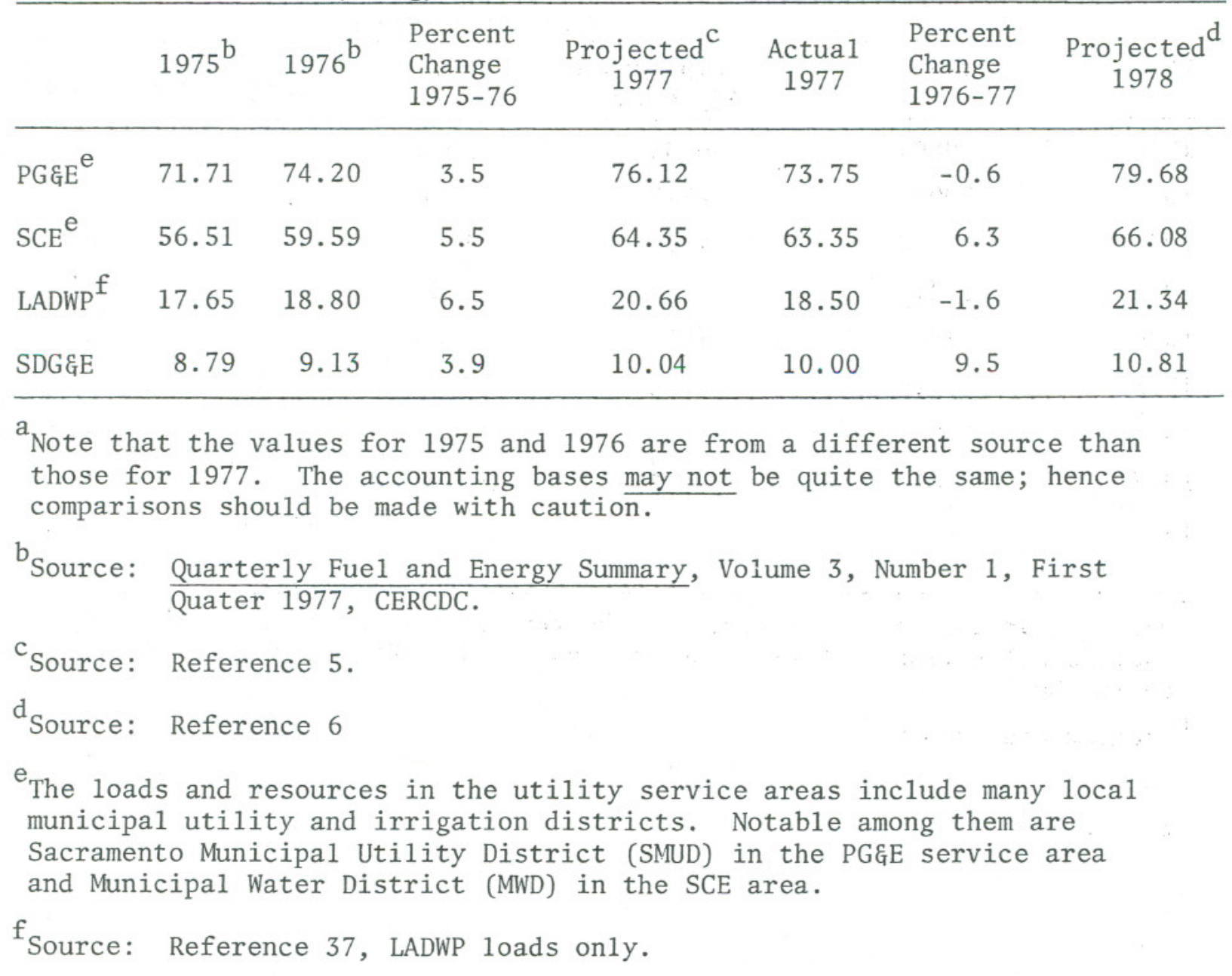


Tab1e 4

PG\&్E Service Area Peak Loads, and Loads Adjusted for Temperature. ${ }^{a}$

\begin{tabular}{|c|c|c|c|c|c|}
\hline \multirow{3}{*}{ Year } & \multicolumn{5}{|c|}{ Peak Demand (MWe) } \\
\hline & \multirow[t]{2}{*}{ Recorded } & \multirow{2}{*}{$\begin{array}{l}\text { Temperature } \\
\text { Adjustment }\end{array}$} & \multirow{2}{*}{$\begin{array}{l}\text { Final } \\
\text { Load }\end{array}$} & \multicolumn{2}{|c|}{ Predicted } \\
\hline & & & & $\overline{\mathrm{PG} E}$ & CERCDC $b$ \\
\hline 1970 & 9864 & +90 & 9954 & & \\
\hline 1971 & 10913 & -127 & 10786 & & \\
\hline 1972 & 11772 & -623 & 11149 & & \\
\hline 1973 & 12212 & +27 & 12239 & & \\
\hline 1974 & 12964 & +379 & 13343 & & \\
\hline 1975 & 13129 & 448 & 12681 & & \\
\hline 1976 & 13932 & -68 & 13864 & & 13858 \\
\hline 1977 & 13815 & +533 & 14348 & $14605^{c}$ & 14425 \\
\hline 1978 & --- & --- & --- & $15316^{\mathrm{d}}$ & 15015 \\
\hline
\end{tabular}

ata and adjustments from Ref. 3. The recorded data and predictions do not include deliveries to Sierra Pacific Power. In 1976 and 1977, this amounted to $108 \mathrm{MW}$.

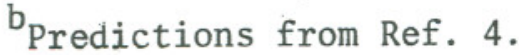

$c_{\text {Kef. } 5}$

$\mathrm{d}_{\operatorname{Ref} .} 6$ 
DEMAND APPRAISAL FOR 1978

The four major electric utility companies in California, Pacific Gas \& Electric (PG\&E), Southern California Edison (SCE), Los Angeles Department of Water and Power (LADWP) and San Diego Gas \& Electric (SDG\&EE) jointly submitted a 1978 electricity demand and supply forecast to the CERCDC in August $1977 .^{6}$ The estimated statewide electricity demand for 1978 is 3.9 percent higher than the 1977 forecast, and coincident peak load is up 4.7 percent over the 1977 prediction. Comparable estimates for the PGEE service area are 4.7 percent increase in both electricity demand and peak load over the 1977 estimates. The actual demand through July 1977 in both cases has been well below the 1977 forecast.

To analyze the factors that may influence the energy impacts of a continued drought in 1978, we have constructed a set of demand scenarios, focusing on the PG\&E service area rather than statewide. Based upon historical data, and the utilities' own projections of demand, we have devised three demand cases; the first assumes a 4.7 percent increase in electrical energy demand, based on PG\&E's estimates; the second assumes no growth in demand over 1977; and the third assumes a decline in demand of two percent compared with 1977. These latter two are motivated by the declining growth recorded between 1976 and 1977. They also assume a continued response to higher electricity prices and public responsiveness in efforts to conserve both water and energy in a third drought year. These cases are summarized in Table 5. The monthly distribution of demand in each case was based on 1977 recorded and estimated demand for PG\&E. Demand for 1978 in the other utility service areas was assumed to remain at the same level forecasted by those utilities in their submittals.

If the drought does extend into a third year, it appears possible that low or negative growth rates might continue, as the public responds to calls for continuing water and energy conservation, and to increasing energy prices. Fig. 1 indicates that there was a sharp change in the growth rates in sales (demand) beginning the fourth quarter of 1976, at least part of which is explained by increased public awareness that the drought was continuing with no sign of slackening during that normally rainy period. The lower growth rates have continued into 1977. 
Tab1e 5

Summary of LBL Scenarios for Energy and Peak Demand ${ }^{a}$

\begin{tabular}{|c|c|c|c|c|c|}
\hline Energy (in & TWh) & Utility & Case A & Case B & Case C \\
\hline \multicolumn{6}{|l|}{ For PG\&E } \\
\hline & Growth Rate & 4.7 & 4.7 & 0 & -2.0 \\
\hline & Energy Supply & 79.68 & 77.29 & 73.82 & 72.34 \\
\hline \multicolumn{6}{|l|}{ Statewide ${ }^{b}$} \\
\hline & Energy Supp1y & 177.91 & 175.52 & 172.05 & 170.57 \\
\hline \multicolumn{6}{|c|}{ Peak Demand (in MWe) } \\
\hline \multirow{3}{*}{ For PGg्षE } & & & Case D & Case E & \\
\hline & Growth Rate & 4.7 & 11.0 & 0 & --- \\
\hline & Peak Demand & 15428 & 15428 & 13815 & --- \\
\hline \multicolumn{6}{|l|}{ Statewide ${ }^{b}$} \\
\hline & Peak Demand & 33445 & 33445 & 31832 & --- \\
\hline
\end{tabular}

$\mathrm{a}_{\text {See text for detailed discussion. }}$

${ }^{b}$ No estimates were made for energy and peak demand for other California utilities, on 1y PG\&E. 
The five reasons stated earlier for the low demand in 1977 compared to PG\&E forecasts for 1977 provide additional insight as to the demand levels for 1978 in the event of a continued drought. Voltage reduction has already been introduced, and further selective reductions may be possible. The decrease in water consumption from 1977 to 1978 will be smaller than the reduction during 1977, thus producing a smaller change in sales. Electricity price increases in 1978 are likely to be less than in 1977 since hydroelectric supplies will decrease only slightly from their already low levels and, the largest factor in these price increases has been the additional cost of oil-fired electricity generation. The actual impact on sales will depend on the price differential, the absolute price and the residual impact of the price increase persisting in 1978 .

For agriculture in 1978, the groundwater that will be used to make up for the surface water deficits is expected to reach 17 million acre-feet compared with 14.7 million acre-feet for 1977. Since this water will be pumped from depths that are five to ten feet lower, on the average, than those of last year, the estimated electrical demand in agriculture will increase about 11 percent over 1977 levels. This increase will not have a major impact on total demand since agriculture forms only a small fraction of demand. Appendix C contains a more in depth discussion of the impacts. Temperature changes primarily affect system peak loads. Milder temperatures prevailed during 1977 with most incidences of high temperatures occurring on weekends, normally a time of lower peak demand. Although the peaks were lower than anticipated this year, the high peak levels forecasted by the utilities could come about if high temperatures prevail on weekdays next summer. PGEE in its forecasts projected a 4.7 percent growth in sales and in peak demand. However, the factors considered here suggest that in the event the drought continues, 1978 PG\&E sales may be 1ess than projected by the company and may not be significantly different from sales in 1977 . Estimated month-by-month PG\&E energy loads for 1978 are shown in Table 6 for each of the three load growths. 
Table 6

Month1y Electrical Energy Loads for PG\&E for 1977, and Three Load Cases for 1978

\begin{tabular}{|c|c|c|c|c|c|}
\hline & \multicolumn{2}{|c|}{1977} & \multicolumn{3}{|c|}{1978 Estimates $^{b}$} \\
\hline & $\underline{\text { Predicted }}^{\mathrm{a}}$ & Actual & Case A & $\underline{\text { Case B }}$ & Case C \\
\hline January & & 6227 & 6520 & 6227 & 6102 \\
\hline February & & 5448 & 5704 & 5448 & 5339 \\
\hline March & & 6375 & 6675 & 6375 & 6248 \\
\hline April & 6282 & 6114 & 6401 & 6114 & 5992 \\
\hline May & 6419 & 5823 & 6097 & 5823 & 5707 \\
\hline June & 6705 & 6510 & 6816 & 6510 & 6380 \\
\hline July & 7229 & 6983 & 7311 & 6983 & 6843 \\
\hline August & 6976 & 6965 & 7292 & 6965 & 6826 \\
\hline September & 6340 & 5983 & 6264 & 5983 & 5863 \\
\hline October & 6007 & 5760 & 6031 & 5760 & 5645 \\
\hline November & 5885 & $5650^{c}$ & 5916 & 5650 & 5537 \\
\hline December & 6227 & $\underline{5978}^{\mathrm{C}}$ & 6259 & $\underline{5978}$ & $\underline{5858}$ \\
\hline TOTAL & 76120 & 73816 & 77286 & 73816 & 72340 \\
\hline
\end{tabular}

$a_{\text {Ref. } 5 .}$

${ }^{\mathrm{b}}$ Al1 three cases are based on 1977 actual (+ 2 months estimated) with the following changes in monthly loads from 1977 to 1978:

Case A: +4.7 percent

Case B: 0 percent

Case C: -2 percent

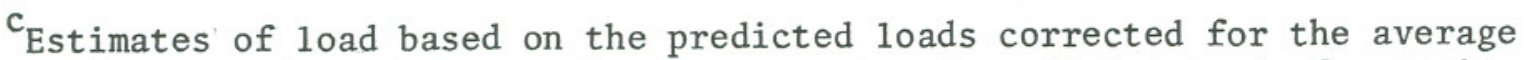
difference of -4.0 percent between actual and predicted loads for April through October. 
SECTION 3

\section{ELECTRICITY SUPPLY}

SUPPLY ASSESSMENT FOR 1977

A review of the supply situation during this past summer reveals few major difficulties in meeting peak loads and energy demands. A number of factors contributed to this. As noted in the discussion of demand, the generally cooler summer combined with conservation efforts reduced energy and capacity requirements. At the same time PG\&E, the utility most significantly affected by the drought, made contractual arrangements for both transfers of energy and capacity support with other utilities for the summer of 1977 . This outside support amounted to a maximum of 600 MWe in August: ${ }^{7} 430$ MWe from SCE, 70 MWe from SDG\&E and 100 MWe from the Salt River Project (Arizona). Additional firm energy supplies from the other California utilities, as high as $300 \mathrm{GWh}$ per month, and from the two Nevada electric utilities. Sierra Pacific Power and Nevada Power Company, totaling about 120 GWh per month were also made available. The summer month energy deficit for PGGE was expected to run about -2 to -2.5 percent of load, or about -120 to $-180 \mathrm{GWh}$ per month. By comparison, the overall statewide energy margin (excess generating capability) was anticipated to be a minimum of $1650 \mathrm{GWh}$ during the summer. PGGE also stored energy with BPA in the Pacific Northwest, totaling about $1000 \mathrm{GWh}$; this energy was withdrawn by PG\&E during the latter part of the summer.

Peak capacity margins for PG\&E were expected to be small, with a minimum margin of 4.3 percent expected for August. However, the cooler maximum summer temperatures and conservation efforts held the peak load for the PGEE service area to 6 percent less than the predicted peak; corrected for temperature variation, this peak load was still about 260 MWe less than predicted. Early in September PG\&E's reserve margins dropped below 6 percent due to an unexpected outage at Pittsburg 7, a large (720 MWe) fossil-fueled plant. The additional capacity required for an adequate operating margin was obtained from operation of additional 
units at the San Luis pumped-storage facility (USBR and DWR) and through use of additional units at the Hyatt-Thermalito generation at Oroville even though the low water conditions made such operation marginal. These additions at the two facilities totaled almost 300 MWe in extra generating capacity. $^{8}$ In addition, 300 MWe of capacity on the PNW intertie was made available by SCE for PGEE. Also, a portion of the energy stored by PG\&E in the BPA system earlier in the year was returned to PG\&E. The peak power available to California on the AC and DC interties totaled over $3200 \mathrm{MWe}^{9}$ in this period.

This pre-planned coordination among the utilities and with the PNW for both capacity support and energy transfer for PG\&E increased system resilience at a time of high peak loads in southern California. The early recognition of the potential problems by the CERCDC and the utilities themselves (including the Engineering and Operating Committee of the California Power Pool) was important in providing for these contingencies.

There were apparently no major problems with regard to the availability of fuels during 1977. The electric utilities in southern California did have considerably more natural gas available than anticipated, which prompted some concerns about storage for contracted oil supplies. It appears since these utilities can no longer obtain priority P-5 gas on a firm basis, the availability of excess or "dump" gas from local gas utilities is quite unpredictable. This compounded by the fact that these local suppliers are dependent upon out-of-state sources of natural gas which serve a variety of other customers as well. Hence changes in the weather, or other factors that can affect gas demand, will sometimes free large quantities of gas on a one-time or "spot" basis. Since California Air Resource Board (CARB) requirements* call for the preferential use of P-5 gas in the South Coast Air Basin on certain episode days when available as a means of reducing emissions, all the excess gas made available is used by the electric utilities.

\section{SUPPLY AVAILABILITY FOR 1978}

There are a number of variables that will affect the amount of power and energy available for loads in 1978. Fundametal to an analysis of the

* Rule 715.1, adopted August 25, 1977, by CARB for the South Coast Air Quality Management District. 
supply picture is the assumed level of runoff into the reservoirs for hydroelectric generation. Several new thermal facilities are also expected to be available during 1978. These supply assumptions and resources are analyzed in the following sections, and the supply-demand balances are constructed for the various supply and demand scenarios we describe.

\section{$\underline{\text { Hydroelectric Supply }}$}

We have investigated the availability of hydroelectric energy and capacity in northern California for 1978 under two conditions: first, a return to normal levels of runoff into streams and reservoirs, and second, a continued drought with the same runoff as during 1977. We have also looked into acquiring additional electrical energy and capacity (primarily hydro) from out-of-state sources.

Hydroelectric energy is generated in northern California by a variety of agencies-public and private utilities, municipal water districts, local irrigation districts, and state and federal water agencies. The reservoirs owned by the water and irrigation districts are primarily used to store water for subsequent delivery to customers. Power generation is a source of additional revenue. The state and federal agencies, DWR and USBR, operate reservoirs for water storage, flood control, stream flow and water quality maintenance, as well as for power generation. In response to a drought these agencies will only generate power with water that must be delivered, whereas during a normal year they may release surpius water to generate electricity.

The scheduling of hydroelectric generation within its service area is done by PGEE. The water agencies inform PG\&E of the total amount of water they plan to release. PG\&E schedules the timing of these releases 24 hours in advance based on its forecast of the next day's loads. These forecasts are updated during the day as more recent weather data are acquired. The DWR power plants at Oroville, for example, are tied into PGEE's computer control system, so they are automatically dispatched under normal conditions. USBR is not yet tied into this system. They are informed by PG\&E of the desired release schedule, and they decide which generators will operate to provide the desired capacity. 
Conditions During 1977. After two years of below normal precipitation the reservoirs in northern California are at their lowest recorded leve1s. Furthermore, the ground is very dry and water tables have been lowered. Even if there is normal precipitation during 1978, runoff into reservoirs will be less than normal.

In Table 7 we present conditions at the major northern California reservoirs which supply hydroelectric energy. Here we compare the carryover storage on 1 October 1977 with the average carryover for the previous ten 'years. For the USBR reservoirs this year's carryover is about 18 percent of normal, and for the DWR reservoirs, it is 30 percent of normal. For the major reservoirs in the PG\&E system, the average carryover is about 44 percent. For power generation the situation is more serious because many of the largest reservoirs have minimum storages below which no power can be generated.* During the summer of 1977 these reservoirs were kept above their minimum power pool. To conserve water, generation was discontinued at some power plants owned by municipal water and irrigation districts where the discharge water was not being delivered to the municipal users.

The lower storage levels reduced the hydroelectric capacity available to PG\&E during July 1977 to 5019 MWe, which is 738 MWe less than what would have been available in a normal year. PG\&E expects about 13 percent of its energy in 1977 will have been supplied by hydroelectric sources compared to about 40 percent during a normal year.

Hydroelectric Supply Under Normal Runoff Conditions. If the amounts of runoff into the reservoirs during the water year beginning 1 October 1977 are at their long-term average levels, then by next October most of the reservoirs will be at their normal carryover storage. Under this same situation, nearly normal supplies of hydroelectric capacity and energy will be available for the critical months next summer. The water impounded to bring the reservoirs up to their normal levels will not generate any electricity this year, so the total hydroelectric energy for 1978 will be lower than usual from normal runoff conditions.

* The minimum power pools shown in Table 7 are engineering design levels. Until this year there has been no operating experience at these low water levels. At some reservoirs power can be generated below the minimum pool if proper precautions are taken; at others power generation might be discontinued above this level if there is a danger of damaging the turbines. 
Table 7

Reservoir Storage on 1 October

$\left(10^{3}\right.$ Acre-feet)

\begin{tabular}{|c|c|c|c|c|}
\hline Reservoir & Capacity & Average Year & 1977 & $\begin{array}{c}\text { Minimum } \\
\text { Power Pool }\end{array}$ \\
\hline \multicolumn{5}{|c|}{ Pacific Gas \& Electric } \\
\hline McCloud & 35.2 & 24.0 & 24.9 & \\
\hline Lake A1manor & 1308.0 & 821.1 & 541.7 & \\
\hline Bucks Lake & 103.0 & 62.6 & 36.6 & \\
\hline Little Grass Valley & 93.0 & 60.5 & 31.1 & \\
\hline Sly Creek & 65.1 & 33.5 & 13.4 & \\
\hline Bullards Bar & 961.3 & 594.2 & 258.1 & \\
\hline Jackson Meadows & 68.5 & 43.3 & 4.6 & \\
\hline Bowman Lake & 68.0 & 46.7 & 16.2 & \\
\hline Fordyce & $46.7)$ & \multirow{2}{*}{65.1} & $\{4.9$ & \\
\hline Spaulding & $74.8\}$ & & 56.3 & \\
\hline Rollins & 66.0 & 50.0 & 5.3 & \\
\hline French Meadows & 133.7 & 68.1 & 38.2 & \\
\hline Hell Hole & 208.4 & 130.5 & 77.8 & \\
\hline Caples Lake & 21.6 & 15.5 & 5.6 & \\
\hline Lower Bear & 48.5 & 23.2 & 7.3 & \\
\hline Salt Springs & 139.4 & 76.9 & 4.2 & \\
\hline Donnel1s & 64.5 & 32.0 & 11.3 & \\
\hline Beardsley & 97.5 & 75.5 & 3.7 & \\
\hline Lake McClure & 1026.0 & 561.8 & 93.7 & 115 \\
\hline So. Cal. Edison & 571.2 & 314.6 & 148.0 & \\
\hline Crane Valley & 45.4 & 26.1 & 17.7 & \\
\hline Courtright & 123.3 & 41.8 & 0.9 & \\
\hline Wishon & 128.0 & 88.6 & 79.8 & \\
\hline Isabe11a & 570.0 & 184.6 & 36.4 & 30 \\
\hline Lake Pil1sbury & 93.7 & 44.0 & 9.8 & \\
\hline \multicolumn{5}{|c|}{ California Department of Water Resources } \\
\hline Orovi11e & 3537.6 & 2461.4 & 915.2 & 852 \\
\hline
\end{tabular}


Table 7 (Continued)

\begin{tabular}{|c|c|c|c|c|}
\hline Reservoir & Capacity & Average Year & 1977 & $\begin{array}{c}\text { Minimum } \\
\text { Power Pool }\end{array}$ \\
\hline \multicolumn{5}{|c|}{ U.S. Bureau of Reclamation } \\
\hline Shasta & 4552.0 & 3152.5 & 627.5 & 502 \\
\hline Clair Engle & 2448.0 & 1859.5 & 241.3 & 313 \\
\hline Whiskeytown & 241.1 & 222.8 & 216.5 & \\
\hline Folsom & 1010.3 & 676.1 & 164.8 & 90 \\
\hline San Luis & 2038.8 & 1521.4 & 277.5 & \\
\hline \multicolumn{5}{|c|}{ Other Agencies } \\
\hline Hetch Hetchy & 360.4 & 238.9 & 113.8 & \\
\hline Pardee & 210.0 & 186.4 & 82.8 & \\
\hline Don Pedro & 2030.0 & 897.5 & 306.4 & 309 \\
\hline Englebright & 70.0 & 50.3 & 65.4 & \\
\hline
\end{tabular}

Source: California Department of Water Resources, personal communication, November 1977. 
In a normal year USBR expects a total inflow of 9.5 million acrefeet into Shasta, Clair Engle and Folsom Reservoirs. ${ }^{10}$ This would permit Shasta and Folsom to reach their usual operating levels by next spring. It would take about two years of average runoff to get storage at Clair Engle to its normal carryover storage. Under current plans USBR will deliver 100 percent water supply to its customers, but no surplus water will be delivered in order to increase carryover storage. Storage on 1 October 1978 in these three reservoirs would total 5.4 million acre-feet which is approximately 86 percent of normal. The generation for the year ending 1 October 1978 would be 2.5 billion kWh with normal runoff as compared to about 6 billion $\mathrm{kWh}$ if the reservoirs had started with norma1 carryover.

DWR has formulated operational criteria for the State Water Project based on the amount of runoff that occurs during 1978. ${ }^{11}$ If there is an average runoff of 4.35 million acre-feet and the SWP meets the contracted deliveries of 1.8 million acre-feet, Lake Oroville would reach normal operating levels by May. Full generating capacity would be reached by April. The total energy generated at Hyatt-Thermalito is would then be nearly 1.1 billion $\mathrm{kWh}$ during the twelve-month period ending 1 October 1978. Usually these plants produce about 2.4 billion kWh annually. Under conditions of normal runoff, PG\&E will be able to meet downstream water requirements and still store water to meet peak summer power demands. The capacity available during July and August would be about 100 MWe lower than would be expected if there were normal carryover storage. A summary of the resources within its service area available to PGEE, including USBR and its share of DWR plants, is shown in Table 8 . About 22 percent of its energy load during 1978 could be supplied by these resources.

Hydroelectric Supply Under Continued Drought Conditions. A continuation of the drought through 1978 will have more severe impacts than during 1977. Water levels in reservoirs will be lower and less water will be released, thus further reducing both hydroelectric energy and capacity. A statewide summary of the situation next year may be found in the response of the California electric utilities to requests for information 
Table 8

Pacific Gas \& Electric Company Area 1978 Hydroelectric Resources Assuming Average Precipitation

\begin{tabular}{|c|c|c|c|c|c|c|c|c|c|c|c|c|}
\hline & Jan & Feb & Mar & April & May & June & July & Aug & Sept & Oct & Nov & Dec \\
\hline $\begin{array}{l}\text { Pacific Gas \& Electric Co. } \\
\text { owned hydro }\end{array}$ & 2396.5 & 2407.4 & 2410.0 & 2421.1 & 2426.6 & 2436.3 & 2428.3 & 2425.3 & 2412.8 & 2412.1 & 2413.7 & 2409.3 \\
\hline \multicolumn{13}{|l|}{ Area Hydro Owned by Others } \\
\hline USBR-CVP & 832.0 & 873.0 & 870.0 & 882.0 & 875.0 & 901.0 & 908.0 & 894.0 & 862.0 & 865.0 & 862.0 & 865.0 \\
\hline $\begin{array}{l}\text { DWR-Hyatt and Thermalito } \\
\text { (PGEE share) }\end{array}$ & 251.0 & 259.0 & 301.0 & 332.0 & 456.0 & 470.0 & 456.0 & 442.0 & 358.0 & 346.0 & 346.0 & 349.0 \\
\hline EBMUD & 7.0 & 7.0 & 7.0 & 7.0 & 7.0 & 7.0 & 7.0 & 7.0 & 7.0 & 7.0 & 7.0 & 7.0 \\
\hline Merced Irrigation District & 32.5 & 35.4 & 40.9 & 51.2 & 61.9 & 78.9 & 81.9 & 77.7 & 72.8 & 66.5 & 60.8 & 56.5 \\
\hline Nevada Irrigation District & 67.5 & 67.5 & 67.5 & 67.5 & 67.5 & 67.5 & 67.5 & 67.5 & 67.5 & 67.5 & 67.5 & 67.5 \\
\hline $\begin{array}{l}\text { Oakdale \& So. San Joaquin } \\
\text { Irrigation District }\end{array}$ & 35.0 & 36.8 & 38.2 & 58.1 & 75.5 & 87.8 & 96.8 & 91.3 & 83.5 & 76.7 & 74.9 & 71.4 \\
\hline $\begin{array}{l}\text { Oroville-Wyandotte Irriga- } \\
\text { tion District }\end{array}$ & 85.0 & 85.0 & 85.0 & 85.0 & 85.0 & 85.0 & 85.0 & 85.0 & 85.0 & 85.0 & 85.0 & $85 . \mathrm{C}$ \\
\hline Placer County Water Agency & 235.1 & 234.9 & 234.9 & 235.7 & 237.5 & 240.8 & 241.1 & 239.8 & 239.0 & 237.5 & 236.2 & 235.5 \\
\hline $\begin{array}{l}\text { City \& County of San } \\
\text { Francisco }\end{array}$ & 303.6 & 302.7 & 302.0 & 302.0 & 306.1 & 309.0 & 315.2 & 312.6 & 309.9 & 307.3 & 305.2 & 302.6 \\
\hline Sacramento MUD & 638.0 & 641.0 & 645.0 & 647.9 & 650.3 & 652.2 & 652.8 & 652.2 & 646.4 & 645.9 & 648.9 & 649.6 \\
\hline Yuba County Water Agency & 242.0 & 247.4 & 261.7 & 286.1 & 290.2 & 328.1 & 314.3 & 304.1 & 297.4 & 283.3 & 274.4 & 280.5 \\
\hline TOTAL & 5125 & 5197 & 5263 & 5376 & 5539 & 5664 & 5654 & 5599 & 5441 & 5401 & 5380 & 5379 \\
\hline $\begin{array}{l}\text { Capacity Not Usable Due to } \\
\text { Energy Limitations }\end{array}$ & 783 & 617 & 945 & 924 & 191 & 0 & 0 & 0 & 0 & 664 & 0 & 0 \\
\hline Usable Area Hydro & 4342 & 4580 & 4318 & 4452 & 5348 & 5664 & 5654 & 5599 & 5441 & 4737 & 5380 & 5379 \\
\hline
\end{tabular}

${ }^{a}$ Usable hydro capacity can be increased by purchasing energy from outside area sources, if available.

Source: Reference 3 
by CERCDC. ${ }^{6}$ More detailed data on usable hydroelectric capacity for next year is presented in Table 9, assuming runoff equal to 1977 leve1s.

USBR operating policy ${ }^{10}$ if there is a repeat of 1977 conditions (total inflow of 3 million acre-feet) will result in a carryover storage of 444,000 acre-feet in their reservoirs. C1air Engle and Whiskeytown lakes will be steadily drawn down throughout the year. Generation at Trinity powerhouse would have ceased in December 1977. Shasta reservoir will reach a peak storage of 1.2 million acre-feet in March while Folsom will reach a peak storage of 200,000 acre-feet in April. Both reservoirs will be drawn down below their minimum power pools by July or August. By September the combined USBR capacity would drop to 323 MWe which is less than one-quarter of the installed capacity. USBR expects to generate 1.26 billion $\mathrm{kWh}$ during the year ending 1 October 1978, or about twenty percent of norma1.

For DWR the situation is similar. If the inflow to Oroville is only 750,000 acre-feet, the reservoir will be drawn down 460,000 acrefeet by October first. Releases would total 1.2 million acre-feet which is two-thirds of normal. There would be no generation at Hyatt after March and the system capacity would then be 48 MWe. Energy generation for the year ending 1 October 1978 will total 0.2 billion kWh. The pumped storage capability at both Hyatt and Thermalito is currently used very little because of of the energy penalty due to 70 percent overall efficiency.

PG\&E expects that after another dry year carryover storage in their reservoirs will be at or below this year's carryover. As shown in Table 9, the useable hydroelectric capacity available to PG\&E will be reduced to 4343 MWe during July and 4249 MWe during August. These are about 700 MWe below the 1977 capacity and about 1400 MWe below rated capacity for the same months. Only 11 percent of PG\&E's energy load will come from hydroelectric sources within its service area, including USBR and DWR.

Out-of-State Transfers. The California utilities have contracts with utilities in the Pacific Northwest for delivery of power and 
Table 9

Pacific Gas \& Electric Company Area 1978 Hydroelectric Resources Assuming 1977 Runoff Megawatts

\begin{tabular}{|c|c|c|c|c|c|c|c|c|c|c|c|c|}
\hline & Jan & Feb & Mar & April & May & June & July & Aug & Sept & Oct & Nov & Dec \\
\hline $\begin{array}{l}\text { Pacific Gas \& Electric Co. } \\
\text { Owned Hydro }\end{array}$ & 2360.6 & 2358.3 & 2350.9 & 2360.6 & 2363.8 & 2365.8 & 2356.1 & 2350.0 & 2349.6 & 2339.0 & 2339.1 & 2337.4 \\
\hline \multicolumn{13}{|l|}{ Area Hydro Owned by Others } \\
\hline USBR & 721.0 & 759.0 & 766.0 & 794.0 & 763.0 & 744.0 & 470.0 & 422.0 & 393.0 & 399.0 & 400.0 & 401.0 \\
\hline $\begin{array}{l}\text { DWR-Hyatt and Thermalito } \\
\text { (PGEE share) }\end{array}$ & 256.0 & 251.0 & 48.0 & 48.0 & 48.0 & 48.0 & 48.0 & 48.0 & 48.0 & 48.0 & 48.0 & 48.0 \\
\hline EBMUD & 0.0 & 0.0 & 0.0 & 0.0 & 0.0 & 0.0 & 0.0 & 0.0 & 0.0 & 0.0 & 0.0 & 0.0 \\
\hline Merced Irrigation District & 32.0 & 32.1 & 32.3 & 33.7 & 34.0 & 34.5 & 32.3 & 0.0 & 0.0 & 0.0 & 0.0 & 0.0 \\
\hline Nevada Irrigation District & 67.5 & 67.5 & 67.5 & 67.5 & 67.5 & 67.5 & 67.5 & 67.5 & 67.5 & 67.5 & 67.5 & 67.5 \\
\hline $\begin{array}{l}\text { Oakdale and So. San Joaquin } \\
\text { Irrigation Districts }\end{array}$ & 35.0 & 35.0 & 35.0 & 60.0 & 60.0 & 60.0 & 35.0 & 35.0 & 35.0 & 35.0 & 35.0 & 35.0 \\
\hline $\begin{array}{l}\text { Oroville-Wyandotte Irriga- } \\
\text { tion District }\end{array}$ & 85.0 & 85.0 & 85.0 & 85.0 & 85.0 & 85.0 & 85.0 & 85.0 & 85.0 & 85.0 & 85.0 & 85.0 \\
\hline Placer County Water Agency & 234.6 & 233.6 & 232.8 & 232.8 & 232.9 & 233.5 & 231.7 & 229.8 & 228.3 & 226.5 & 224.9 & 223.6 \\
\hline $\begin{array}{l}\text { City \& County of San } \\
\text { Francisco }\end{array}$ & 119.0 & 56.0 & 56.0 & 57.0 & 87.0 & 117.0 & 117.0 & 117.0 & 117.0 & 87.0 & 57.0 & 57.0 \\
\hline Sacramento MUD & 627.0 & 632.0 & 635.0 & 639.0 & 644.0 & 646.0 & 643.0 & 640.0 & 636.0 & 635.0 & 634.0 & 632.0 \\
\hline Yuba County Water Agency & 244.5 & 244.5 & 247.0 & 251.5 & 254.0 & 258.5 & 257.5 & 255.0 & 251.5 & 248.9 & 242.5 & 242.0 \\
\hline TOTAL & 4782 & 4754 & 4564 & 4629 & 4639 & 4660 & 4343 & 4249 & 4211 & 4171 & 4133 & 4128 \\
\hline $\begin{array}{l}\text { Capacity Not Usable Due to } \\
\text { Energy Limitations }\end{array}$ & 1275 & 1146 & 1529 & 1267 & 624 & 0 & 0 & 0 & 28 & 482 & 316 & 274 \\
\hline Usable Area Hydro & 3507 & 3608 & 3035 & 3362 & 4015 & 4660 & 4343 & 4249 & 4183 & 3689 & 3817 & 3854 \\
\hline
\end{tabular}

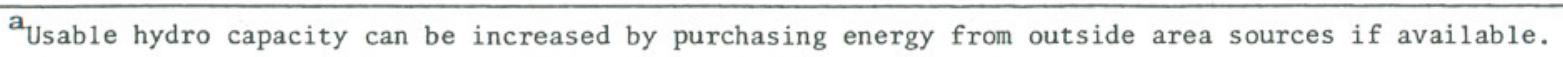

Source: Reference 3 
energy on an energy-exchange basis. The energy taken with the capacity must be returned within a fixed period of time. Up to 2687 MWe of firm power will be available during July and August 1978. This is down by 114 MWe from that available in August 1977 because of a contractual change in Canadian Entitlement power. PGEE expects to receive 1400 MWe in its service area next summer compared with 1500 MWe this year. In addition, the service area will receive firm energy up to 252 GWh per month and SDG\&E will receive up to $30 \mathrm{GWh}$ per month from the northwest utilities. Over the calendar year 1978 these transfers will total about 3170 GWh. In the first year of the drought in California in 1976, excess energy from the Pacific Northwest amounted to more than 7000 GWh for PG\&E. Last year the drought conditions extended genera1ly over the Western U.S. and little, if any, excess energy was available from the Pacific Northwest. The energy available from the Northwest primarily offsets oil-fired generation in California.

PGEE banked energy with BPA during the winter and spring last year. Energy from thermal power plants in California was sent north to displace hydroelectric energy there. The water not released was stored until the summer when PG\&E drew its "bank account" to provide additional energy, especially during the time when the Rancho Seco nuclear power plant was shut down for maintenance.

New peaking hydroelectric units are scheduled to be added at several facilities in the Columbia River system totaling an additiona 2900 MWe (name plate) by August 1978. Since the energy potential of the Columbia River system is almost fully utilized at these facilities, additional peaking resources add capacity but do not represent new sources of energy.

The BPA has recently investigated the possibilities of having excess energy available in the Pacific Northwest Coordinated System as a function of historical rainfall conditions. ${ }^{12}$ Recent heavy rainfalls and reduced loads in the Pacific Northwest have increased the probability of having surplus energy available to California during 1978, especially during the summer months. Presently, firm energy contracts between the PNW and utilities in California utilize less than 20 percent of the full transmission capability of the AC and DC intertie; hence surplus energy in excess of $2000 \mathrm{GWh}$ per month could be transferred if it were available. 
Energy surplus projections based upon rainfall and stream flow conditions during the past forty years have been made, and by April 1 maximum energy would be available if rainfall and runoff in the first half of 1978 match conditions in 9 out of 40 years. By April 15, the maximum energy would be available in 21 out of 40 years, and by May 1 in 30 out of 40 years. In general the availability of surplus energy extends only through the end of July, at which point the storage capability on the Columbia River system is at its maximum value. Large amounts of surplus energy would have the additional benefit for California utilities in that part of it could be purchased as peaking capacity exchange energy. Thus the California utilities would not be required to actually generate and transmit this exchange energy to the PNW.

If rainfall and runoff in the Pacific Northwest return to normal, there is little reason to bank energy in the BPA system. If the drought continues throughout the west, PG\&E plans to bank energy again next year. The decision on banking will be made after January first when the hydrological conditions in the Pacific Northwest will be better known.

\section{Therma1 Supply}

In general, the thermal supply picture for 1978 is similar to that for 1977. PGE्षE is the only utility expecting to be able to burn P-5 natural gas in any sizable quantity, although if the experience of this past summer is any guide, additional gas in substantial quantities might be available to utilities in southern California on an unpedictable "spot" basis. Under continued drought conditions in 1978, the make-up energy source will continue to be oil. The further decline in hydroelectric energy will be partially offset by an additional 643 MWe of new thermal resources (not including Diablo Canyon 1), scheduled to be available by August 1978. We have listed these units and their expected completion dates in Table 10.

Our supply scenarios are based primarily on the utility submittals to CERCDC $^{6}$ with changes presented in the next two paragraphs. Diablo Canyon Units 1 and 2 (1060 MWe each) are presently in the licensing process. The date on which these nuclear power plants may be placed in service will be determined largely by the Nuclear Regulatory Commission (NRC). It now 
appears that June is the earliest possible startup date for Unit 1, with Unit 2 delayed until 1979. We have analyzed the supply situation with and without Diablo Canyon Unit 1 and discuss this further below. Additional PG\&E resources, Geysers geothermal Units 12 (106 MWe) and 15 (55 MWe), have also been delayed until September and December 1978, respectively. The nuclear unit at Humboldt Bay (63 MWe), out of service since July 1976, is not expected to return. The seismic safety of this plant is presently undergoing review by the NRC. We have assumed it will not be available in 1978. For SCE and SDG\&E, the planned refueling of San Onofre (430 MWe) in July and August has been delayed past September, based on information from SCE and CERCDC.

Finally, we assume full use of both the Castaic pumped storage facility (1170 MWe) operated by LADWP and the LADWP share of the Pacific Northwest DC intertie (an additional $200 \mathrm{MWe}$ ). While LADWP in their submittal to CERCDC $^{6}$ does not include all the capacity available from these facilities, conversations ${ }^{13}$ with LADWP indicate that the reason for this derating is due to the diseconomies of using oil-fired generation to use as pump-back energy for Castaic, or return energy for the DC intertie. However, there are no physical limitations on the full use of these resources; hence, we have included them at their full value in our resource list. It should be noted that neither facility adds very much in the way of energy, since Castaic is a net energy consumer (60-70 percent overal1 efficiency, so it consumes about $3 \mathrm{kWh}$ pumping energy to produce $2 \mathrm{kWh}$ ) and the energy on the DC intertie must be returned (exchange energy), usually with about a 24-hour turnaround. However, the additional peaking capacity might well be an essential state resource next summer.

We have treated the issue of Diablo Canyon as a separate element. The latest estimate from PG\&E is for commercial operation under an interim license by August 1, 1978, with a two month pre-commercial start-up period. With a 30-45 day period to load fuel, the issuance of an interim operating license would have to be done no later than the end of April, 1978, in order for this schedule to be met. However, the latest estimate from the $\mathrm{NRC}^{14}$ is that an interim operating license proceeding will not begin until about April 15. The issues surrounding the application for an operating license are in contention and are not likely to be resolved in a short time period. 
Table 10

New Generating Units Expected in 1978 (MWe)

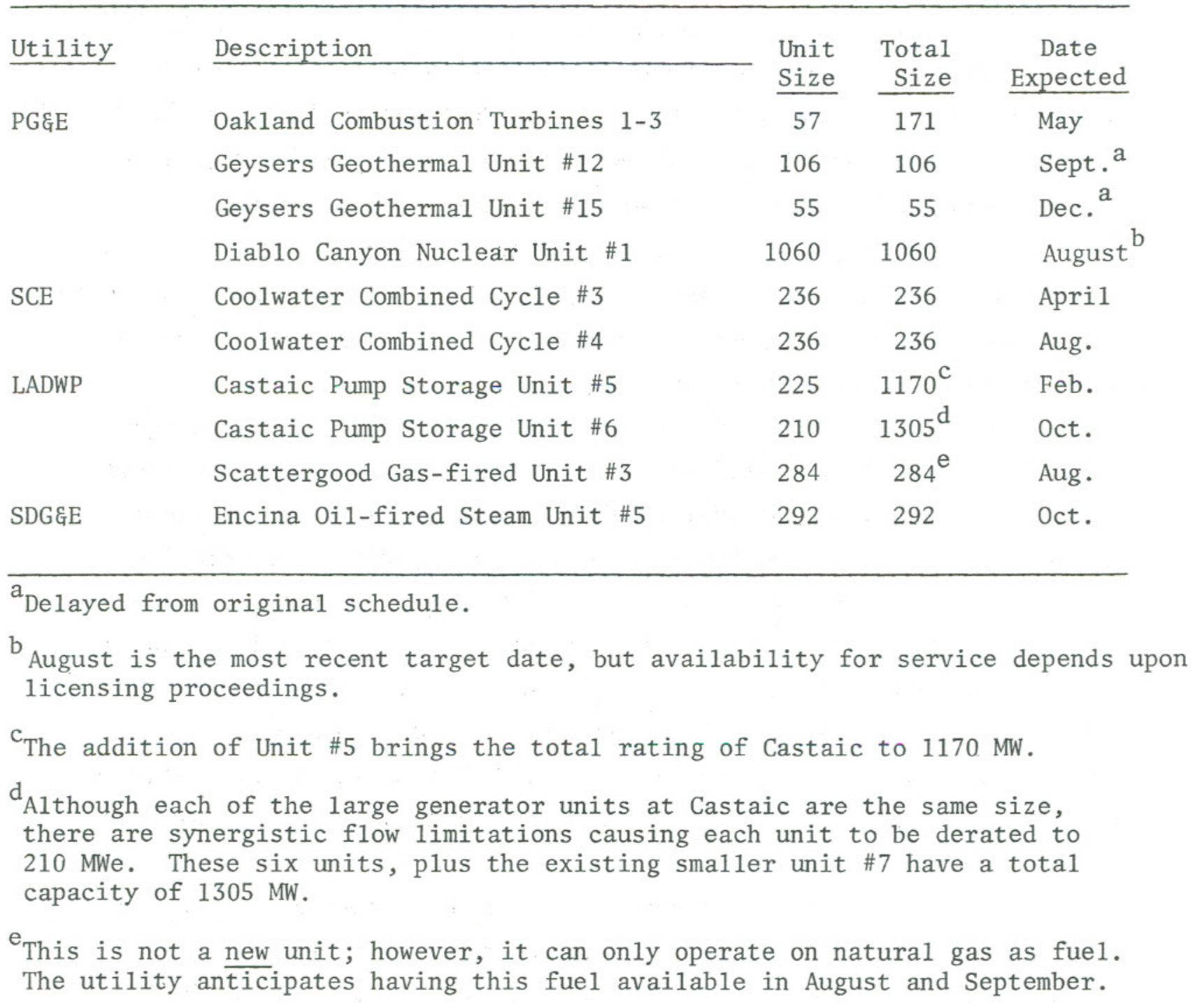


According to data from the $\mathrm{NRC},{ }^{15}$ the average time from startup to commercial operation for nuclear power plants larger than $400 \mathrm{MW}$ is about six months, with five of the 51 nuclear plants in this size category achieving commercial operation in two months or less from start-up. The time required to achieve commercial operation at Trojan, a plant very similar to the Diablo Canyon units, was approximately six months. Nevertheless we have assumed that commercial operation will begin August 1, in order to assess the impact of the availability of Diablo Canyon on system reliability, prices in the PGEE system, and the leve1 of imported energy required by PG\&E. Clearly, the introduction of Diablo Canyon Unit 1 during 1978 will reduce the amount of imported energy PG\&्षE will require. Given our assumed start-up date, the estimates here can be thought of as the most optimistic case in that regard.

We have indicated in Tables 11 and 12 the energy and capacity available in the PGGE system for 1978. As we noted in our earlier discussion two changes have been made in PGE्G's assumptions shown in their submittal to CERCDC. ${ }^{1}$ First, we do not include the 63 MWe Humboldt Bay nuclear unit, and Geysers 12 and 15 are delayed, as shown in Table 11. Based on PGEEE estimates we use an 82.5 percent month1y capacity factor for energy from Rancho Seco and an 85 percent capacity factor for gas and oil generation (with a $400 \mathrm{MW}$ forced outage level). We have calculated the energy expected from Diablo Canyon, using PG\&E's estimate for two months of pre-commercial energy and a 60 percent capacity factor after August 1. This capacity factor assumption is close to the industry-wide average and is probably optimistic in view of the experience at other nuclear facilities during the first months of commercial operation.

These resources are then compared with the peak load and energy demand scenarios we have described earlier. It should be noted that having Diablo Canyon on-line does not completely obviate the need for imported energy for PG\&E for 1978, although for the lowest demand case no further imports would be required beyond July.

The demand assumptions have the largest effect on the supply-demand balance for both energy and capacity requirements. The capacity margins shown inTable 12 do not reflect operating reserve requirements. We 
Table 11

Energy Supply-Demand Balances for PG\&్६E for 1978 Assuming Continued Drought Conditions

\begin{tabular}{|c|c|c|c|c|c|c|c|c|c|c|c|c|c|}
\hline \multirow[b]{2}{*}{ Supply } & \multicolumn{11}{|c|}{ Energy (GWh) } & \multirow[b]{2}{*}{ Dec. } & \multirow[b]{2}{*}{$\begin{array}{l}1978 \\
\text { Total } \\
\end{array}$} \\
\hline & Jan. & Feb. & Mar. & Apr. & May & June & July & Aug. & Sept. & Oct. & Nov. & & \\
\hline \multicolumn{14}{|l|}{ Resource Type } \\
\hline Total Area Hydro ${ }^{a}$ & 590 & 573 & 629 & 747 & 760 & 866 & 1078 & 1001 & 817 & 686 & 506 & 480 & 8733 \\
\hline Northwest Firm Hydro & 236 & 208 & 228 & 252 & 252 & 252 & 252 & 252 & 252 & 252 & 232 & 152 & 2820 \\
\hline Nuclear ${ }^{b, c}$ & 554 & 500 & 552 & 532 & 542 & 5.19 & 537 & 537 & 520 & 70 & 0 & 501 & 5364 \\
\hline Geotherma $1^{b, d}$ & 336 & 304 & 336 & 325 & 336 & 325 & 336 & 336 & 396 & 407 & 396 & 444 & 4277 \\
\hline Other Receipts ${ }^{\mathrm{e}}$ & 287 & 276 & 297 & 253 & 234 & 240 & 264 & 285 & 273 & 253 & 276 & 270 & 3208 \\
\hline Gas \& Oil Generation ${ }^{b, f}$ & 3780 & 3300 & 3591 & 3383 & 3780 & 4087 & 4350 & 4350 & 3965 & 3717 & 3720 & 4097 & 46120 \\
\hline I. Total Energy - PG\&E System & 5783 & 5161 & 5633 & 5492 & 5904 & 6289 & 6817 & 6761 & 6223 & 5385 & 5130 & 5944 & 70522 \\
\hline Diablo Canyon Unit ${ }^{1}$ & 0 & 0 & 0 & 0 & 0 & 260 & 400 & 473 & 458 & 473 & 458 & 473 & 2995 \\
\hline II. Total Including D.C. & 5783 & 5161 & 5633 & 5492 & 5904 & 6549 & 7217 & 7234 & 6681 & 5858 & 5588 & 6417 & 73517 \\
\hline \multicolumn{14}{|l|}{$\underline{\text { Demand }}^{g}$} \\
\hline Case A & 6520 & 5704 & 6675 & 6401 & 6093 & 6816 & 7311 & 7292 & 6264 & 6031 & 5916 & 6259 & 77286 \\
\hline Case B & 6227 & 5448 & 6375 & 6114 & 5823 & 6510 & 6983 & 6965 & 5983 & 5760 & 5650 & 5978 & 73816 \\
\hline Case C & 6102 & 5339 & 6248 & 5992 & 5707 & 6380 & 6843 & 6826 & 5865 & 5645 & 5537 & 5858 & 72340 \\
\hline \multicolumn{14}{|l|}{ Balances } \\
\hline I-A & -737 & -543 & -1042 & -909 & -189 & -527 & -494 & -531 & -41 & -646 & -786 & -315 & -6764 \\
\hline I- B & -444 & -287 & -742 & -622 & +81 & -221 & -166 & -204 & +240 & -375 & -520 & -34 & -3294 \\
\hline I-C & -319 & -178 & -615 & -500 & +197 & -91 & -16 & -65 & +358 & -260 & -407 & +86 & -1818 \\
\hline II-A & -737 & -543 & -1042 & -909 & -189 & -267 & -94 & -58 & +417 & -173 & -328 & +158 & -3769 \\
\hline II-B & -444 & -287 & -142 & -622 & +81 & +39 & +234 & +269 & +698 & +98 & -62 & +439 & -299 \\
\hline I I-C & -319 & -178 & -615 & -500 & +197 & +169 & +374 & +408 & +816 & +213 & +51 & +559 & +1177 \\
\hline
\end{tabular}

aascd on data from Ref. 6, with changes discussed in text.

$\mathrm{b}_{\text {After scheduled maintenance. }}$

${ }^{\mathrm{c}}$ Includes only Rancho Seco, using c.f. $=82.5$ percent .

$\mathrm{d}_{\text {Geysers }} 12$ available Sept. 1; Geysers 15 available Dec. 1.

${ }^{\mathrm{e}}$ Includes output from combustion turbines, four units operated on refinery by-products, hydroelectric generation allocated to PGE्ष on the SWP system but out of PGE्द's service area.

$\mathrm{f}_{\text {Assumes c.f. }}=85$ percent and 400 MWe forced outage level.

$\mathrm{g}_{\text {See Table }} 6$ for details. 
Table 12

Peak Load Capacity for PG\&E for the Summer of 1978

Capacity (MWe)

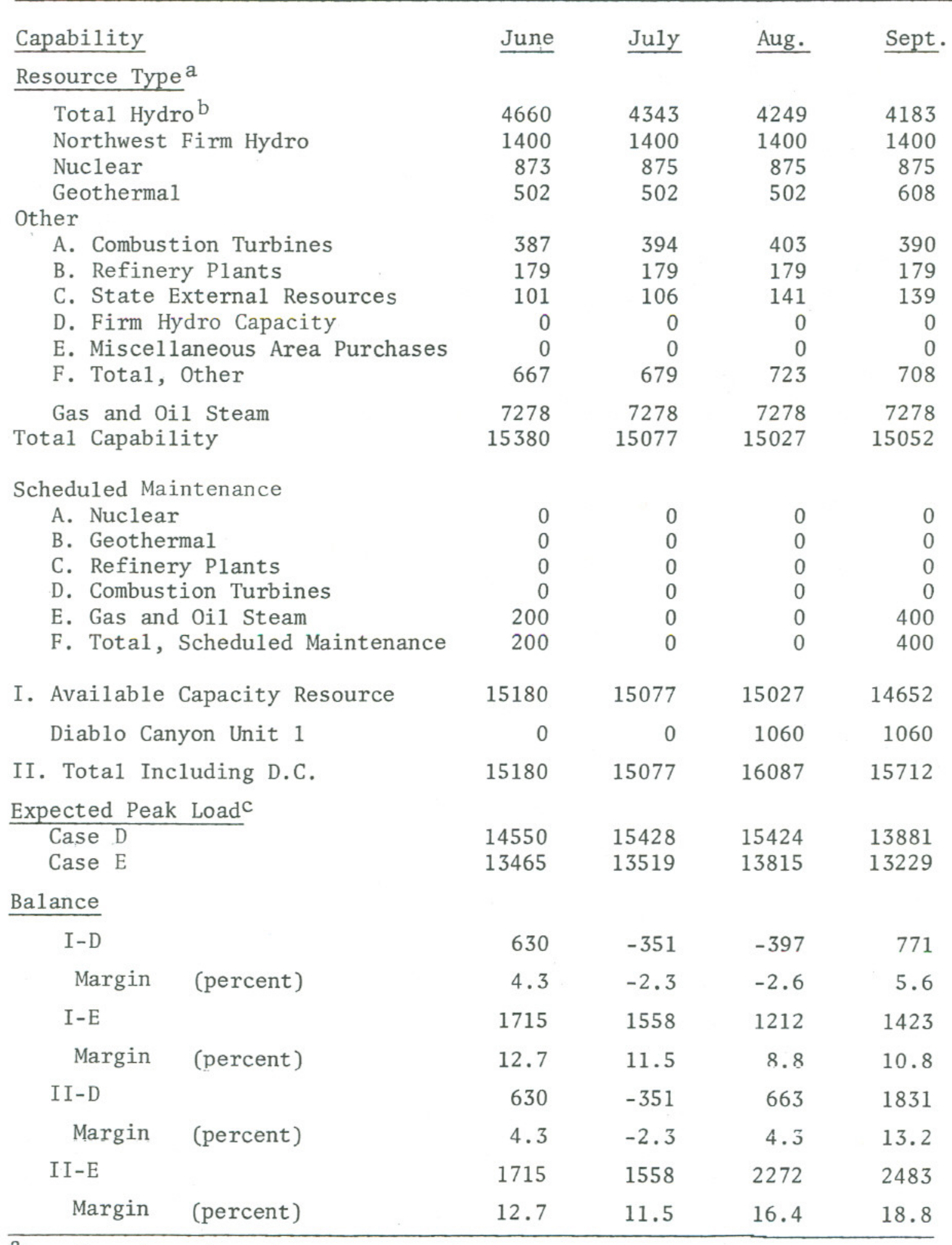

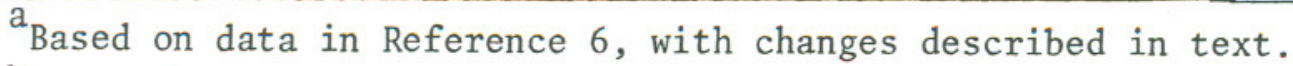

$\mathrm{b}_{\text {See Table }} 9$ for details.

${ }^{\mathrm{c}}$ See Table 5 . 
discuss this below in our analysis of the effects of our scenarios on system reliability.

Up to this point, we have focussed on PG\&E in our supply-demand assessments. PG\&E is expected to require interconnection support and imported energy for several months in 1978, depending upon the demand scenario chosen. We next analyze the supply-demand picture from a statewide perspective. As noted earlier, we have used the supply and demand projections of the three other major electric utilities in California as reported to the CERCDC, ${ }^{6}$ with basically three changes: the deferral of refueling for San Onofre past the summer peak months, the full use of the pumped storage generating capacity at Castaic, and full use of firm capacity in the DC intertie. The detailed monthly resource schedules for the southern California utilities are shown in Appendix A. Tables 13 and 14 show the statewide energy and capacity balances for each scenario for PG\&E. By way of comparison the energy and capacity margins from the joint utility submittal to CERCDC ${ }^{6}$ are a1so shown.

On a statewide basis, there is instate energy generation capability to service the highest energy for load demands in 1978. If one distributed PG\&E's imported energy requirements among the other three utilities as was done in 1977, the fractional increase in oil-fired generation is small in each of these utility service areas. It is interesting to note that the lowest energy margins are expected for February and March, a time when the scheduled maintenance is expected to be large and the hydroelectric generation low. Also shown in Table 13 is a summary of the minimum surplus energy expected from the Pacific Northwest on the basis of 30 out of the last 40 years. Should excess energy be available, it can be seen that it offsets completely PGGE's energy input requirements for all months from March to July.

A key element in the discussion of interconnection support are the transmission line linkages between PG\&E and the utilities in southern Califormia and in the Pacific Northwest. The main links with the Pacific Northwest are the two $500 \mathrm{kV}$ AC lines, operated in California primarily by PGGE and in Oregon by BPA and Portland General Electric, and the $800 \mathrm{kV}$ DC 1 ine operated by BPA and LADWP between Celilo, Oregon (near Dalles) 
Table 13

Statewide Supply-Demand Balances for Energy

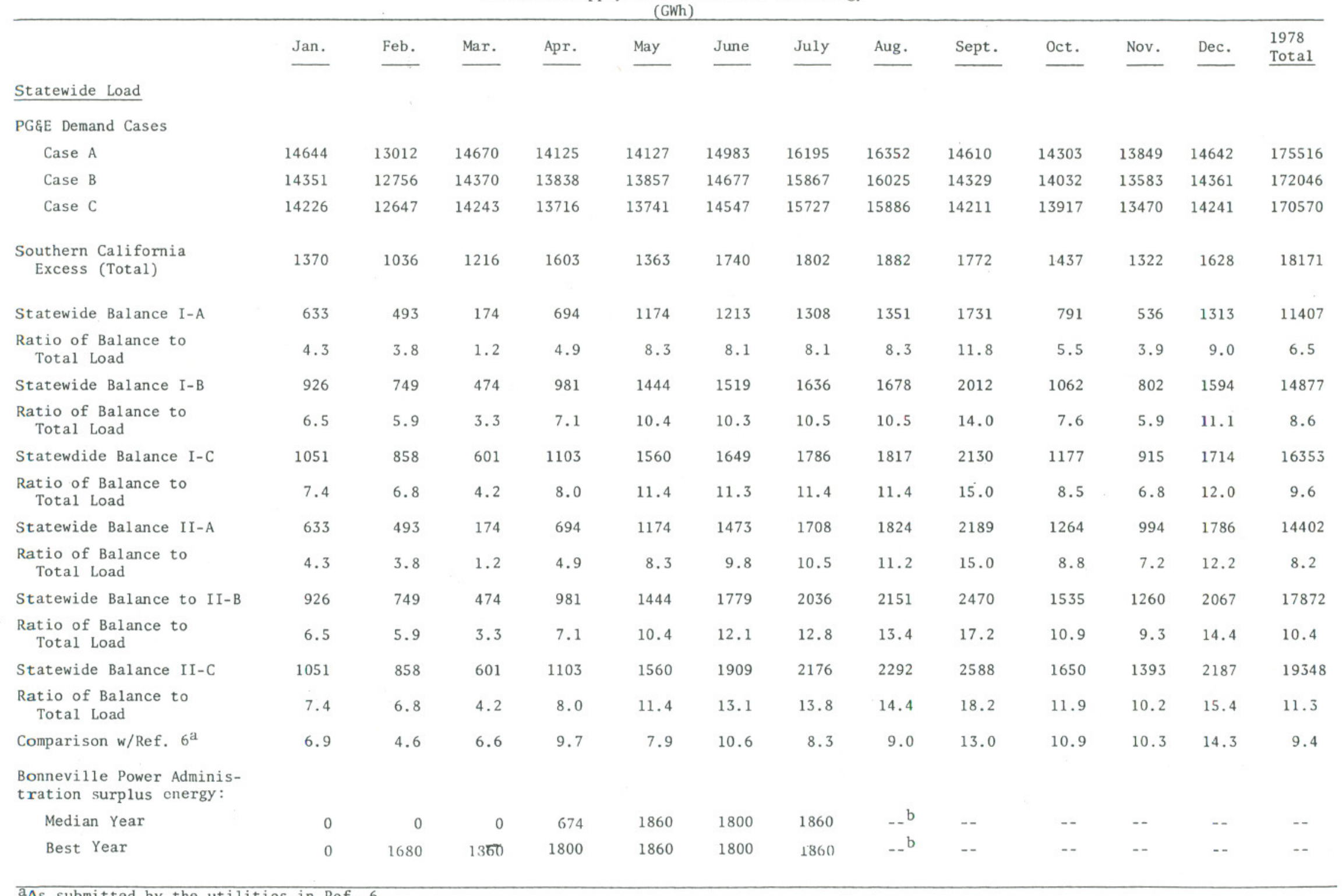

${ }^{a}$ As submitted by the utilities in Ref. 6 .

burplus energy is generally unavailable beyond the end of July. 
Table 14

Statewide Capacity Balance and Reserve Margins (in MWe)

\begin{tabular}{lccccc}
\hline & & June & July & August & September \\
\hline Capacity Margin in Southern CA & & 4803 & 3809 & 3703 & 3405 \\
PGqE Area Spinning Reserve & & & & & \\
$\begin{array}{l}\text { Requirements } \\
\text { Three Percent of Load }\end{array}$ & Case D & 437 & 463 & 463 & 416 \\
& Case E & 404 & 406 & 414 & 397 \\
Largest Risk & Case I & -875 & (Rancho Seco - al1 4 months) - \\
& Case II & 875 & 875 & 1060 (Diablo Canyon 1)
\end{tabular}

Total PG\&्षE Reserve

Requirement

$\begin{array}{lllll}\text { I-D } & 1312 & 1338 & 1338 & 1291 \\ \text { I-E } & 1279 & 1281 & 1289 & 1272 \\ \text { II-D } & 1312 & 1338 & 1523 & 1476 \\ \text { II-E } & 1279 & 1281 & 1474 & 1457\end{array}$

PGGE : Balance ${ }^{c}-$ Reserves

$\begin{array}{lrrrr}\text { I-D } & -682 & -1689 & -1735 & -520 \\ \text { I-E } & 436 & 277 & -77 & 151 \\ \text { II-D } & -682 & -1689 & -860 & 355 \\ \text { II-E } & 436 & 277 & 798 & 1026\end{array}$

Statewide Capacity Balance

\begin{tabular}{llccc} 
I-D & 4121 & 2120 & 1968 & 2885 \\
Ratio to Coincident Peak & $13.8 \%$ & $6.4 \%$ & $5.9 \%$ & $9.3 \%$ \\
I-E & 5239 & 4086 & 3626 & 3556 \\
Ratio to Coincident Peak & $18.2 \%$ & $13.2 \%$ & $11.4 \%$ & $11.8 \%$ \\
II-D & 4121 & 2120 & 2843 & 3760 \\
Ratio to Coincident Peak & $13.8 \%$ & $6.4 \%$ & $8.5 \%$ & $12.2 \%$ \\
II-E & 5239 & 4086 & 4501 & 4431 \\
Ratio to Coincident Peak & $18.2 \%$ & $13.2 \%$ & $14.1 \%$ & $14.6 \%$ \\
\hline
\end{tabular}

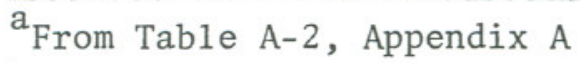

$\mathrm{b}_{\text {PGEE }}$ uses a more stringent spinning reserve requirement than other California utilities of $3 \%$ of the expected peak load plus the single largest contingency.

$\mathrm{c}_{\text {From Table }} 12$.
} 
and Sylmar, California (near Los Angeles). These lines are rated at continuous load carrying capabilities of $1250 \mathrm{MW}$ for each AC line and 1400 MW on the DC line for a total of 3900 MW. (These ratings on the AC lines are conservative.)

The interconnection with southern California is primarily through three $500 \mathrm{kV}$ AC lines between PG\&E and SCE. Physically, two of these share a common right-of-way, with the third loacted in a separate corridor. The continuous load carrying capability of this interconnection is rated by SCE and PGEE as 2000 MW. Because this interconnection is vital to both systems, the contingency planning conservatively assumes the loss of two of the three lines. This results in the $2000 \mathrm{MW}$ rating as being the higest load a single $500 \mathrm{kV} \mathrm{AC}$ line may carry reliably.

Other factors play a considerable role in the complex question of power transmission and utility system interconnections. It is not the intention here to discuss these issues in authoritative detail but to note that transmission issues within the WSCC are complicated by "loopflow" problems cause by non-uniform transmission path impedances in the interconnected WSCC area. For planning purposes, BPA usually assumes that $300 \mathrm{MW}$ of the AC intertie is not available in the summertime due to loop-flow problems. Recent loading of the connection between the Pacific Northwest and the northeast portion of theWSCC (Montana, Idaho, Wyoming) resulted in about 800 MWe of south to north loop-flow through the California interties. This flow uses transmission capacity going in the same direction; hence it inhibits full use of the transmission line links. A detailed study of the loop-flow implications of the interconnection support required by PG\&्षE has not been made; such a study is beyond the scope of this analysis.

Examination of the energy and capacity requirements exhibited in Tables 11 and 12 shows that in every case the transmission links can provide the support required, over and above firm capacity commitments already made for 1978. One should note, however, that the backup support will also require transmission line capability. We pursue this point in the following discussion of reliability and reserve margins. 
Supply System Reliability

The risk of bulk power outages has been estimated for PG\&E and for the statewide bulk power system using the loss-of-load-probability (LOLP) method. As in our earlier report, ${ }^{16}$ which contains a more detailed discussion of the interpretation of LOLP, we use PG\&E's interpretation of the one day in 10 years criterion for loss of load. This yields a lower value for the limit on LOLP than other interpretations of the same one day in 10 years criterion. For the purposes of this study, we adopt PG\&E's evaluation, which gives an upper limit on the monthly LOLP of $8.5 \times 10^{-3}$.

The method of calculating LOLP is different than in our earlier report. Instead of an analytic approximation for the probability of outages using an expansion of the normal distribution, we arrive at LOLP from a straight-forward combination of the probability of outages for each unit. These probabilities can then be tabulated as a function of available capacity for each utility or as a regional or statewide system. This method is fairly standard and is in use within the utility industry. ${ }^{17}$

Associated with each power plant or unit available for load is the probability of a full outage (the forced outage rate, FOR), the possibility of a partial outage (for some units, but not all), and the probability of full-1oad service (which is simply 1 - the partial and full outage rates). In a system with more than one unit, the probability of having a given amount of capacity available is the combination of the probabilities of all possible ways of arriving at that given capacity. Once such a table of probabilities for a given utility system is constructed, the probability of not being able to meet a given load (that is, a lossof-load) is simply the integral along that curve from 0 MWe to the load in question. This approach treats the individual units at each power plant, as well as the individual plants as independent operational entities. A more sophisticated approach might be to include common-mode failures, or probabilities, as well, but the data available to us do not include these types of system failures. In general, it is felt that the individual plant outage rates dominate in bulk power system failures. 
To illustrate our LOLP method, consider a system with two plants, $50 \mathrm{MW}$ and $25 \mathrm{MW}$, with forced outaged rates $\mathrm{FOR}_{1}$ and $\mathrm{FOR}_{2}$, respectively. The probability that unit 1 is on is $\left(1-\mathrm{FOR}_{1}\right)$, and similarly, for unit 2 it is $\left(1-\mathrm{FOR}_{2}\right)$. The following table illustrates the possible generating configurations and their associated probabilities:

both plants on $(50+25=75 \mathrm{MWe}):\left(1-\mathrm{FOR}_{1}\right) \times\left(1-\mathrm{FOR}_{2}\right)$

plant 1 on; p1ant 2 off $(50$ MWe): (1 - FOR 1$) \times$ FOR $_{2}$

p1ant 1 off; p1ant 2 on (25 MWe): FOR $_{1} \times\left(1-\mathrm{FOR}_{2}\right)$

both plants off $(0 \mathrm{MWe}): \quad \mathrm{FOR}_{1} \times \mathrm{FOR}_{2}$

For a system load of $60 \mathrm{MW}$, the LOLP is then the sum of the possible outage states up to $60 \mathrm{MW}$, or

$$
\begin{aligned}
& \mathrm{FOR}_{1} \times \mathrm{FOR}_{2}(@ 0 \mathrm{MW})+\left(1-\mathrm{FOR}_{2}\right) \times \mathrm{FOR}_{1}(@ 25 \mathrm{MW})+\left(1-\mathrm{FOR}_{1}\right) \\
& \times \mathrm{FOR}_{2}(@ 50 \mathrm{MW}) .
\end{aligned}
$$

If a third power plant is added to this system with, for example, 75 MW of capacity with a partial outage state of 50 MW at probability FOR $_{4}$ and a complete outage rate of $\mathrm{FOR}_{3}$, then the probability vs. available capacity table (or curve) looks like:

$$
\begin{aligned}
& 0 \mathrm{MW}: \mathrm{FOR}_{1} \times \mathrm{FOR}_{2} \times \mathrm{FOR}_{3} \\
& 25 \mathrm{MW}:\left(1-\mathrm{FOR}_{2}\right) \times \mathrm{FOR}_{1} \times \mathrm{FOR}_{3} \\
& 50 \mathrm{MW}: \quad\left(1 \mathrm{FOR}_{1}\right) \times \mathrm{FOR}_{2} \times \mathrm{FOR}_{3}+\mathrm{FOR}_{1} \times \mathrm{FOR}_{2} \times\left(1-\mathrm{FOR}_{4}\right) \\
& 75 \mathrm{MW}: \quad\left(1-\mathrm{FOR}_{1}\right) \times\left(1-\mathrm{FOR}_{2}\right) \times \mathrm{FOR}_{3}+\mathrm{FOR}_{1} \times \mathrm{FOR}_{2} \times\left(1-\mathrm{FOR}_{3}\right) \\
&+\mathrm{FOR}_{1} \times\left(1-\mathrm{FOR}_{2}\right) \times\left(1-\mathrm{FOR}_{4}\right) \\
& 100 \mathrm{MW}: \quad\left(1-\mathrm{FOR}_{1}\right) \times \mathrm{FOR}_{2} \times\left(1-\mathrm{FOR}_{4}\right)+\left(1-\mathrm{FOR}_{2}\right) \times\left(1-\mathrm{FOR}_{3}\right) \\
& 125 \mathrm{MW}: \quad\left(1-\mathrm{FOR}_{1}\right) \times\left(1-\mathrm{FOR}_{2}\right) \times\left(1-\mathrm{FOR}_{4}\right)+\left(1-\mathrm{FOR}_{1}\right) \\
& \quad \times \mathrm{FOR}_{2} \times\left(1-\mathrm{FOR}_{3}\right) \\
& 150 \mathrm{MW}: \quad\left(1-\mathrm{FOR}_{1}\right) \times\left(1-\mathrm{FOR}_{2}\right) \times\left(1-\mathrm{FOR}_{3}\right)
\end{aligned}
$$

This can be extended to systems containing a larger number of units, and a simple computer algorithm has been constructed to keep track of the number of capacity states available and their associated probabilities. For a system such as PG\&E, with nearly 170 units, the complicated process of keeping track of these states and probabilities is then straightforward. Loss-of-load-probability curves under several assumptions have been calculated for both PGEE as a separate system, with interconnection support, and for the state considered as a fully interconnected system. 
The individual generating units, their full forced outage rates, and their partial outage states (where these exist) have been tabulated in Appendix B .

We first show a comparison among the risk curves for PG\&E for July 1977 and July and August 1978 in Figure 3. The curves a11 have nearly identical shapes, but the curves for 1978 are displaced by about 400 MWe from July 1977; that is, in order to achieve an equivalent level of reliability for the same load, an additional 400 MWe of support beyond the 1977 level will be needed for the PG\&E system should the drought continue into a third year. One can also see from this comparison that for PG\&E the July risk curve is about 15 percent lower than for August, for the same load. This is due primarily to the additional hydro PGE्E expects to have available in July beyond the hydro capacity in August.

Throughout the rest of this discussion we focus on August loads and resources as the month with greatest "risk" for PG\&E. As noted earlier in the supply-demand discussion, we have selected two cases for analysis, one case with essentially no change over 1977, and one which adopts the utility peak load projections (see Table 5). In order to arrive at monthly LOLP risk figures, one must know what the second, third, fourth, etc. peak days will be in a given month. We use an average of the historical data for July, August and the first part of September of 1977 to construct the monthly load ranking one might expect for August 1978. These are tabulated in Table 15. From the ratios presented in this table, one can estimate the peak loads given an expected peak day for the month. One can then compute the additional support PG\&E will require in order to have $\Sigma_{i}$ LOLP $\leq 8.5 \times 10^{-3}$. The risk curves for 1978 plotted in Figure 3 include 600 MW of "perfect" support (that is, no FOR is associated with this capacity). Using the two peak demand cases we described previously and the relationship among peak days, the amount of displacement of the August risk curve can be derived in order to meet the monthly LOLP criterion. For Case D, with the maximum peak demand of approximately 15400 MWe, the August 1978 curve requires a displacement of 1900 MW of additional support. For Case E, with no change 

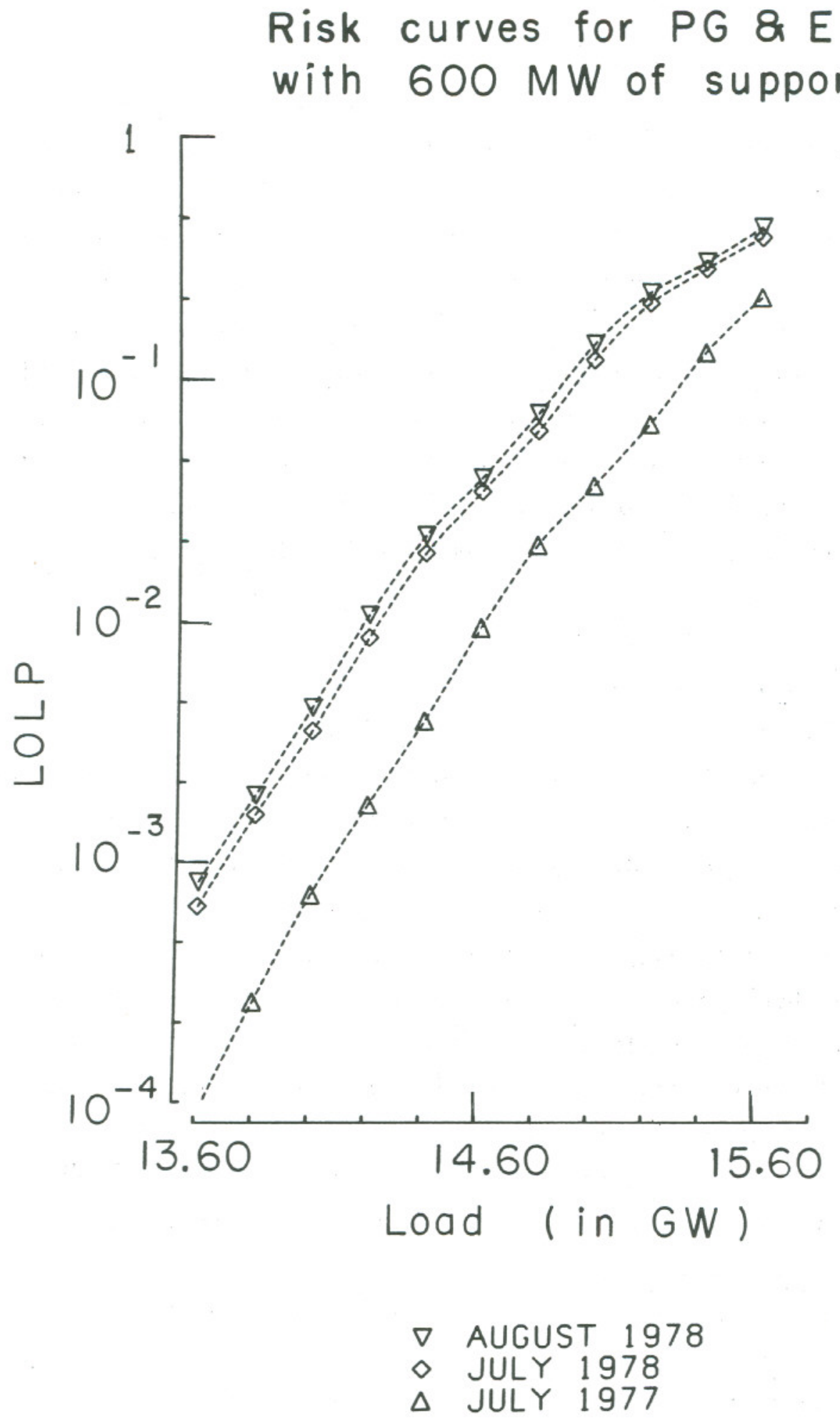

XBL $782-225$

Figure 3. Comparison of Risk of Loss-of-Load for PG\&E Assuming 600 MWe of Interconnection Support 
in peak demand from 1977, the displacement of the curve amounts to 300 MWe of support (Figure 4) In the first case, the amount of outside support arrived at through this procedure is larger than the support PGEE contracted for during the summer of 1977. In the second case the extra support is actually smaller than that acquired by PG\&E for the summer of 1977. In actuality, such support is available through the transmission system and hence has the forced outage rate of the transmission system. However, the effect of the transmission system FOR of 0.1 percent is negligible compared with FOR's for generators in the PG\&E system. As discussed earlier, the transmission line capacity interconnecting the PGGE system with southern California utilities and the Pacific Northwest is substantial and should be able to carry this additional load.

We then proceed to investigate the effect on the PG\&E system of having Diab1o Canyon Unit 1 on-1ine. As noted in earlier supplydemand discussion, the most optimistic projection calls for commercial power by August 1, which is one of the months of highest load for PG\&E. As shown in Appendix B, the forced outage rates have been estimated for this plant for the period before the first refueling, after this refueling and at "maturity." However, it is difficult to estimate these outage rates for the first month of service of this plant. We have followed the procedure suggested in Reference 18 that the difference between the immature and mature forced outage rates declines exponentially from plant start-up. Using the outage rates given by $\mathrm{PGEE}$, this allows one to estimate the outage rates close to start-up. The details are described in Appendix B. In order to assess the effects of including Diablo Canyon 1 in the resource mix for August, we bracket the FOR's by using the values derived in Appendix B and the immature outage rates given by PG\&E.

It is then of interest to calculate the resulting LOLP curves for the PGEE system and compare the results including Diablo Canyon Unit 1 with those for the PGGE system without Diablo Canyon. This comparison will give the amount of outside support this plant would replace. The risk curves for PG\&E with and without Diablo Canyon are shown in Figure 5. The difference between curves A and B is equivalent to displacing the curve with Diablo Canyon on-1ine by about $500 \mathrm{MW}$. 


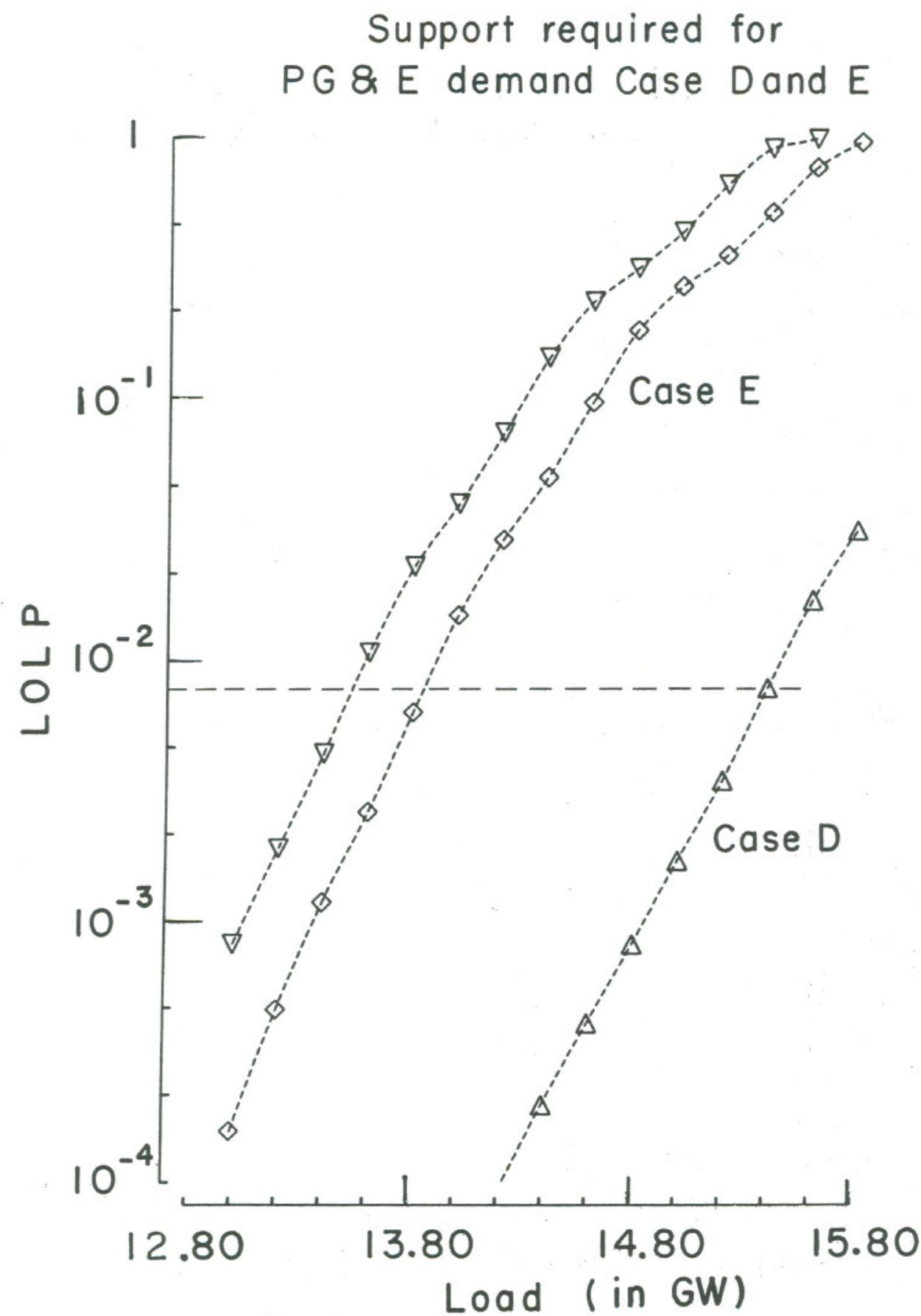

$\nabla$ AUGUST 1978 NO SUPPORT

$\checkmark$ LOAD CASE E

$\triangle$ LOAD CASE D

$$
X B L 782-223
$$

Figure 4. Support Required by Demand Cases D and E in Order to Meet Loss-of-Load Criterion of One Day in Ten Years 


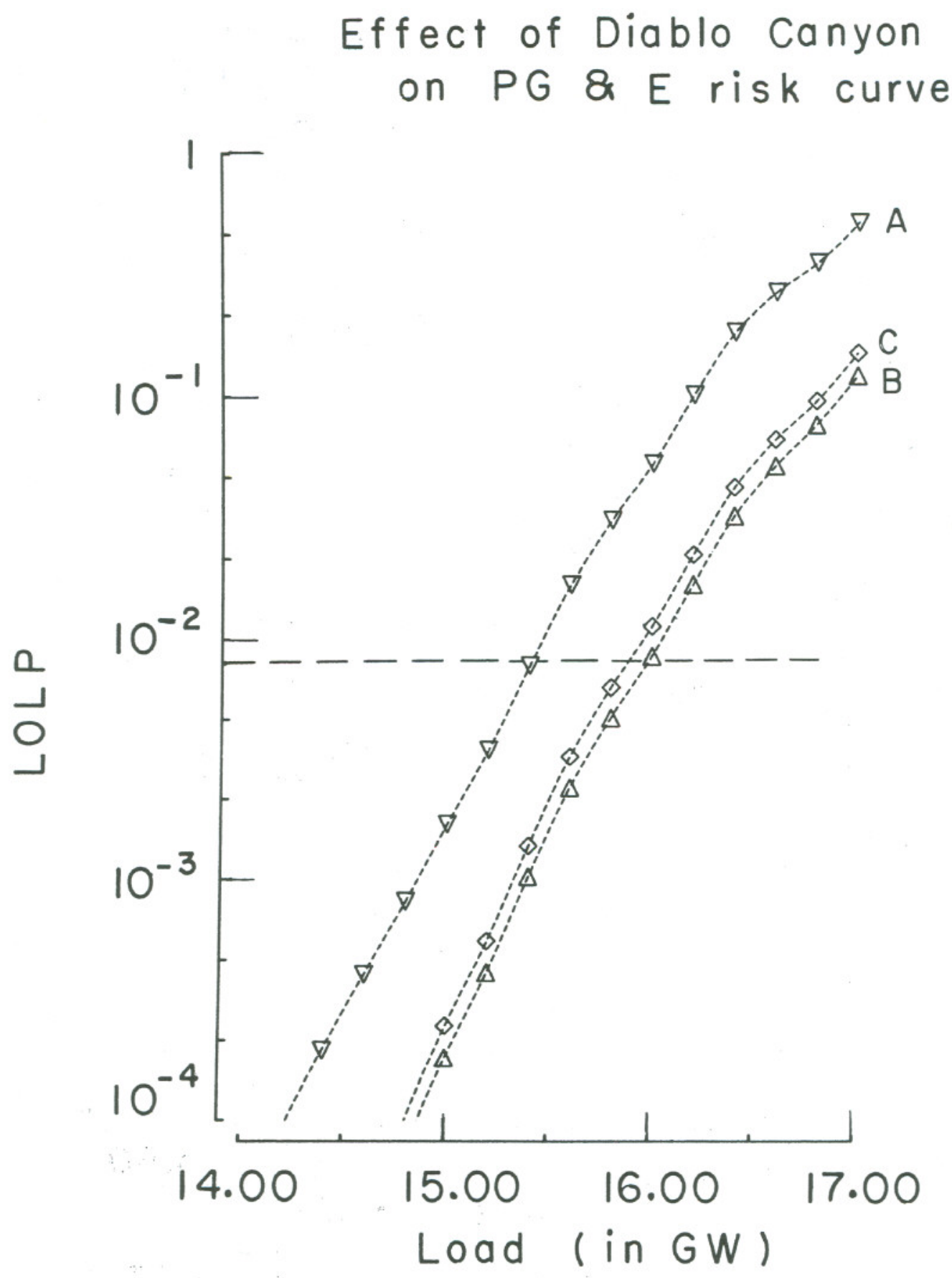

$\nabla$ CURVE A NO DIABLO CANYON

$\checkmark$ CURVE C WIDIABLO CANYON

$\triangle$ CURVE B WID.C. LOWER FOR

$$
X B L 782-226
$$

Figure 5. Comparison of PGE्E Risk of Loss-of-Load With and Without Diablo Canyon. The difference between curves $B$ and $C$ indicates the sensitivity to the assumed value for the forced outage rate. 
Also shown in Figure 5 is the curve (curve C) resulting from the assumption of the higher outage rate for the Diablo Canyon plant. If this curve were matched up with curve A, the effect of having Diablo Canyon Unit 1 available for load in August would be even smaller, equivalent to about 400 MWe of support.

Thus, the inclusion of Diablo Canyon into the PG\&E resources for August 1978 adds the equivalent of 400-500 MWe to peak load capability. At the same time, operating reserve margin requirements would increase, since Diablo Canyon would then be the largest single unit in the PG\&E system. According to Reference 3, PG\&E uses as an operating margin 3 percent of the load plus the largest single risk. With Diablo Canyon on-line, this latter element increases by about $200 \mathrm{MWe}$ since the next largest risk in PG\&E's service area system is the 875 MWe Rancho Seco nuclear power plant.

For the statewide system, LOLP has been calculated for four different cases. As discussed in the supply section, several changes have been made in the list of resources available for the summer of 1978, including full use of Castaic pumped storage, San Onofre, and full use of the DC intertie to the Pacific Northwest. We treat this as the reference case (curve A), and the results are presented graphically in Figure 6. As noted in Appendix B, the utilities do not use identical forced outage rates for the same, jointly-owned facilities. Curve B in Figure 6 labelled "higher FOR" shows the effect on the reference case of using the highest value for the forced outage rates on the DC intertie, Mohave 1, 2 and San Onofre 1. The resulting aggregate difference is almost a factor of two in LOLP compared with the reference case. By way of comparison, the risk curves based upon utility submittals to the CERCDC in August 1977, 6 with and without Diablo Canyon 1 have also been computed. The results are shown in Figure 6 as curves $C$ and D, respectively. These results include the use of San Onofre during August, since the refueling schedule has been pushed back, and do not include Geysers 12 or Humboldt Bay 3 .

Using the statewide peak load information in Table 15, we then tabulate the monthly LOLP for our reference case and the utility 


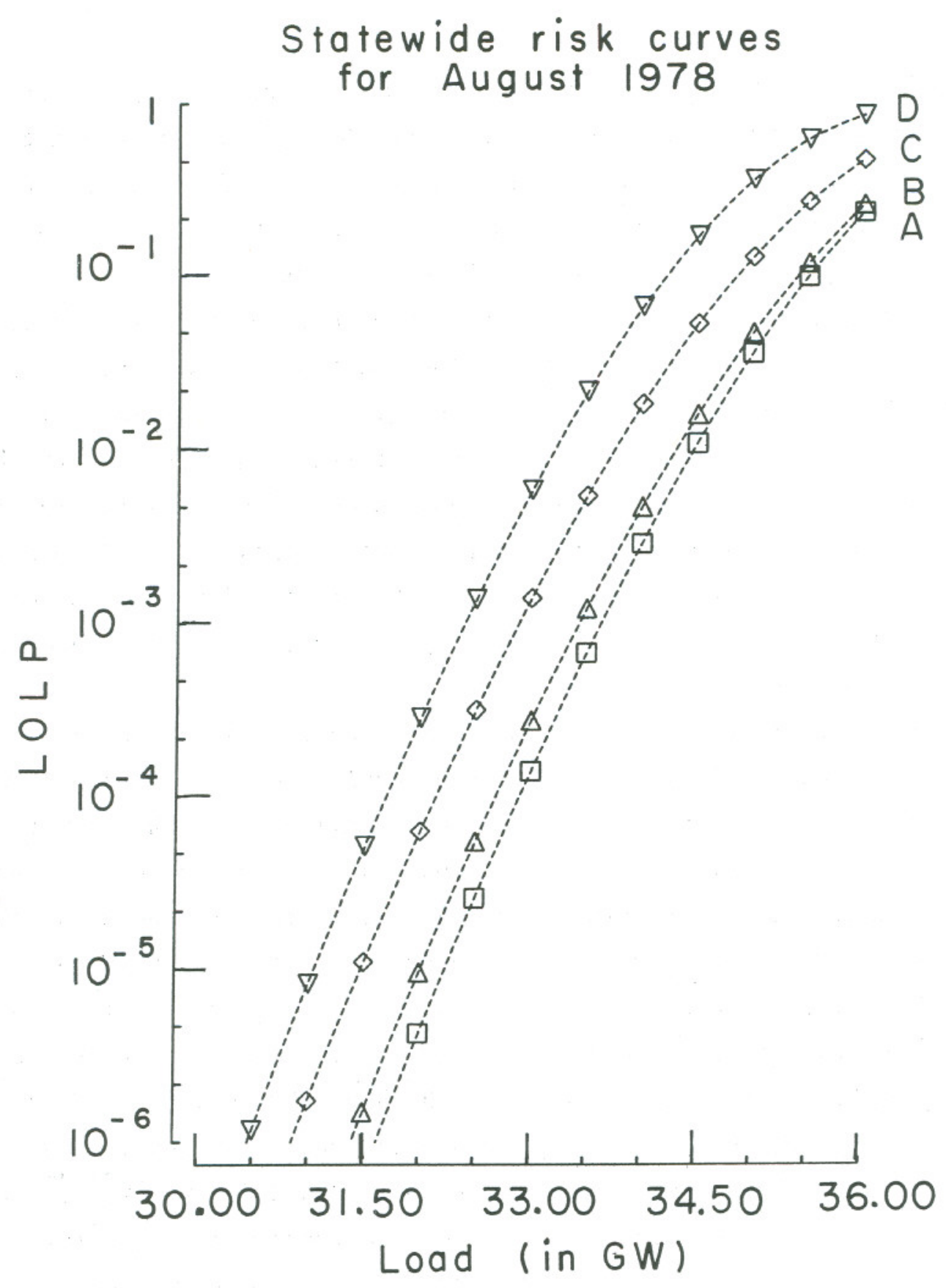

$\nabla \quad D \quad$ UTIL ITY SUBMITTAL

$\diamond$ C AS D WIDIABLO CANYON

$\triangle$ B AS A W/HIGHER FORS

$\square$ A REFERENCE CASE

$X B L 782-222$

Figure 6. Comparison of the Effect of Different Statewide Generating Resources Upon Loss-of-Load Probability. See text for details. 
Table 15

Summer Peak Load Order by Month for 1977 and Estimated Loads for 1978

\begin{tabular}{|c|c|c|c|c|c|c|c|c|c|c|}
\hline \multirow[b]{2}{*}{1977 Historical } & \multirow{2}{*}{$\begin{array}{c}\begin{array}{r}\text { Peak } \\
\text { Day }\end{array} \\
1 \\
\end{array}$} & \multicolumn{9}{|c|}{ In Order of Decreasing Load } \\
\hline & & 2 & 3 & 4 & 5 & 6 & 7 & 8 & 9 & 10 \\
\hline \multicolumn{11}{|l|}{ PGGE: } \\
\hline July & 13519 & 12913 & 12859 & 12854 & 12852 & 12777 & 12772 & 12634 & 12549 & 12489 \\
\hline Ratio to peak & 1. & .955 & .951 & .951 & .951 & .945 & .945 & .935 & .928 & .924 \\
\hline August & 13815 & 13443 & 13394 & 12777 & 12771 & 12716 & 12417 & 12381 & 12344 & 12320 \\
\hline Ratio to peak & 1. & .973 & .920 & .925 & .924 & .920 & .899 & .896 & .894 & .892 \\
\hline September & 13299 & 13276 & 13039 & $---^{a}$ & --- & --- & --- & --- & --- & --- \\
\hline Ratio to peak & 1. & .998 & .980 & & & & & & & \\
\hline Average Ratio & 1. & .976 & .967 & .938 & .938 & .933 & .922 & .915 & .911 & .908 \\
\hline \multicolumn{11}{|l|}{$\underline{\text { Statewide }}$} \\
\hline July & 29853 & 29517 & 29127 & 29102 & 28032 & 27730 & 27694 & 27600 & 27160 & 27084 \\
\hline Ratio to peak & 1. & .989 & .976 & .975 & .939 & .929 & .928 & .925 & .910 & .907 \\
\hline August & 29766 & 29234 & 29114 & 28585 & 28462 & 27887 & 27535 & 27237 & 27132 & 27042 \\
\hline Ratio to peak & 1. & .982 & .978 & .960 & .956 & .937 & .925 & .915 & .912 & .908 \\
\hline Sept ember & 30030 & 29657 & 29445 & $--^{a}$ & -- & --- & --- & --- & --- & --- \\
\hline Ratio to peak & 1. & .988 & .981 & & & & & & & \\
\hline Average Ratio & 1. & .986 & .978 & .968 & .948 & .933 & .926 & .920 & .911 & .908 \\
\hline \multicolumn{11}{|c|}{1978 Estimates $^{\mathrm{b}}$ (in MWe) } \\
\hline PG\&EE - Case D & 15428 & 15058 & 14919 & 14471 & 14471 & 14394 & 14225 & 14117 & 14055 & 14009 \\
\hline Statewide - Case D & 33445 & 32977 & 32709 & 32375 & 31706 & 31204 & 30970 & 30769 & 30468 & 30368 \\
\hline
\end{tabular}

\footnotetext{
${ }^{\mathrm{a}}$ On 1y the three highest peak days were used for September, since September generally is a cooler month and the loads decrease.

Peak days are taken from Table 5 .
} 
submittal cases. These are shown in Table 16. In a11 but one of these cases, the month1y LOLP is we11 below the PGGE criterion of $8.5 \times 10^{-3}$. For the modified utility submittal case, without Diablo Canyon, the peak day would exceed the LOLP criterion of $8.5 \times 10^{-3}$. Note that with the inclusion of either Diablo Canyon (curve D) or ful1 use of Castaic and the DC intertie (reference case, curve A), the total monthly LOLP drops below this criterion. It would appear that, from a statewide perspective, the utilities' projected coincident load for summer 1978 can be met with little risk. Further, the least risk case arises from full use of the Castaic pumped storage facility and the DC intertie. This statewide result indicates that the additional support that may be required by PG\&E for August can be provided by other California utilities without the risk, as measured by LOLP, increasing beyond PG\&E's planning criterion.

As we noted in our earlier paper, the shape of these risk curves a1so suggest that conservation or load management can have significant benefit in reducing risk, since the curve is steepest in that region. Hence, 200 to 300 MWe of load reduction through load management results in a bigger change in LOLP than an equivalent amount of outside support. 
Table 16

Statewide Loss-of-Load-Probability Results for August 1978

\begin{tabular}{|c|c|c|c|c|c|c|c|}
\hline \multirow{2}{*}{$\begin{array}{l}\text { Peak } \\
\text { Load }^{a} \\
(\mathrm{MWe})\end{array}$} & \multicolumn{7}{|c|}{ LOLP } \\
\hline & & $A^{b}$ & & $B^{C}$ & $C^{d}$ & & $D^{e}$ \\
\hline 33445 & 4.23 & $\times 10^{-4}$ & 7.81 & $\times 10^{-4}$ & $1.47 \times 10^{-2}$ & 3.53 & $x 10^{-3}$ \\
\hline 32977 & 9.34 & $\times 10^{-5}$ & 1.87 & $\times 10^{-4}$ & $4.17 \times 10^{-3}$ & 9.55 & $x 10^{-4}$ \\
\hline 32709 & 3.75 & $\times 10^{-5}$ & 2.82 & $\times 10^{-5}$ & $1.91 \times 10^{-3}$ & 4.27 & $\times 10^{-4}$ \\
\hline 32375 & 1.17 & $\times 10^{-5}$ & 2.56 & $\times 10^{-5}$ & $6.97 \times 10^{-4}$ & 1.52 & $\times 10^{-4}$ \\
\hline 31706 & 9.21 & $\times 10^{-7}$ & 2.25 & $\times 10^{-6}$ & $7.54 \times 10^{-5}$ & 1.58 & $\times 10^{-5}$ \\
\hline 31204 & 1.25 & $\times 10^{-7}$ & 3.08 & $x 10^{-7}$ & $1.20 \times 10^{-5}$ & 2.46 & $\times 10^{-6}$ \\
\hline 30970 & 4.83 & $x 10^{-8}$ & 1.21 & $\times 10^{-7}$ & $5.04 \times 10^{-6}$ & 1.02 & $\times 10^{-6}$ \\
\hline 30769 & 2.07 & $\times 10^{-8}$ & 5.25 & $\times 10^{-8}$ & $2.32 \times 10^{-6}$ & 4.69 & $\times 10^{-7}$ \\
\hline 30468 & 5.66 & $\times 10^{-9}$ & 1.46 & $\times 10^{-8}$ & $7.05 \times 10^{-7}$ & 1.41 & $\times 10^{-7}$ \\
\hline 30368 & 3.64 & $\times 10^{-9}$ & 9.46 & $\times 10^{-9}$ & $\underline{4.70 \times 10^{-7}}$ & 8.29 & $\times 10^{-8}$ \\
\hline TOTAL & 5.67 & $\times 10^{-4}$ & 1.07 & $\times 10^{-3}$ & $2.16 \times 10^{-2}$ & 5.08 & $\times 10^{-3}$ \\
\hline
\end{tabular}

$\mathrm{a}_{\text {From Table } 15 .}$.

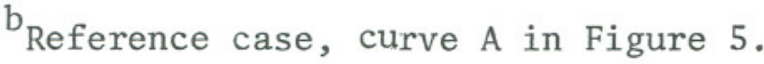

${ }^{\mathrm{c}}$ Curve $\mathrm{B}$ in Figure 5 .

Modified utility submittal, without Diablo Canyon, curve $\mathrm{C}$ in Figure 5 .

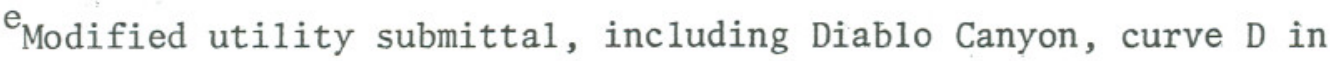
Figure 5 . 

IMPACTS OF SUPPLY OPTIONS

\section{ENVIRONMENTAL EFFECTS}

$\underline{\text { Introduction }}$

This section provides an estimate of the amount of air pollutants to be expected in the South Coast Air Basin due to transfers of energy to PG\&E from Southern California Edison (SCE) and Los Angeles Department of Water and Power (LADWP) during 1978. To provide the proper perspective in which to view these emissions, the amount of total emissions and the relative contribution from power plants are discussed, as are the geographical and temporal distributions of these emissions. Regulation of the oil sulfur content and decreased gas availability and their effects on emissions patterns are also considered.

The effect of these emissions on air quality in the South Coast Air Basin is difficult to estimate. Air quality is a complex function of emissions, meteorology, topography, the complex interaction of pollutants, and removal processes. We have looked at historical air quality indices in the Basin and the impact of the drought as measured by these indices.

\section{Emission Inventories}

A1though emission inventories taken ${ }^{19-23}$ in the South Coast Air Basin differ in geographical area and number of sources covered, they show no serious disagreement with regard to the magnitude of power plant emissions. These emissions, expressed as annual averages, comprised 149 tons per day ${ }^{20}$ or 43 percent of the $\mathrm{NO}_{\mathrm{x}}$ and 140 tons per day $^{21}$ or 45 percent of the ${ }^{2}{ }_{x}$ from stationary sources in $1972-73$ and 1974, respectively. When mobile sources are also taken into account, these values decrease to 12 percent of total $\mathrm{NO}_{\mathrm{x}}$ and 43 percent of total $\mathrm{SO}_{\mathrm{x}}$ emissions. ${ }^{19}$ Approximately 80 percent of these power plant emissions occur in Los Angeles County.

Combustion of liquid fuels is the largest stationary source of $\mathrm{SO}_{\mathrm{X}}$, and utility power plant boilers are the biggest stationary users 
of liquid fuels. The amount of $\mathrm{SO}_{\mathrm{x}}$ released is directly proportional to the amount of fuel burned and the sulfur content of the fuel. The dominant sources of $\mathrm{SO}_{\mathrm{x}}$ after power plants are refineries and carbon plants. Basin-wide stationary sources such as these contribute more than four times as much oxides of sulfur as do mobile sources.

The geographical distribution of emissions is shown in Figure 7. of the nine grid squares with the highest emissions, eight contain power plants as the largest source.

Combustion of fuels produces $\mathrm{NO}_{x}$, primarily as NO, with oil fuel generating more $\mathrm{NO}_{x}$ than gas. The amount of $\mathrm{NO}$ released is dependent on many factors (including combustion temperature and concentrations of atmospheric nitrogen and atomic oxygen) and, in power plants, is load-dependent. The dominant stationary sources in the South Coast Air Basin are electric utilities, petroleum industries, mineral processing industries, and metallurgical industries.

The geographical distribution of $\mathrm{NO}_{\mathrm{x}}$ emissions from stationary sources is shown in Figure 8. Five grid squares with high values are located close together in southwest Los Angeles County and contain power plants and refineries. These major sources are usually upwind of the heavily populated areas.

Power P1ant Emission Trends

The amount of emissions depends upon the amount of energy generated for a given time period as well as the type of fuel used. The use of natural gas in those plants capable of using either gas or oil will significantly reduce emissions. The amounts of emissions from power plants using gas and oil respectively are: ${ }^{\mathrm{NO}}{ }_{x}, 0.79 \mathrm{vs}$. $1.37 \mathrm{SO}_{\mathrm{x}}, 0.005$ vs. 1.40 (0.22 percent sulfur content of oil); and particulates, 0.015 vs. 0.300 pounds per equivalent barre1. ${ }^{24}$ (The amount of gas equal in energy to a barrel of oil is taken to be 6000 cubic feet.)

The enactment of Rule 431.2 by the South Coast Air Quality Management District (SCAQMD) requires steam generators in power plants in the Basin to burn oil with a sulfur content of 0.25 percent or less. Previously, Rule 431 required all stationary sources to burn 


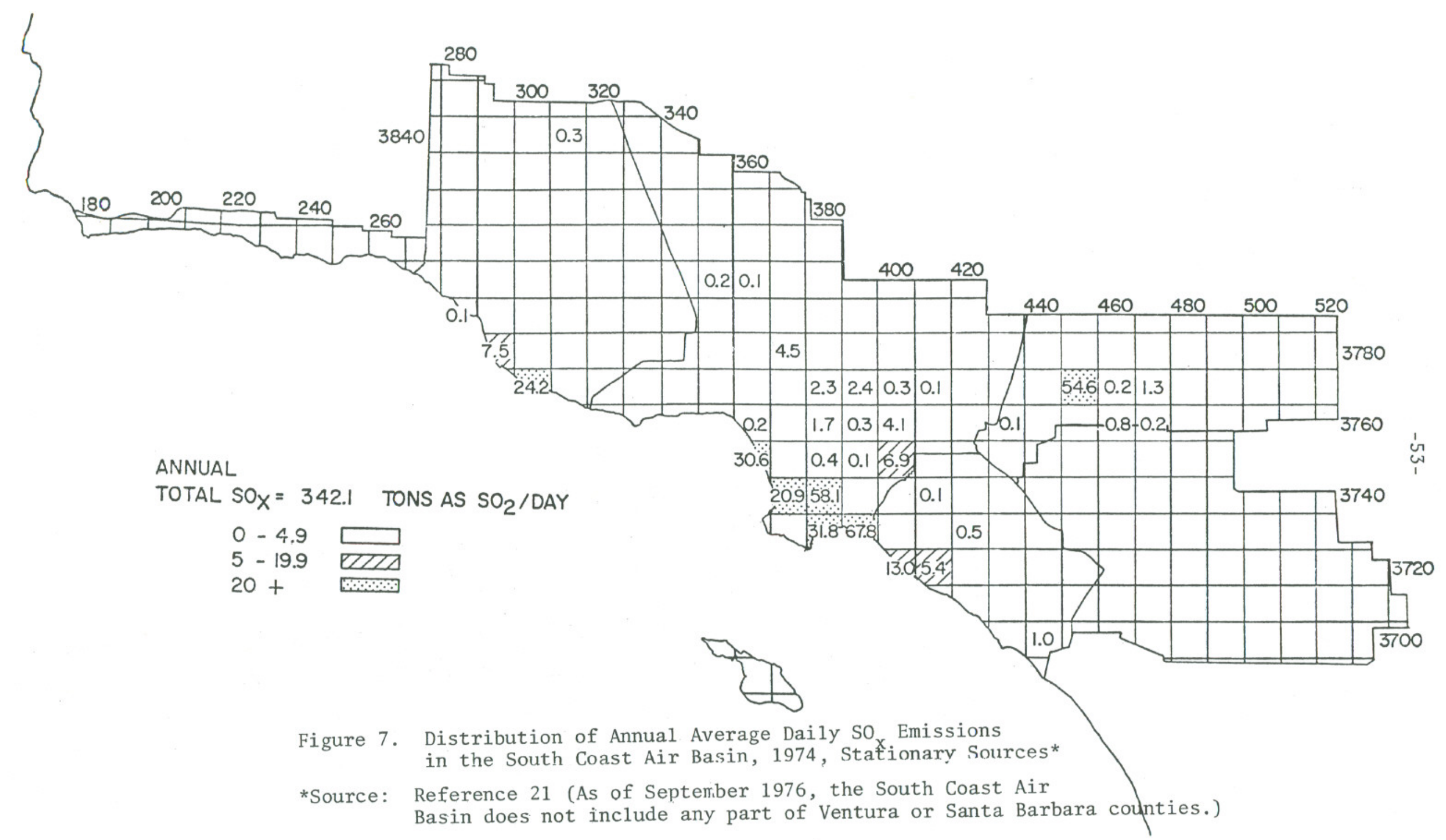



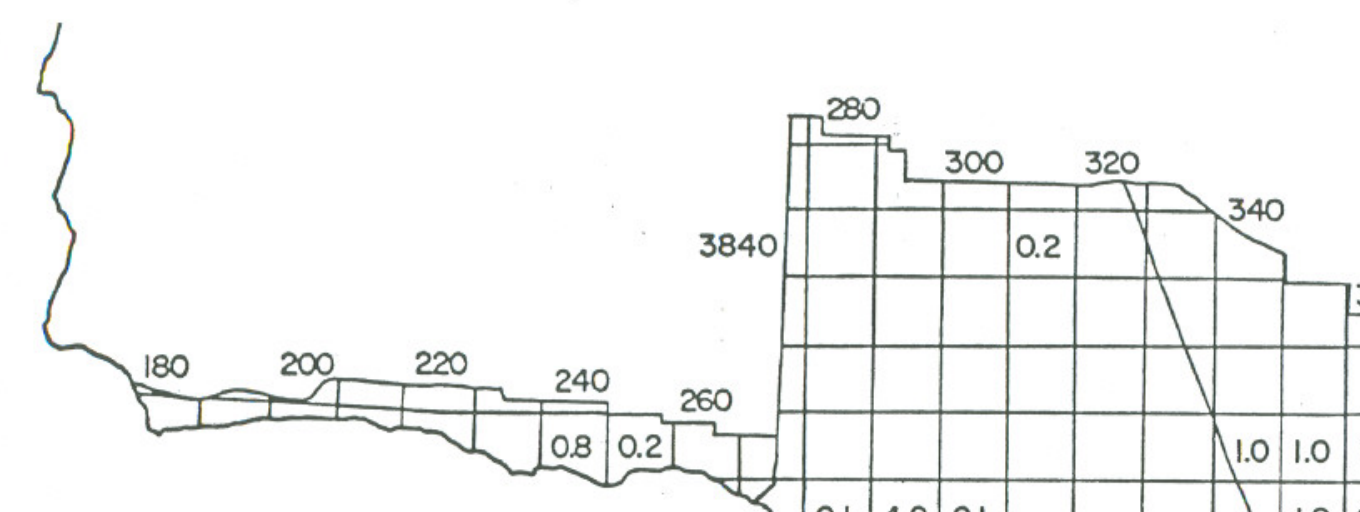

\section{0}
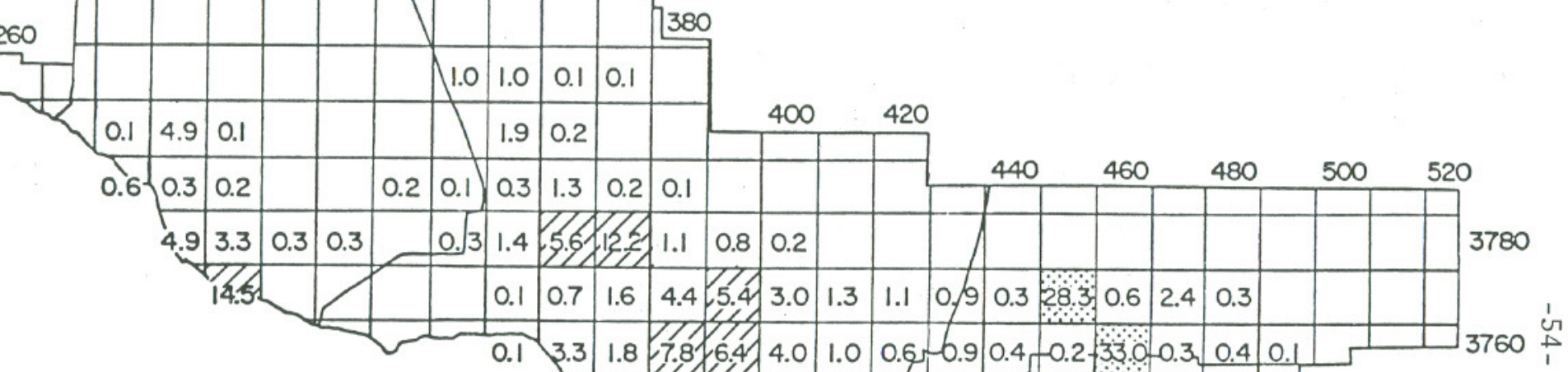

$\begin{array}{llllllll}35.3 & 21 & 4.1 & 2.7 & 9.0 & 2.4 & 0.1\end{array}$

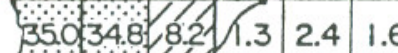

070 난 1.7

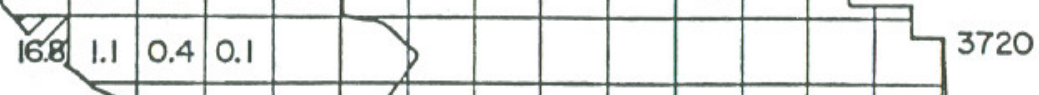

Daily NOx Emissions, tons/day

$\begin{array}{cc}0-4.9 & \square \\ 5.0-19.9 & \square Z \square \\ 20.0+ & \square\end{array}$

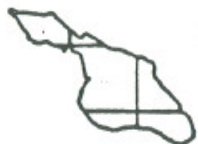

0.10 .30 .2

Figure 8. Distribution of Annual Average Daily NO Emissions

in the South Coast Air Basin, 1972-73, Stationary Sources*

*Source: Reference 20 
oil with 0.5 percent sulfur. Since utilities have been using oil averaging 0.32 percent sulfur in 1977, this change will significantly reduce power plant $\mathrm{SO}_{\mathrm{x}}$ emissions in 1978. Estimates of future emissions must include consideration of increasing total fuel use, decreasing gas supplies and changes in regulation of sulfur content of oil. A projection by staff at SCAQMD indicates that the $1978 \mathrm{SO}_{\mathrm{x}}$ emissions from power plants will be 75 percent of the 1977 levels, thus bringing emissions down to a level between the 1974 and 1975 amounts (Table 17). Other estimates, when corrected for the low sulfur restriction, are in agreement. $21,22,24$

Increased fuel use and decreasing availability of gas have meant a dramatic increase in $\mathrm{NO}_{x}$ emissions from power plant boilers, about 70 percent higher in 1977 than in 1976 (Table 17). It is expected (from utilities' and SCAQMD projections) that 1978 will be a year of further increases in $\mathrm{NO}_{x}$ emissions, up 5-10 percent from 1977. While automobiles are the major contributors of $\mathrm{NO}_{x}$ emissions, any increase in emissions of precursors to smog in this air basin can adversely affect air quality.

Seasonal emission patterns have also changed as a result of decreased gas availability. Historically, power plants burned gas in summer and oil in winter but now use oil year round. Thus, while winter emissions have increased with increased fuel use, summer power plant emissions have increased more rapidly as cleaner burning gas has been replaced by oil.

The relative importance of power plant emissions can change, even if the absolute amounts (in tons) of emissions from power plants do not change. For example, attempts are being made through regulation to reduce $\mathrm{NO}_{x}$ emissions from automobiles, their principal source. As these restrictions succeed in reducing the automotive contribution, stationary sources (if not simultaneously regulated) can come to represent an increasing percentage of total $\mathrm{NO}_{\mathrm{x}}$ emissions. This situation is expected to bring stationary and mobile sources to parity in their $\mathrm{NO}_{\mathrm{x}}$ emissions around $1980 .{ }^{20}$

\section{Power Plant Emissions and Transfers}

Total and peak day emission estimates for each month in 1978 are given in Table 18. These peak day estimates are derived from the 
Table 17

History and Outlook of Power Plant Fossil Fuel Use and Emissions in South Coast Air Quality Management District

\begin{tabular}{|c|c|c|c|c|c|}
\hline \multirow[t]{2}{*}{ Year } & \multicolumn{2}{|c|}{$\begin{array}{c}\text { (10 }{ }^{6 \text { Fuel }} \text { barrels } \\
\text { of oil } \\
\text { equivalent/ } \\
\left.\text { year }{ }^{a}\right)\end{array}$} & \multirow{2}{*}{$\begin{array}{c}\text { Fraction of } \\
\text { Gas in } \\
\text { Fuel Use } \\
(\%)\end{array}$} & \multicolumn{2}{|c|}{$\begin{array}{l}\text { Emissions } \\
\text { (tons/day) }\end{array}$} \\
\hline & $\begin{array}{r}\text { Total } \\
\text { Fuel }\end{array}$ & Gas & & $\mathrm{SO}_{2}$ & ${ }^{\mathrm{NO}}{ }_{x}$ \\
\hline 1974 & 56 & 17 & 31 & 147 & 93 \\
\hline 1975 & 58 & :3 & 22 & 167 & 98 \\
\hline $1976^{b}$ & 55 & 10 & 18 & 166 & 95 \\
\hline $1977^{\mathrm{b}}$ & 80 & 6 & 8 & $208^{c}$ & $163^{\mathrm{e}}$ \\
\hline $1978^{b}$ & 81 & -- & -- & $156^{\mathrm{d}}$ & $172^{\mathrm{e}}$ \\
\hline $1979^{\mathrm{b}}$ & 84 & -- & -- & $162^{\mathrm{d}}$ & $178^{\mathrm{e}}$ \\
\hline $1980^{b}$ & 84 & -- & -- & $162^{d}$ & $178^{\mathrm{e}}$ \\
\hline
\end{tabular}

Source: John Stuart, "Fossil Fuel Emissions in the South Coast Air Quality Management District and the Role of Solar Energy in Reducing These Emissions," paper presented at the Helioscience Institute Conference, Palm Springs, May 2, 1977.

${ }^{a}$ One barrel of oil is equivalent to $6000 \mathrm{cf}$ of natural gas.

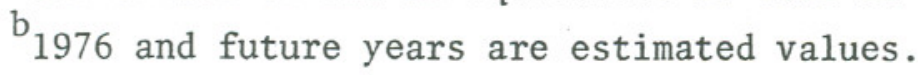

${ }^{\mathrm{c}}$ Fuel is estimated to have an average sulfur content of 0.32 percent.

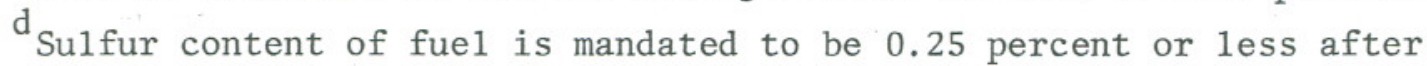
1978. SCAQMD expects an average sulfur content of .22 percent.

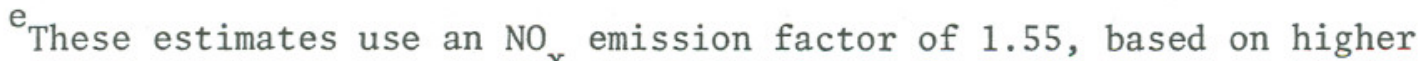
expected loads for power plants in the South Coast Air Basin. cf. D. Danie1son, Testimony before CPUC, Case No. 10292, South Coast Air Quality Management District, May 1977. 
Table 18

Estimated Peak Day Emissions from Power Plants in

South Coast Air Quality Management District, $1978^{\mathrm{a}}$

\begin{tabular}{|c|c|c|c|c|c|c|}
\hline \multirow{2}{*}{ Month } & \multicolumn{3}{|c|}{$\begin{array}{l}\text { Monthly Emissions } \\
\text { (Tons) }\end{array}$} & \multicolumn{3}{|c|}{$\begin{array}{l}\text { Estimated Peak Day } \\
\text { Emissions (Tons) }\end{array}$} \\
\hline & ${ }^{\mathrm{SO}_{\mathrm{X}}}$ & ${ }^{\mathrm{NO}} \mathrm{X}$ & $\begin{array}{l}\text { Partic- } \\
\text { ulate }\end{array}$ & ${ }^{\mathrm{SO}} \mathrm{X}$ & ${ }^{\mathrm{NO}}{ }_{\mathrm{X}}$ & $\begin{array}{l}\text { Partic- } \\
\text { ulate }\end{array}$ \\
\hline April & 4758 & 4752 & 640 & 172 & 179 & 23 \\
\hline May & 4973 & 4809 & 658 & 176 & 174 & 23 \\
\hline June & 4945 & 4803 & 668 & 190 & 188 & 26 \\
\hline July & 5718 & 5400 & 772 & 214 & 215 & 29 \\
\hline August & 5503 & 5379 & 791 & 215 & 224 & 31 \\
\hline September & 5064 & 5057 & 729 & 196 & 206 & 28 \\
\hline October & 5519 & 5251 & 739 & 208 & 209 & 28 \\
\hline November & 5139 & 4823 & 699 & 200 & 194 & 27 \\
\hline December & 5255 & 4927 & 713 & 191 & 179 & 25 \\
\hline
\end{tabular}


projected monthly emissions using ratios of peak day to average day emissions from 1976 data, ${ }^{25}$ the latest year for which the data are available. Transfers are not included, since the amount of energy transfers that will occur on a peak day is not known.

A continued deficit in water available for hydroelectric plants would cause increased dependence on steam generation plants in the South Coast Air Basin, in part due to transfers of energy to PG\&्षE. Because of uncertainties about gas supplies, it is assumed that all transfers will be met by the combustion of oil, with concomitant increased emissions of air pollutants.

Data supplied by the utilities to CERCDC include projections of monthly oil usage and emissions of $\mathrm{SO}_{x}, \mathrm{NO}_{x}$ and particulates for 1978. Emission factors based on oil consumption by power plants were derived as follows.

A linear relationship is observed (as expected) between emissions of $\mathrm{SO}_{\mathrm{x}}$ and particulates and the amount of oil burned whereas for ${ }^{\mathrm{NO}_{\mathrm{x}}}$ emissions the linear relationship serves as a close approximation. The load and choice of units to meet that load and the individual plant parameters must be known for estimating emissions. Use of a linear approximation for each utility is estimated to give less than a 5 percent error in the Basin-wide totals. The emission factors (pounds per barrel oil) used for calculating emissions due to transfers are shown in Table 19.

Table 19

Emission Factors for Southern California Electric Utilities ${ }^{a}$ (pounds per barre1 oil)

\begin{tabular}{llll}
\hline & $\mathrm{SO}_{2}$ & $\mathrm{NO}_{2}$ & Particulates \\
\hline SCE & 1.492 & 1.372 & $0.159^{\mathrm{b}}$ \\
LADWP & 1.591 & 1.671 & 0.300 \\
SCAQMD & 1.40 & 1.370 & 0.300 \\
\hline
\end{tabular}

${ }^{a_{\text {Source }}}$ Reference 6

$\mathrm{b}_{\text {This emission factor differs from the factor of } .382 \text { for }}$ SCE in Reference 25. It is not clear why this emission factor for particulates has changed. 
From Section 3, two estimates of expected transfers were obtained. The ratio of energy per quantity of oil burned, obtained from submittal data, ${ }^{6}$ are used to calculate the amount of oil required for a given amount of transferred energy. From this the expected emissions are calculated, using ratios of emissions to oil consumption derived from the linearity assumption. The transfers are partitioned between SCE and LADWP in the amounts 71 percent and 17 percent, respectively (based on actual transfers from April through July, 1977). The balance of PGGE's shortfall is expected to be met by SDGGE.

The emissions resulting from energy transfers from the South Coast Air Basin to PGEE, shown in Table 20, would add as much as 10 percent to the power plant $\mathrm{SO}_{\mathrm{x}}$ and $\mathrm{NO}_{\mathrm{x}}$ emissions during the summer peak months. These calculations are performed using averages for each utility. Note that if less efficient, or "dirtier," plants are used at high load, and if transfers occur at high loads, then the values in Table 20 will be underestimates of true emissions resulting from transfers. The calculation of particulate emissions does not include the significant contribution of secondary particulates, i.e., those formed by oxidation of $\mathrm{SO}_{\mathrm{x}}$ to sulfate and $\mathrm{NO}_{\mathrm{x}}$ to nitrate.

Table 20

Expected Emissions Due to Energy Transfers in 1978

\begin{tabular}{lcccc}
\hline & June & July & August & September \\
\hline Transfers: & & & & \\
GWH $\left(10^{9} \mathrm{kWh}\right)^{\mathrm{a}}$ & $200-500$ & $150-475$ & $0-200$ & $0-100$ \\
$10^{3}$ bbls oil & $(275-689)$ & $(207-654)$ & $(0-275)$ & $(0-138)$ \\
Emissions (tons): & & & & \\
$\mathrm{SO}_{\mathrm{x}}$ (as SO$)_{2}$ & $208-520$ & $156-495$ & $0-208$ & $0-104$ \\
$\mathrm{NO}_{\mathrm{x}}$ (as NO & \\
Particulates & $196-493$ & $148-468$ & $0-196$ & $0-98$ \\
\hline
\end{tabular}

a See Table 13 . 
Air Quality

California air quality standards are violated on a regular basis in the South Coast Air Basin. ${ }^{*}$ While the exact relationship between emissions and air quality is elusive, it seems reasonable to infer that increased violations may be expected for the nitrogen dioxide and perhaps oxidant standards in 1978 unless other circumstances offset the increased $\mathrm{NO}_{\mathrm{x}}$ emissions from power plants. On the other hand, violations of the sulfur dioxide and sulfate standards should decrease as a result of decreased emissions when lower sulfur oil is burned in power plants.

It is important to note that seasonal patterns strongly affect when these violations occur. Thus oxidant and oxidant-sulfate episodes occur with greater frequency in summer, ${ }^{26}$ when electricity demand is a1so high. This effect tends to amplify the importance of additional power plant emissions due to transfers at these times when ambient pollutant levels are already high. (Care must be exercised when relying on historical data; where power plants traditionally burned gas in summer and oil in winter, oil is now used all year. ${ }^{20}$ Therefore, measures to decrease oil burning, including conservation efforts and increased use of gas, while important at al1 times, are particularly critical during peak days of summer months.

So far it has not been possible to quantify the impact of power plant emissions on 1ocal air quality. One study ${ }^{22}$ has been able to show a correlation between $\mathrm{SO}_{\mathrm{x}}$ emissions from non-utility sources and ambient (annual average) $\mathrm{SO}_{2}$ measured at Los Angeles and Long Beach because identifiable sources (automobiles, chemical plants, and other non-utility combustion of fuel) had low effective stack heights and were located close to the air quality monitoring stations.

In the absence of a known quantitative relationship between power plant $\mathrm{SO}_{\mathrm{x}}$ emissions and air quality, it is difficult to predict the quantitative effects on air quality due to changes in those emissions. Part of the difficulty in obtaining such a relation resides in the changing geographical distribution of emissions from year to year as generating capacity increases and in the domination of ground level air quality monitors by nearby, ground leve1 sources.

* In 1975, there were 78 violations of the one-hour nitrogen dioxide standard, 62,48 and 307 violations of the 24-hour sulfur dioxide, particulate sulfate, and suspended particulate standards, respectively. 
The effect of $\mathrm{NO}_{x}$ emissions on air quality are even more difficult to predict. Both reactive hydrocarbons and oxides of nitrogen are precursors of oxidants, particularly ozone. The formation of oxidants depends upon the topography of the area. In addition many other parameters which change with time are important, including the geographical distribution and amounts of emissions (or ambient levels) of several pollutants (including carbon monoxide, nitric oxide, nitrogen dioxide, hydrocarbons of different reactivities and ozone). Meteorological parameters describing the solar radiation intensity, temperature, relative humidity, and wind speed and direction at different altitudes are needed. Chemical interactions among the pollutants are complex and various species may be absorbed by clouds or by substances on the earth's surface.

A detailed analysis of oxidant prediction models has been published. ${ }^{27}$ The simplest methodologies-rollback models-apply to changes in hydrocarbon emissions for a constant hydrocarbon-to$\mathrm{NO}_{\mathrm{x}}$ ratio. The most sophisticated models employ physicochemical relationships and large amounts of input data to give a detailed description in time and space distributions of pollutant concentrations. Due to their complexity, these models are used to describe relatively short time periods (i.e., worst day) in great detail, rather than giving statistical information for a season. Empirical relationships are best suited to this type of statistical prediction and may be based on smog chamber or atmospheric measurements.

Both an empirical relationship based on aerometric data ${ }^{28}$ and a smog chamber mode1 ${ }^{29}$ agree that an increase in present levels of $\mathrm{NO}_{\mathrm{x}}$ emissions (or ambient levels) for fixed hydrocarbon emissions (or air quality) will result in lower maximum oxidant concentrations locally. Yet the maximum oxidant concentration possible at a site downwind of the source at a later time will be dependent on precursor levels including transported $\mathrm{NO}_{\mathrm{x}}$, with the effect that air quality at this site would be adversely affected.

No stronger effort was made to quantify air quality predictions because 1) new models promising improved predictive capability are 
under development but not yet verified and 2) data essential to the accuracy of such an analysis is currently incomplete. (An inventory of hydrocarbon emissions by source and reactivity is expected to be completed by early 1978.)

Even when emissions for the Basin are well characterized, the air quality (and subsequent health effects) is highly dependent upon meteorological conditions. To estimate ozone levels on a particular day, the SCAQMD uses a composite Meteorological Index which includes data on inversion strength and height, atmospheric stability, radiation and pressure gradients. ${ }^{30}$ An examination of the monthly average of this index for the summer months of 1977 indicates that the drought conditions did not, on the average, create meteorological conditions significantly different from previous years. The average of the meteorological index for the summer months in the base period, 1970-1974, is 17.8 parts per hundred million of equivalent ozone concentration. The average of that index for the summer months of 1977 is 17.7 parts per hundred million of equivalent ozone concentration.

In conclusion, transfers of electricity to PG\&E from the South Coast Air Basin would add as much as 10 percent to the emissions next summer. Of the two major pollutant emissions, $\mathrm{SO}_{\mathrm{x}}$ emissions are expected to decrease during 1978 due to lower sulfur content of oil while $\mathrm{NO}_{\mathrm{x}}$ emissions are expected to increase due to increased generation and to a larger fraction of oil fuel use. Air quality standards have been violated regularly in the past in this basin so any additional emissions due to transfer of electricity to PG\&्षE will further deteriorate air quality in this basin.

\section{AVERAGE PRICES* FOR PACIFIC GAS AND ELECTRIC COMPANY}

During 1977 electric utilities in the state resorted to thermallygenerated electricity to make up for the losses in hydroelectric generation. However, meeting the state's electricity demand with increased oil- and gas-fired generation is costly; average prices for the 12

\footnotetext{
* The term prices, as used throughout this section for 1978, refers to
} average revenues at an assumed 9.2 percent rate of return. 
months prior to September 30, 1977, for PG\&E, the utility most affected by the drought, were $38 \mathrm{mills} / \mathrm{kWh}$, up from $28 \mathrm{mills} / \mathrm{kWh}$ during $1976 .{ }^{31}$ If the drought were to continue for another year, these prices would increase further. To what extent these prices would increase and how they would respond to changes in demand and supply during 1978 are questions we examine in this section.

To compare the effect of the drought on electricity prices during 1978, we estimated average prices for 1978 for two cases. The main difference in these cases is the amount of hydroelectric generation which would be available during 1978. In the first case we assume the amount of hydroelectricity anticipated by the utilities if the drought continued in 1978.6 In the second case, prices are evaluated under normal rainfall conditions, and hydroelectricity is assumed available at the 1975 level of generation.

In each case three options were considered for nuclear and new geothermal supplies: 1) the PG\&E supply forecast as submitted to the CERCDC, ${ }^{6}$ 2) the PGक्षE forecast but with Diablo Canyon 1 power plant delayed until August and Geysers 12 and 15 delayed until the fall,* and 3) the PG\&E forecast with Diablo Canyon 1 delayed past 1978 and with the Geysers delayed as in the second option. Increased hydroelectric generation during a wet year would displace expensive transfers and oil-fired electricity generation in each of the three options. The second and third options are identical to those examined in Section 3 .

Electricity rates were estimated for each of these supply options to satisfy three levels of demand for 1978. The three levels called for a 4.7 percent, zero percent and -2.0 percent change from 1977 sales as explained in Section 2. In all 18 scenarios, 9 under each weather case were examined ( 3 options $\times 3$ demand levels $\times 2$ weather cases).

Mode1

Our model to predict average electricity prices given various electricity supply and demand scenarios is based on a "rate equation" presented in Kahn et al. ${ }^{32}$ The rate equation performs a simple

\footnotetext{
* Humboldt Bay Unit 3 assumed not available in options 2 and 3 .
} 
accounting of the various elements which enter into the cost of generating and distributing electricity. The equation considers both fixed costs such as administrative expenses and capital charges and variable costs, such as fuel and maintenance, as well as tax impacts of both federal income taxes and investment tax credits.

The rate euqation determines an average price of electricity as follows :

$$
P=\left[\frac{I+D+M_{F}+T+F}{\left(1-r_{R}\right)}+\frac{E-\left(r_{F} a+i\right) \Delta K}{\left(1-r_{R}\right)\left(1-r_{F}\right)}\right] \frac{1}{Q}+\frac{M_{V}}{1-r_{R}}
$$

where

$$
\begin{aligned}
\mathrm{P} & =\text { average price per } \mathrm{kWh} \\
\mathrm{Q} & =\text { annual energy demand }(\mathrm{kWh}) \\
\mathrm{I} & =\text { interest expenses on bonded debt } \\
\mathrm{D} & =\text { depreciation charges } \\
M_{F} & =\text { fixed maintenance expenses } \\
\mathrm{T} & =\text { property taxes } \\
\mathrm{F} & =\text { fuel expenses } \\
\mathrm{E} & =\text { earnings after interest expense } \\
\Delta_{\mathrm{K}} & =\text { capital additions to rate base } \\
M_{\mathrm{V}} & =\text { variable maintenance expenses per } \mathrm{kWh} . \\
\mathrm{a} & =\text { accelerated depreciation factor } \\
\mathrm{i} & =\text { investment tax credit rate } \\
\mathrm{r}_{\mathrm{R}} & =\text { revenue tax rate } \\
\mathrm{r}_{\mathrm{F}} & =\text { federal income tax rate }
\end{aligned}
$$

This rate equation assumes that tax savings are "flowed-through" to the customers, which is the accounting practice in California. We further assume that the utility earns its allowed rate of return, that is,

$$
\mathrm{E}=\mathrm{Kr} \mathrm{B}_{\mathrm{B}}-\mathrm{I}
$$

where

$\mathrm{I}$ and $\mathrm{E}=$ interest and earnings after interest, as above

$$
\mathrm{K}=\text { rate base }
$$

$r_{B}=$ authorized rate of return on rate base 
Table 21

1978 Estimates of Variables Constant Across Scenarios

\begin{tabular}{|c|c|c|}
\hline Variable & Comments & 1978 Value \\
\hline K & Net value of electric plant in $1976^{a}$ & $\$ 5.052 \times 10^{9}$ \\
\hline $\mathrm{r}_{\mathrm{b}}$ & As authorized in 1977 & $9.2 \%$ \\
\hline B & $\begin{array}{l}1976 \text { proportion of debt attributable } \\
\text { to electric plant }=\text { (bonded debt) } x \\
\left(\frac{\text { net electric plant }}{\text { total utility plant }}\right)^{a}\end{array}$ & $\$ 2.465 \times 10^{9}$ \\
\hline$i_{b}$ & $\begin{array}{l}\text { Based on } 1976 \text { embedded interest rate } \\
\text { of } 6.97 \%\end{array}$ & $8 \%$ \\
\hline $\mathrm{D}$ & As in $1976^{\mathrm{a}}$ & $\$ 150.1 \times 10^{6}$ \\
\hline $\mathrm{M}_{\mathrm{F}}$ & $\begin{array}{l}\mathrm{M}_{\mathrm{F}}=\text { Administrative and General } \\
\text { Expenses + Customer Accounts + Purchased } \\
\text { Power - Franchise Requirements - Regulatory } \\
\text { Commission Expenses. As in } 1976^{\text {a }} \text { plus } 9 \% \\
\text { annual growth (annual growth rate of } 16.5 \% \\
\text { in } 1969-74^{\mathrm{b}} \text { ) }\end{array}$ & $\$ 323.85 \times 10^{6}$ \\
\hline $\mathrm{T}$ & $\begin{array}{l}\text { As in } 1976^{a} \text { plus } 2 \% \text { annual growth (average } \\
\text { annual rate } 1969-73 \text { ) b }\end{array}$ & $\$ 108.45 \times 10^{6}$ \\
\hline$\Delta \mathrm{K}$ & Estimate as of September $1975^{\mathrm{C}}$ & $\$ 435.0 \times 10^{6}$ \\
\hline $\mathrm{M}_{\mathrm{v}}$ & $\begin{array}{l}\mathrm{M}=\text { Operating and Maintenance Expenses - } \\
\text { Fuel Expenses }-M_{\text {G }} \text { As in } 1976^{\mathrm{a}} \text { plus } 6 \% \\
\text { annual growth }(7.5 \% \text { annual rate } 1969-74)^{\mathrm{b}}\end{array}$ & $3.6 \mathrm{mil} 1 \mathrm{~s} / \mathrm{kWh}$ \\
\hline a & $\begin{array}{l}\text { Assumes first year accelerated deprecia- } \\
\text { tion is } 20 \% \text { greater than book deprecia- } \\
\text { tion }\end{array}$ & $20 \%$ \\
\hline i & Investment tax credit & $10 \%$ \\
\hline $\mathrm{r}_{\mathrm{R}}$ & Average of $1969-74$ rates $^{b}$ & $1.3 \%$ \\
\hline $\mathrm{r}_{\mathrm{F}}$ & Federa1 income tax rate & $46 \%$ \\
\hline $\begin{array}{l}{ }^{a} \operatorname{Refe} \\
b_{\text {Refe }}\end{array}$ & 33 & \\
\hline
\end{tabular}


Table 22

Estimated 1978 Fuel Expense

\begin{tabular}{lc}
\hline Type of Generation & $\begin{array}{c}\text { Unit Cost } \\
\text { (mills/kWh) }\end{array}$ \\
\hline Hydroelectric & 0 \\
Other Receipts ${ }^{\mathrm{a}}$ & 17 \\
Nuclear & 7 \\
Geotherma1 & 11 \\
Gas & 19 \\
Oil & 24 \\
$\begin{array}{l}\text { Intrastate Transfers } \\
\text { a Other receipts include refinery and gas tur- } \\
\text { bine generation. }\end{array}$
\end{tabular}

Table 23

PGEE Generation in 1976 by Fuel Type and Average Price

\begin{tabular}{lc} 
& Fuel Type and Average Price \\
\hline & $\begin{array}{c}\text { Generation } \\
\text { (GWh) }\end{array}$ \\
\hline Hydroelectric & 8,112 \\
Gas and Oil & 37,276 \\
Nuclear & 197 \\
Geothermal & 3,615 \\
Gas Turbines & 73 \\
Purchases & 2,773 \\
Interchanges & $\underline{10,338}$ \\
$\quad$ TOTAL & $\underline{62,384}$ \\
Average Price of & \\
Electricity & $32.8 \mathrm{mil1s} / \mathrm{kWh}$ \\
\hline
\end{tabular}


$I$, the interest expense on bonded debt, is determined as

$$
I=B i_{b}
$$

where

$$
\begin{aligned}
B & =\text { bonded debt } \\
i_{b} & =\text { embedded interest rate on bonded debt }
\end{aligned}
$$

Three of the inputs to the rate equation change with the scenario being examined. In particular, these variables include $Q$, the annual energy demand, $F$, the fuel expense and $K$, the rate base. Other variables are assumed constant across scenarios. $\Delta K$, the capital additions to rate base, through which the impact of the investment tax credits is registered, is held constant. For rate-making purposes, these credits are based on a five-year moving average of capital additions to rate base. If large changes in rate base were entirely reflected in $\Delta \mathrm{K}$, the one-year impacts would be overstated in our equation. However, additions to rate base are added to $\mathrm{K}$, the rate base, thus influencing earnings through the rate-of-return-on-rate-base multiplier.

In order to estimate the total fuel expenses ( $F$ in the rate equation) under different generation scenarios, we need to estimate the fuel expense per $\mathrm{kWh}$ of each type of generation. Fuel expense for hydroelectric power is assumed zero. Nuclear fuel is assumed to cost 7 mills per kWh. ${ }^{34}$ Conversations with SMUD officials indicate that the expected cost of electricity from Rancho Seco to PG\&E would be around $11 \mathrm{mills} / \mathrm{kWh}$. This figure is equivalent to our assumed fuel costs plus the variable maintenance costs. Rancho Seco power delivered to PGEE is therefore considered in our model as though it were part of the PG\&E system. Geothermal "fuel" is assumed to cost 11 mills per $\mathrm{kWh}$ in steam expense. ${ }^{33}$ Intrastate transfers are assumed to cost 32 mills per $\mathrm{kWh}$ to PGEE. Although these are not strictly fuel costs, they are treated as such in the model. We assume $6.287 \times 10^{6}$ Btu per barrel of fuel oil, and costs of $\$ 2.40$ per $10^{6}$ Btu for fuel oil and $\$ 1.90$ per $10^{6} \mathrm{Btu}$ for gas. Assuming equal heat rates for oil and gas generation, we arrive at costs of $24 \mathrm{mills}$ per $\mathrm{kWh}$ for oil generation and 19 mills per $\mathrm{kWh}$ for gas generation. These figures are summarized in Table 22 . 
The model was validated with data for 1976. Data on electricity generation by fuel type and on electricity sales were available to us for $1976 .^{33}$ Financial and fuel price data was also available from the same source. Table 23 shows the generation by fuel type for 1976. Our estimated average revenue for 1976 is $32.8 \mathrm{mills} / \mathrm{kWh}$, as compared

with the actual revenue of $27.8 \mathrm{mi} 11 \mathrm{~s} / \mathrm{kWh} .{ }^{31}$ The 1 ower actual revenue is mainly due to deduction from expenses of excess fuel adjustment costs accumulated prior to 1976. These costs estimated at $4 \mathrm{mil1s} / \mathrm{kWh}$ bring our estimates within a reasonable range of the actual revenue.

\section{Estimates of 1978 Prices}

Our earlier demand and supply analysis in Sections 2 and 3 was based on projections for PG\&E's entire service area. This service area includes utilities such as USBR, DWR and SMUD along with several smaller utilities. Since the intent of this section is to estimate average prices for PGEEE, the service area generation figures had to be adjusted to reflect generation required for PG\&E.

The 1978 energy for loads for the PG\&E service area shown in Tables 24 and 25 are our projections as outlined in Section 2. Generation requirements for PG\&्षE are estimated by subtracting the electricity generated or the electricity acquired for sale by USBR and SMUD in the PGE्E service area. These two utilities would have generated or purchased outside the PG\&E area approximately $7500 \mathrm{GWh}$ during a dry 1978 and approximately 9,800 GWh during a wet year for sale to their customers. Firm transfers from USBR to SMUD are included in the SMUD figure. Electricity supplied to DWR by other utilities is also deducted from the load and other receipt categories.

To meet the PG\&E generation requirements, two sets of generation mixes, one each for a dry and a wet year, were developed. Hydroelectric generation for a dry 1978, by PG\&E and by the sma1ler utilities that supply energy to PGE्षE such as EBMUD, Merced Irrigation District, etc., was assumed at the level anticipated by PG\&E under adverse water conditions. ${ }^{5}$ Wet year hydroelectric generation was assumed at the 1975 level of generation. 
Table 24

Dry Year 1978 Generation for PGE्E

by Fuel Type (GWh) and Average Electricity Prices (mills/kWh)

\begin{tabular}{|c|c|c|c|c|c|c|c|c|c|}
\hline & \multicolumn{3}{|c|}{ Case I } & \multicolumn{3}{|c|}{ Case II } & \multicolumn{3}{|c|}{ Case III } \\
\hline $\begin{array}{l}\text { Energy for Load } \\
\text { PG\&E Service Area }\end{array}$ & \multicolumn{3}{|c|}{77286} & \multicolumn{3}{|c|}{73816} & \multicolumn{3}{|c|}{72340} \\
\hline USBR Generation ${ }^{b}$ & \multicolumn{3}{|c|}{2100} & \multicolumn{3}{|c|}{2100} & \multicolumn{3}{|c|}{2100} \\
\hline SMUD Generation ${ }^{c}$ & \multicolumn{3}{|c|}{5440} & \multicolumn{3}{|c|}{5440} & \multicolumn{3}{|c|}{5440} \\
\hline External DWR Load & \multicolumn{3}{|c|}{1078} & \multicolumn{3}{|c|}{1078} & \multicolumn{3}{|c|}{1078} \\
\hline Generation for PG\&्षE & \multicolumn{3}{|c|}{68668} & \multicolumn{3}{|c|}{65198} & \multicolumn{3}{|c|}{63722} \\
\hline $\begin{array}{l}\text { Dry Year Generation } \\
\text { Mix Scenarios }\end{array}$ & 1 & 2 & 3 & 4 & 5 & 6 & 7 & 8 & 9 \\
\hline Hydroelectric ${ }^{e}$ & 7126 & 7126 & 7126 & 7126 & 7126 & 7126 & 7126 & 7126 & 7126 \\
\hline Nuclear & 9795 & 5356 & 2361 & 9795 & 5356 & 2361 & 9795 & 5356 & 2361 \\
\hline Geothermal & 4522 & 4277 & 4277 & 4522 & 4277 & 4277 & 4522 & 4277 & 4277 \\
\hline Other Receipts $f$ & 2130 & 2130 & 2130 & 2130 & 2130 & 2130 & 2130 & 2130 & 2130 \\
\hline Gas & 16505 & 16505 & 16505 & 16505 & 16505 & 16505 & 16505 & 16505 & 16505 \\
\hline Oil & 28590 & 28944 & 28944 & 25120 & 28944 & 28944 & 23644 & 28328 & 28944 \\
\hline Transfers & 0 & 4330 & 7325 & 0 & 860 & 3855 & 0 & 0 & 2279 \\
\hline Average Electricity & 41.7 & 42.7 & 43.0 & 42.9 & 43.1 & 43.1 & 42.5 & 42.9 & 43.2 \\
\hline
\end{tabular}

${ }^{\mathrm{a}}$ Generation for load figures from Section 2 .

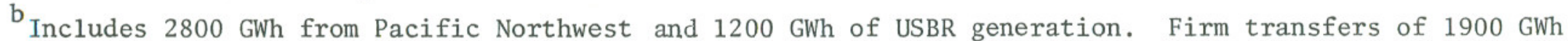
from USBR to SMUD are deducted and shown in the SMUD figure.

${ }^{c}$ From SMUD, Reference 37.

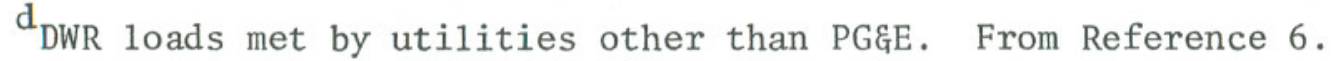

e From Reference 35.

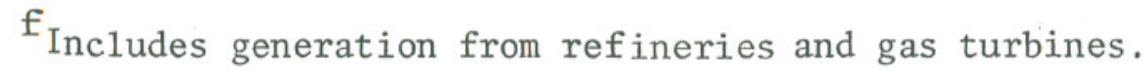


Table 25

Wet Year 1978 Generation for PG\&E

by Fuel Type (GWh) and Average Electricity Prices (mil1s/kWh)

\begin{tabular}{|c|c|c|c|c|c|c|c|c|c|}
\hline & \multicolumn{3}{|c|}{ Case I } & \multicolumn{3}{|c|}{ Case II } & \multicolumn{3}{|c|}{ Case III } \\
\hline $\begin{array}{l}\text { Energy for Load } \\
\text { PGGE Service Area }\end{array}$ & \multicolumn{3}{|c|}{77286} & \multicolumn{3}{|c|}{73816} & \multicolumn{3}{|c|}{72340} \\
\hline USBR Generation ${ }^{b}$ & \multicolumn{3}{|c|}{4452} & \multicolumn{3}{|c|}{4452} & \multicolumn{3}{|c|}{4452} \\
\hline SMUD Generation ${ }^{c}$, & \multicolumn{3}{|c|}{5440} & \multicolumn{3}{|c|}{5440} & \multicolumn{3}{|c|}{5440} \\
\hline External DWR Load & \multicolumn{3}{|c|}{1078} & \multicolumn{3}{|c|}{1078} & \multicolumn{3}{|c|}{1078} \\
\hline Generation for PGGE & \multicolumn{3}{|c|}{66316} & \multicolumn{3}{|c|}{62846} & \multicolumn{3}{|c|}{61370} \\
\hline $\begin{array}{l}\text { Wet Year Generation } \\
\text { Mix Scenarios }\end{array}$ & 1 & 2 & 3 & 4 & 5 & 6 & 7 & 8 & 9 \\
\hline Hydroelectric & 24169 & 24169 & 24169 & 24169 & 24169 & 24169 & 24169 & 24169 & 24169 \\
\hline Nuclear & 11495 & 7056 & 4061 & 11495 & 7056 & 4061 & 11495 & 7056 & 4061 \\
\hline Geothermal & 4522 & 4277 & 4277 & 4522 & 4277 & 4277 & 4522 & 4277 & 4277 \\
\hline Other Receipts $f$ & 2130 & 2130 & 2130 & 2130 & 2130 & 2130 & 2130 & 2130 & 2130 \\
\hline Gas & 16505 & 16505 & 16505 & 16505 & 16505 & 16505 & 16505 & 16505 & 16505 \\
\hline Oil & 7495 & 12179 & 15174 & 4025 & 8709 & 11704 & 2549 & 7233 & 10228 \\
\hline Average Electricity & 34.7 & 35.1 & 35.1 & 34.9 & 35.3 & 35.3 & 34.9 & 35.4 & 35.4 \\
\hline
\end{tabular}

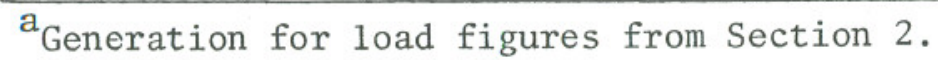

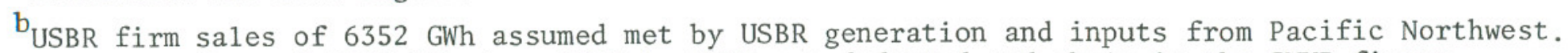

Firm transfers of $1900 \mathrm{GWh}$ from USBR to SMUD are deducted and shown in the SMUD figure.

c $_{\text {From }}$ Reference 37 .

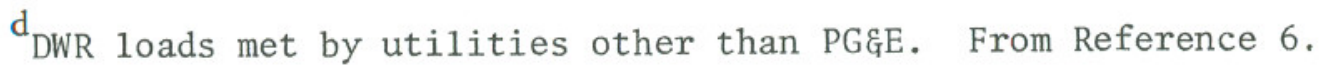

$\mathrm{e}_{1975}$ PGEE service area generation of 30521 GWh minus USBR generation for its own $10 a d$ of 6352 GWh.

${ }^{\mathrm{f}}$ Includes generation from refineries and gas turbines. 
Table 26 illustrates the various assumptions regarding annual generation and additions to rate base for nuclear and new geothermal units. Generation from natural gas fuel is assumed to be at the level anticipated for 1978 in the utility submissions. ${ }^{2}$

With changing demand scenarios, varying amounts of electricity generated from oil and transfers from southern California utilities are necessary. Tables 24 and 25 present the oil generation and transfers which when added to generation by other fuel types are adequate to meet demand under each scenario.

The difference in average price (as shown in Tables 24 and 25) is significant under wet and dry meteorological conditions. Under drought conditions large amounts of expensive oil generation must be substituted for hydroelectric power that has no fuel cost. The difference in prices between comparable wet and dry year scenarios is approximately 20 percent.

Prices increase when less nuclear and geothermal generation is available and higher cost oil generation and intrastate transfers must be relied upon. However, this increase is less than one percent. The impact of having larger nuclear generation in the supply system is more pronounced during a dry year. In this case nuclear generation displaces oil generation and transfers that are a larger proportion of total generation.

Average prices always decline with increasing demand as fixed capital charges are distributed over larger electricity sales. However, the decrease in price is again less than one percent in each case.

We should emphasize that these average revenue figures are better estimates of differences among scenarios than of absolute levels of revenue. There is always considerable uncertainty to the actual rate of return on rate base that utilities will realize, as distinguished from the authorized rate of return. Inflation forecasts are also, of course, uncertain. On the other hand, under present accounting practices authorized by the California Public Utilities Commission, all changes in fue 1 expenses are reflected in customer bills as a result of the fuel adjustment clause. Although PUC reviews these adjustments the procedures are simpler than for other rate increases. 
Table 26

Nuclear and Geothermal Generation Assumptions

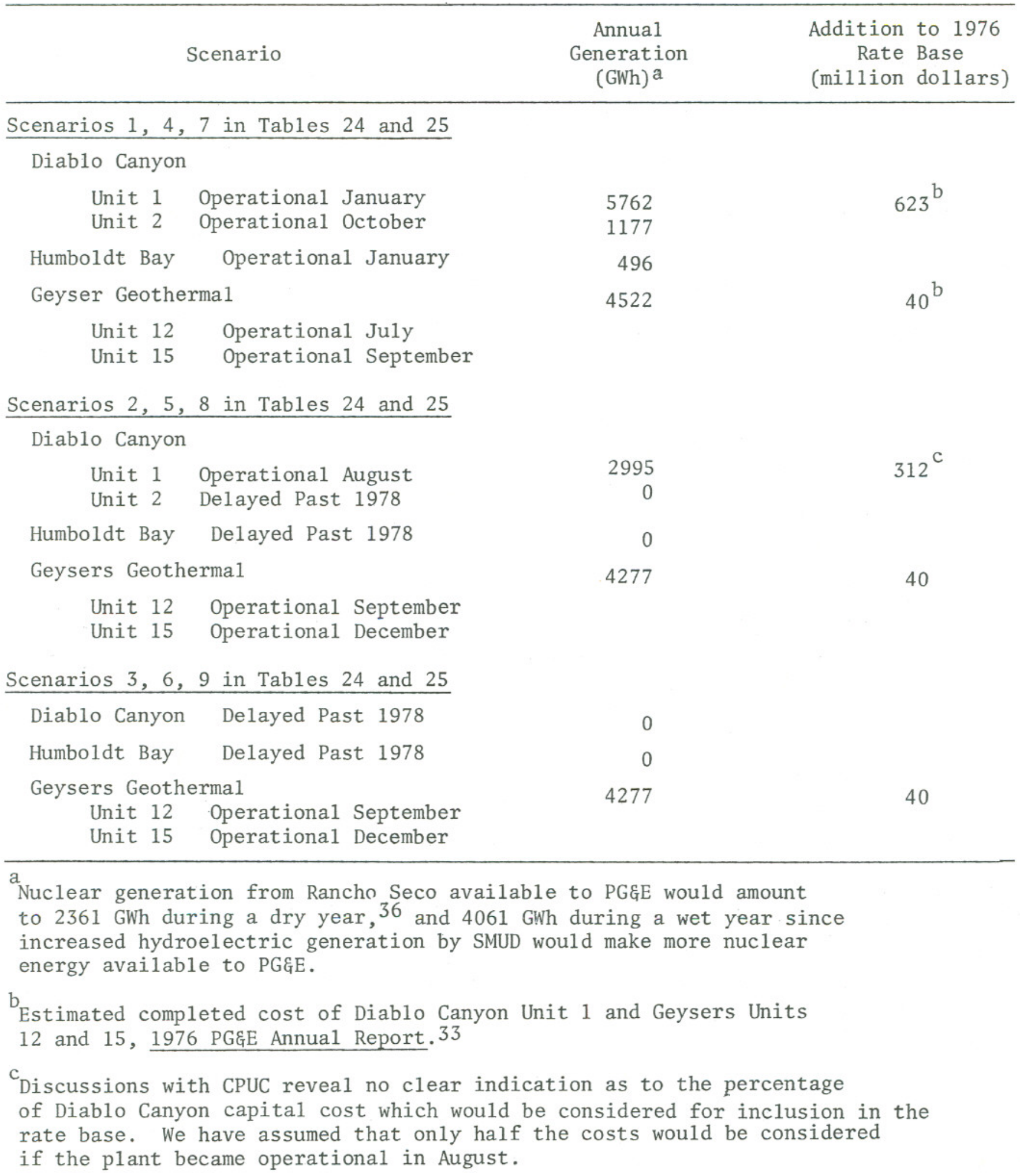




\section{SECTION 5}

REMEDIAL MEASURES FOR DEMAND

In view of the supply alternatives that are available to meet loads during a continued drought, it does not appear that measures to restrain demand are essential to avert an emergency. However, there are several reasons why any plan for dealing with electricity needs during the drought should contain measures aimed at reducing demand. First, a growth in demand significantly beyond the 4.7 percent projected by PG\&E could seriously strain the supply system. Second, the available supply a1ternatives are more cost1y, hence measures which can avert the need for some of the alternatives will reduce the financial burden that must be borne by the California economy. Third, demand reduction can provide insurance against unforeseen system failures or conditions such as extremely hot weather during the summer which might otherwise create excessive peak demand. Finally, measures for moderating demand growth should be pursued because of 1ongterm benefits. The heightened conservation consciousness of consumers during the drought should increase the receptivity to energy conservation initiatives and thus provide an opportunity to make progress toward longterm objectives.

We have examined three strategies for reducing demand:

- conservation,

- load management, and

- load shedding.

The conservation strategy aims at reducing electricity consumption. The load management strategies shift electricity consumption from periods when demand for electricity is high (hot summer afternoons) to periods of lower demand (nights and weekends). The load shedding strategies reduce electrical loads during extreme peaks in demand or at times when equipment failures create a sudden shortage of generating capacity.

These three strategies already play a role in the operation of the electricity supply system in California. They have importance both for the short term in dealing with the present adverse weather conditions and for the long term in improving the efficiency of the system. We discuss each of these strategies in turn, first describing existing continuing 
programs and emergency programs adopted during the past year, then examining additional measures that might be adopted if adverse weather conditions continue.

\section{CONSERVATION}

Energy conservation measures can be divided into two types: improved efficiency of use and curtailment of use. Improved efficiency measures aim to "do the same job" with less energy. Examples include improved performance for refrigerators and air conditioners, increased insulation, cogeneration, etc. Curtailment measures are usually first aimed at superfluous uses such as outdoor lighting during daylight hours, and lighting and space conditioning in unoccupied spaces. The next targets for curtailment are usually lighting for competitive purposes and measures which require minor adjustments in living habits. Examples of the former are display lighting and outdoor advertising, the latter include changes in thermostat settings and reduced lighting levels.

\section{Continuing Programs}

Existing electricity conservation programs in California are aimed primarily at improved efficiency, but there are also some efforts to achieve curtailments. Two state agencies, the CPUC and the CERCDC, and the utility companies are the institutions with primary responsibility for carrying out these programs.

Performance standards are probably the most significant element in the CERCDC conservation program. These standards, which the CERCDC is mandated to establish [PRC 254021(G)-(C)], are of two types: appliance standards and building codes. Appliance standards establishing the maximum permissible energy consumption for new refrigerators, freezers, and air conditioners became effective on Nov. 1, 1977. Initially, these standards will only remove a few of the most inefficient appliances from the market, but the second phase of standards, which come into force two years after the initial standards, will have a more significant impact. The CERCDC estimates that annual electricity savings from the new standards will be about 1.9 billion kWh by 1985. ${ }^{38}$ Appliances for which the Commission is now developing standards include water heaters and space heaters. 
Building codes mandating reduced energy consumption have been in effect for residential construction for about three years and will come into force for commercial structures on Jan. 1, 1978. Stronger provisions governing residential buildings have been developed and will be in effect on March 11, 1978. The commercial standards will have a large impacts on electricity consumption in new construction because they will reduce energy requirements for lighting and for air conditioning. The existing residential standards have resulted in improved thermal integrity of new construction largely by requiring increased insulation and by limiting window area. The new standards will result in further improvements in thermal integrity and will place stringent restrictions on the use of electric resistance heating.

In addition to mandatory standards, the CERCDC is sponsoring a number of programs which are expected to achieve their ends primarily through education. Included among these are building energy audit programs, a program to aid commercial building operators in reducing lighting, and consumer education programs.

The most significant conservation step by the CPUC was undoubtedly its decision (Decision No. 84902) that the rate of return on investment allowed to regulated utilities would be in part determined by their effectiveness in promoting energy conservation. As a consequence, all of the regulated electric and gas utilities have established energy conservation programs; these are discussed further below.

The CPUC also has regulations which curtail certain uses of electricity. CPUC Rule 14.1 includes provisions which

- prohibit the lighting of billboards,

- prohibit outdoor lighting during daylight hours,

- require thermostat settings of $65^{\circ} \mathrm{F}$ for heating and $78^{\circ} \mathrm{F}$ for cooling

- require a 15 percent reduction in lighting for recreational or cultural activities, and

- prohibit interior lighting in commercial buildings during non-business hours.

However, the first of these measures has been suspended and efforts to enforce the remaining measures have been relaxed since the rule was established in 1974 . $^{39}$

The PG\&E program is typical of the conservation efforts of the regulated utilities. The program, which had a 1976 budget of about $\$ 9$ million 
includes efforts to stimulate insulation, commercial and industrial energy audits, and solar energy demonstrations. The emphasis of these programs is on public and consumer information. In a recent attempt to evaluate the effectiveness of these programs, PG\&E estimated that its efforts had saved a total of $218,000 \mathrm{kWh}$ in 1976 . The largest share of this saving, $103,000 \mathrm{kWh}$, was attributed to the commercial-industrial audit program. 40 In addition to its efforts to encourage conservation actions by its customers, PGE्FE has reduced the voltage supplied to residential circuits. This measure was accomplished by reducing the upper limit of the "norma1 range" for service voltage from 126 volts to 122 volts. (The lower limit, 114 volts, was not changed.) The effect is to reduce the amount of energy supplied to electricity-using devices. In some cases, e.g., lights, this results in lower energy consumption; in other cases, e.g., electric heat, equipment just operates for a longer period with no change in total energy consumption. An added consumer benefit of voltage reduction is increased service life for some equipment, particularly incandescent light bulbs.

The voltage reduction program was undertaken at the urging of the CPUC which had proposed the measure as early as 1962. Based on test results in PG\&E's service area, C.T. Coffey of the CPUC has estimated that the effect of the voltage reduction was a three percent savings in energy for those customers affected. ${ }^{41}$ This will mean a total annual savings of more than $750 \mathrm{GWh} .{ }^{*}$ Coffey believes that technology is available to se1ectively reduce the voltage even further without causing any customers to receive service at voltages below the lower limit of the normal range.

In addition to the programs of the state energy agencies and the utilities, a number of other agencies are attempting to encourage conservation. The federal role has been limited for the most part to funding support for some of the programs described above. There are also some direct federal efforts such as the weatherization program conducted by the Economic Opportunity Commission in Fresno. Some other state agencies have established conservation offices (Caltrans, for example) and a number of local programs are underway.

* Coffey estimates that 1977 savings by voltage reduction were 620 million kWh. Since the program was implemented after February 1977, annual savings should be significantly greater than this. 
1977 Adverse Weather-year Programs

Neither the CERCDC nor the CPUC has initiated any conservation programs in 1977 designed to deal with electricity shortages caused by the drought. However, staff from these agencies did conduct studies of possible measures; efforts were also made to monitor the situation so that vigorous public appeals for conservation could be made if a shortage appeared to be imminent. PG\&E mounted an advertising campaign in its service area to alert its customers to the fact that electricity supplies were tight and that shortages might develop.

Although formal programs for dealing specifically with drought-induced energy supply problems have been limited, the very vigorous water conservation programs may have served to build a "conservation consciousness" among the public which affected demand for electricity. This could, in part, account for the very slow growth in electricity sales during 1977 although other factors including higher prices and temperate weather may a1so have contributed.

Possible Additional Emergency Measures

In developing 1ong-term strategies for energy conservation, those programs which improve the efficiency of energy use are usually favored since they do not require changes in living habits. However, efficiency programs usually require changes in energy-using equipment. This means either that new equipment must be produced or that technically-trained persons must refit old equipment. The time involved in carrying out these processes is such that new programs for improving efficiency rarely have much impact in the short term. Thus, if adverse weather conditions necessitate a significant reduction in the demand for electricity, a heavy reliance will have to be placed on curtailment measures.

While efficiency measures can have only a limited impact in the short run, other policy considerations dictate that these measures should not be neglected in the current situation. The drought has focussed attention on immediate supply constraints, but the long-term need for energy conservation is, of course, still with us. Programs which combine some measure of efficiency with curtailment will have long-term benefits as well as shortterm impact. 
In the present situation, with both supply and demand uncertain, it is prudent to consider a range of conservation programs. The most modest of these might be a voluntary program emphasizing efficiency and curtailment of superfluous uses; the most drastic, a mandatory program requiring some curtailment by all users.

Voluntary programs are, as noted above, already in effect. However, several factors suggest that efforts in this direction could be increased substantially in the near term, especially in the area of public information. First, the existing programs are rather modest. Advertising has been limited most1y to radio spots and there has been almost no media coverage of droughtrelated electricity supply problems. Many people are unaware that any problems exist. Second, the heightened "conservation consciousness" induced by the drought is likely to make people more responsive to appeals for electricity conservation. Third, emphasis on improved efficiency as been surprisingly absent in much of the advertising. Except for the insulation campaigns, most appeals have been for curtailment of superfluous uses.

Thus, a logical first step toward increased conservation in the shortterm would be a greatly expanded public information program. To maximize long term as we11 as short term impacts, the program should include increased emphasis on efficient use of energy. For example, the energy use 1abels now appearing on many new refrigerators and air conditioners should be explained, and consumers should be told of the life-cycle cost savings that can be realized by purchasing energy-efficient appliances. Increased public information efforts by federal and state agencies would be especially valuable since many people are distrustful of utility-sponsored advertising.

A second step, which would be warranted if the situation grew more serious, is enforcement of CPUC Rule 14.1, especially where it affects conspicuous consumption. Curtailment of outdoor lighting and lighting in unoccupied spaces (e.g., office buildings at night) would save only a relatively small amount of energy (less than one percent), 39 but this action would have a public impact similar to that achieved by turning off water fountains and other decorative uses of water. Many people would be encouraged to curtail non-essential uses in their homes and places of work. It should be noted that complete enforcement of Rule 14.1 would be very difficult if not impossible. This is especially true in the case of thermostat settings $\left(68^{\circ} \mathrm{F}\right.$ for heating and $78^{\circ} \mathrm{F}$ for cooling) in the residential sector. 
However, as shown by the results of water conservation programs, when the public perceives a need for conservation, voluntary compliance can be substantial.

A more drastic step is a conservation program which mandates electricity use reductions by all customers. While such a program is not likely to be required in the present situation, it is prudent to develop a plan for implementing such reductions so that unforeseen events will not find the state unprepared. The CPUC, in the context of its Case No. 9884, is attempting to deal with the issues raised by mandatory plans. However, the major regulated utilities all contend that such programs would be unworkable.

Recent California experience demonstrates that mandatory programs can be very effective. (But they are not necessarily "workable" administratively, as we discuss below.) In 1973 the Los Angeles Department of Water and Power (LADWP) was purchasing fuel oil from Arab suppliers. When the Arab oil embargo was imposed, LADWP's supplies were disrupted and the city of Los Angeles was faced with the potential of severe electricity shortages. To meet this crisis the City Council adopted an ordinance in December 1973 which mandated electricity use reductions. The ordinance required cutbacks relative to the previous year's usage of 10 percent, 20 percent, and 10 per cent for residential, commercial, and industrial users respectively. The ordinance was expected to achieve an overall savings of 12 percent and this target was exceeded during the entire period that the ordinance was in effect. Adverse economic impacts resulting from the ordinance appear to have been minor or non-existent. 42

The ordinance contained stiff penalties for noncompliance: a 50 percent surcharge on the entire bill and, if the surcharge failed to induce compliance, service disconnection. However, for a variety of reasons, these penalties were never invoked. First, the crisis was short-lived-a wet year in the Pacific Northwest made it possible to import substantial hydroelectric power, and the fuel market eased. Thus, the City Council was able to suspend the penalty provisions of the ordinance on January 24, 1974 and suspend the entire ordinance on May 22, 1974. Second, there were major administrative problems. The ordinance had established an appeal procedure for customers who felt that the amount of electricity allotted to them should be adjusted and LADWP was inundated with appeals. Little headway was made in processing these appeals before the penalty provisions were suspended. 
Some observers felt that proper processing of appeals was completely beyond the resources of LADWP and thus, that enforcement of the ordinance would have been impossible.

One view of the Los Angeles experience is that compliance was essentially voluntary and was motivated by the public perception that conservation was necessary. Another view is that the threat of enforcement was sufficient to insure compliance by all of those who could do so without great difficulty. Whatever the case, it is clear that the practice of adopting a mandatory program and then not enforcing its sanctions cannot be repeated very often without engendering serious credibility problems for public authorities. Thus, the CPUC faces a very considerable difficulty in developing contingency plans, especially in view of the negative attitude of the regulated utilities.

It must be emphasized that, while the conservation measures discussed above can have a short-term impact, it will take some time and effort to put them in place. If these measures are to be available for dealing with adverse weather conditions, some of this effort must be expended before it is certain that any measures are in fact necessary. Still, in view of the potential cost of power outages, it would be irresponsible to take no action. At the very least, a program should be undertaken to inform the public of potential shortages and of the conservation measures that could avert these shortages.

\section{LOAD MANAGEMENT}

As the earlier sections of this report show, electricity shortages caused by a continuation of the drought are most likely to be manifested as shortages of generating capacity during periods of high electricity demand. In California these high demand periods occur during very hot weekday afternoons. Conservation measures can reduce demand during these periods, but their impact is more "across the board" as opposed to "on-peak." Load management is a strategy aimed specifically at reducing peak demand. This strategy attempts to shift the time of electricity consumption from peak to off-peak periods. 
There are two basic methods of load management: operational shifts and energy storage. Operational shifts involve changing the time during which energy consuming operations are conducted. Examples include rescheduling of operations in industrial plants (running electric furnaces, large compressors, etc. during off-peak hours), and night irrigation of croplands (water pumping for this purpose now consumes substantial amounts of onpeak energy). Energy storage involves the use of systems which draw electricity during off-peak hours but perform their functions at other times. Some technologies such as pumped storage regenerate electricity. However, most of these methods have substantial economies of scale and thus, with the exception of electric car batteries, are more appropriate for utilities than for utility customers. Most customer-owned energy storage systems involve thermal storage for space conditioning and water heating. Storage space heaters and water heaters are widely used in western Europe but are not common in the United States. Storage air conditioners, which make ice or chill a tank of water during off-peak hours and draw on this cold storage during peak hours would be the most useful storage technology for summer peaking utilities such as California's. However, this technology is not we11 established and only a few systems, in demonstration projects, are operating at this time.

\section{Continuing Programs}

Existing efforts to improve electrical load management in California are based primarily on an indirect method, time-of-use (TOU) pricing. TOU pricing sets higher charges for the use of electricity during peak demand periods than for use during off-peak periods. It is assumed that customers who can shift their operations or develop storage systems will do so if the benefits of lower off-peak electricity costs exceed the cost of making changes. In western Europe, where this strategy is widely used, experience has shown that TOU pricing can be effective. ${ }^{43}$

The CPUC has primary responsiblity for implementing TOU pricing in California. Based on the proceedings of its Case 9804, the CPUC has ordered the regulated utilities to establish TOU rate schedules for all customers who have peak demands in excess of $500 \mathrm{~kW}$ (Decision No. 85559). 
At this time only one of the mandated TOU schedules, PG\&E's A-17 has been in force for more than a few months. * A-17 is for customers with peak demands of $4000 \mathrm{~kW}$ or more and it affects about 7-8 percent of PG\&E's total peak demand. The rates on the schedule reflect changes in demand which occur on a seasonal, weekly, and daily basis. Details of the schedule are given in Table 27.

Under the shedule shown in Table 27, a customer operating electricity-using equipment continuously during a summer month** would pay $\$ 29: 40$ per $\mathrm{kW}$-month, corresponding to an average price of 4.1 cents $\mathrm{kWh}$. (Note that about three-fourths of this cost is accounted for by the energy cost adjustment.) With continuous operation the price per kWh would be about 6.6 cents on peak, 3.8 cents on partial peak, and 3.4 cents off-peak. If this same customer shifted all of his on-peak operations to off-peak, he would then pay about $\$ 25.00$ per $\mathrm{kW}$-month for a saving of about 13 percent on his monthly bills. Customers whose operations were initially predominantly on-peak could, of course, achieve relatively larger savings by shifting to off-peak operation.

Estimates of the impact of A-17 on peak demand are just becoming avai1able. PG\&E has released an analysis which indicates that between February, when the schedule became effective, and July, A-17 customers had shifted their use patterns so that peak demands were about three percent ( $\sim 30 \mathrm{MW})$ lower than would have been expected without the new rate schedule. ${ }^{44}$ It is difficult to make such estimates because many factors other than TOU prices influence demand. Among the factor that must be considered are the very steep increase in the average cost of electricity during 1977 and changes in the general level of economic activity. However, the fact that a few of its customers have reduced their on-peak demands very dramatically has persuaded PGgE that at least some of the observed shift is due to the new rates. Even if the other factors could be separated out, the full impact of A-17 would not be known for some time. First, it can be expected that

\footnotetext{
* SDG\&E's schedule No. A-6 for customers with demands in excess of $4000 \mathrm{kWh}$ became effective on Sept. 17, 1977; SCE's schedule No.TOU-8 for customers with demands in excess of $5000 \mathrm{~kW}$ became effective on Oct. 14, 1977. LADWP although not under CPUC jurisdiction, will begin implementing TOU rate schedules on Dec. 25, 1977.

** Assumed to be 30 days with 21 weeksdays, 5 Saturdays, and no holidays.
} 
Table 27

PGE्षE's Schedule No. A-17

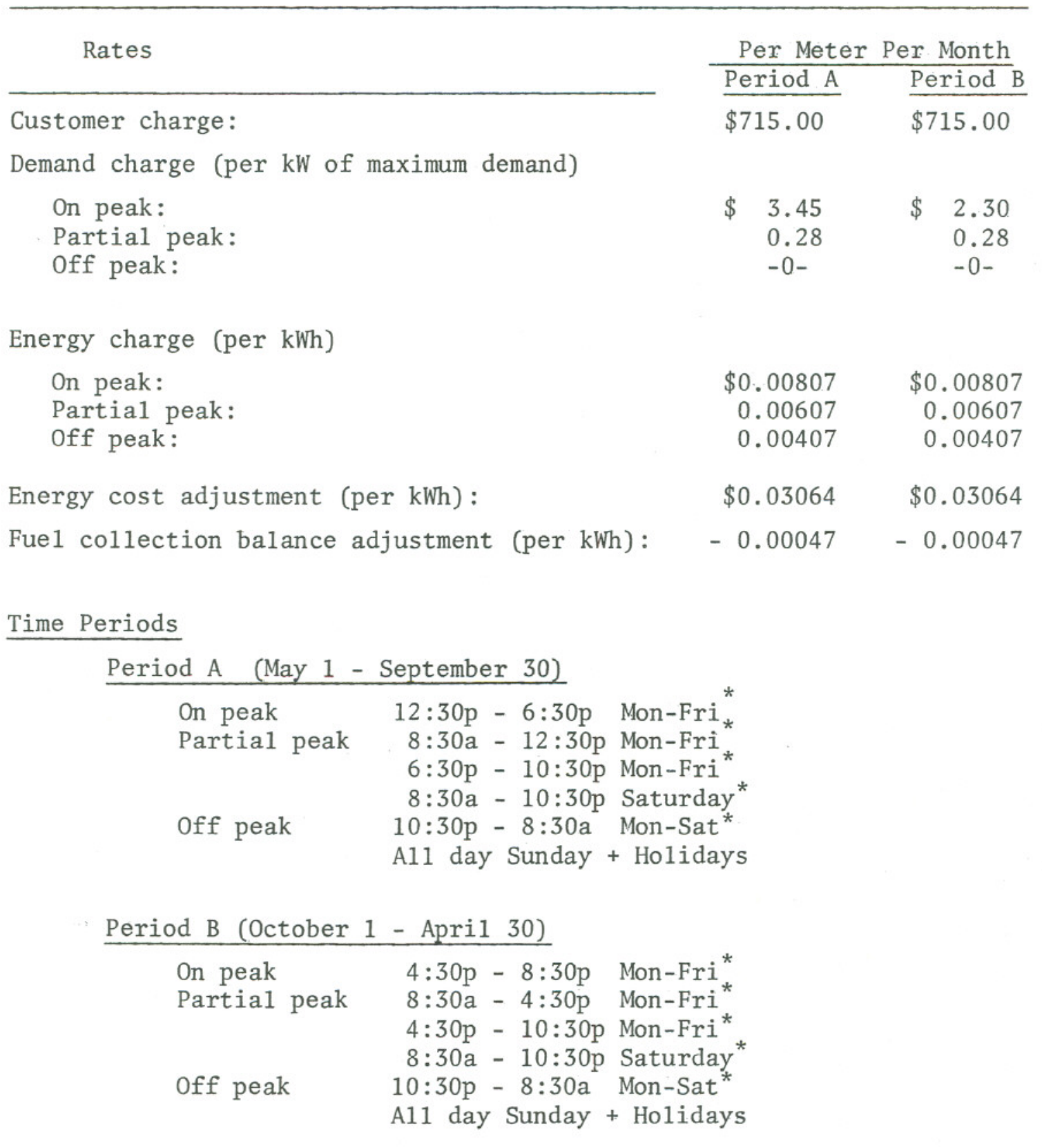

Except holidays 
customers will take some time to learn the most efficient operating practices under the new rates and second, the new rates may have made it economic to make capital improvements to facilitate off-peak operation-such improvements frequently take several years to implement. On the basis of trends observed through July 1977, PG\&E estimates that peak demands for A-17 customers may be more than seven percent lower by the end of 1978 than would have been expected in the absence of A-17.

The CERCDC is also making efforts to promote load management. These efforts are centered on two programs: load management standards for utilities and the "Electric Utilities Demonstration Project." The Public Resources Code (PRC 25403.5) requires the CERCDC to "... adopt standards by regulation for a program of electrical load management for each utility service area." In establishing these standards the Commission is to consider at least the following measures:

1) adjustments in rate structure

2) end-use storage systems, and

3) mechanical and automatic devices for load contro1.

The Commission is to enforce its standards by refusing to certify new power plant sites for any utility that is not in compliance.

Although the load management standards are still being developed, the Commission staff has already indicated that it will recommend implementation of TOU pricing for the large customers of the non-regulated utilities (municipal utilities, irrigation districts, etc.). Since the regulated utilities are already adopting TOU rate schedules under CPUC order, almost all large electricity users in the state will have to pay TOU pricesthe one major exception being customers of the U.S. Bureau of Reclamation.

The CERCDC staff is also considering additional load management standards, but has indicated that it believes further studies are needed before the standards are promulgated. Much of the necessary work is now being conducted in the Electric Utilities Demonstration Project. This project, coordinated by the Commission and funded in part by the Department of Energy, is exploring a variety of load management methods. Several of the demonstrations are related to the implementation of TOU pricing for small customers. For example, existing electricity meters for these customers only record total use and cannot supply information about the time of use. Experiments are being conducted with different types of metering systems in 
in the hope of finding one that can provide the necessary information reliably and at a reasonable cost. Air-conditioner cyclers and other devices which can periodically interrupt the operation of electricity-using equipment are also being studied. We will examine these further when we discuss load shedding.

The utility companies, in addition to implementing the TOU pricing orders of the CPUC, are participating in the Demonstration Project. In part, this participation is motivated by CPUC Decision 85559 which ordered investigations of load management methods. Utility studies are not limited to participation in the demonstration project-they are conducting a number of experiments on their own. For the most part, these experiments are similar to those in the Demonstration Project.

\section{Adverse Weather-year Programs}

The only load management effort directly related to the drought has been the inclusion of messages encouraging load management in utilities advertising campaign. This campaign, in addition to promoting conservation, has urged consumers to defer such activities as clothes and dish washing to off-peak hours. As discussed earlier, these advertising efforts have been fairly modest.

While not directly drought related, an advertising campaign which emphasizes load management has also been developed by the CERCDC in 1977 . This campaign uses a cartoon alligator called "Later Gator" who urges consumers to defer the use of electricity to off-peak hours. However, this campaign has as yet received very little exposure.

\section{$\underline{\text { Possible Additiona1 Emergency Measures }}$}

Many load management measures, such as energy storage and operational shifts that require equipment modifications, have long lead times. Measures of this type cannot have much impact in the short term. If a continuation of the drought necessitates emergency load management efforts, then we will have to rely on measures that shift electricity use patterns without requiring new equipment. Such measures can be encouraged both by incentive and by public information campaigns. 
At this time, load management differs from electricity conservation in that, while the latter results in direct financial rewards, most customers have no direct incentives to undertake the former. This may make it difficult to promote load management with advertising campaigns. Thus, a priority concern in dealing with the current situation is the improvement of the incentive structure.

Since new metering systems would be required, it is not possible in the short term to extend load management incentives to residential and sma11 commercial customers. However, it may be possible to accelerate the implementation of TOU rates for customers with maximum demands in excess of 500 $k W$. If the schedules now in effect are followed TOU rates for these customers will not be fully implemented before the summer of 1978 (CPUC Decision No. 86543). Again there is a problem with metering since, a1though the technology of TOU recording meters for large users is well established, not all of the customers have the right type of meter. The current plan is to install proper meters at all customers'services and then implement the rates. Given the present circumstances, it might be better to establish the rates and implement them customer-by-customer as the meters are installed. PGEE estimates that customers with loads between 500 and 4000 $\mathrm{kW}$ are about 14 percent of its peak load. 45 If these customers respond in the same way as the larger customers, then implementation of TOU prices by February 1978 would reduce peak demand about $60 \mathrm{MW}$ by the summer of 1978 . A second measure, which could be implemented for customers already on TOU rate schedules, is the inclusion of TOU incentives in the energy cost adjustment. This adjustment is now based on the average cost of fuel and purchased energy and constitutes the biggest fraction of the electricity bill for large customers. An advantage of including TOU incentives in the energy cost adjustment is that it encourages load shifting by customers who cannot reduce their monthly maximum demand. That is, some customers may conduct operations which require the maximum demand on only a few days each month. Since the present rate structure places almost all of the penalty for peak use in the demand charge, these customers will have 1ittle reason to shift any of their routine daily operation to off-peak if this has no impact on their maximum demand.

Load shifting at times other than the day of the customer's maximum demand has two benefits: first, the customer's maximum demand may not be 
coincident with the system's maximum demand and second, load shifting can produce significant energy savings. This latter benefit has not always been recognized because it is not evident from the time of use variation in average fuel cost. Because hydroelectric power is used for peaking, the average fuel cost on peak may actually be lower than for off-peak. But this is beside the point if reducing peak demands will result in a lower total cost for energy during the entire operating period. This would appear to be the case in California. For example, a significant amount of peak energy is supplied by banked energy in the Pacific Northwest. Energy generated in California off-peak is sent north permitting BPA to reduce generation at its dams. The energy is then returned on peak. If, instead of banking, the off-peak energy were used directly in-state, there would be two savings: there would be no north-south losses in transmission (about a 15 percent effect) ${ }^{46}$ and capacity payments would be avoided.

While the absence of direct financial incentives may make it difficult to promote load management with advertising campaigns, it may be possible to persuade consumers that the less tangible benefit of a lower risk of outages makes the effort worthwhile. This should be easiest to do for load management measures which do not require either much inconvencience or persistent effort. An example of such a measure is shifting the operation of swimming pool filter pumps. These pumps are activated by timers and usually operate for between 4 and 8 hours; many of them now operate during peak hours. The CERCDC estimates that if filter pump and other pool system operations were shifted to off-peak hours in the PG\&E service area, more than $100 \mathrm{MW}$ could be realized. ${ }^{47}$ A campaign to reset filter pump timers could be especially effective if it were done in cooperation with swimming pool maintenance contractors. 
LOAD SHEDDING

As we use the term here, load shedding means to discontinue the operation of electricity-using equipment on short notice (0-24 hours) and may be done either by the customer or by the utility. (Others have used the term to mean utility controlled service interruption made without notice.) In principle, some load shedding can occur even when there is not an unplanned capacity shortage such as might occur in 1978. Some customers have equipment that can be interrupted occasionally without great loss. If the loss caused by interruptions is less than the cost of building sufficient generating capacity to guarantee reliable supply during peak demand periods, then these customers will prefer to be interrupted on occasion if they receive a rate reduction commensurate with the capacity savings that this makes possible.

If the drought continues and neither the supply alternatives described elsewhere in this report nor energy conservation and load management measures are sufficient to maintain the supply-demand balance, then load shedding will be necessary to maintain the stability of the supply system. The first to be affected by load shedding would be those customers who were contractually obligated to reduce their loads when requested to do so. Then efforts would probably be made to achieve voluntary load reductions based on appeals to the public. If this were not sufficient, rotating outages would have to be initiated. One objective in planning for a possible continuation of the drought is to increase the probable response in the first two steps above so that losses associated with indiscriminant outages can be avoided.

\section{Continuing Programs}

On a continuing basis there are two load shedding issues: the deve1opment of appropriate rate schedules for interruptible service to large users and the development of load controllers (e.g., air-conditioner cyclers). Only PGGE serves customers on an interruptible schedule at this time. Rates for this schedule, No. A-18, are shown in Table 28. (SCE has offered an interruptible rate schedule for about two years but has no interruptible customers.) A-18 is 1imited to very large customers (more than $50 \mathrm{C} 0 \mathrm{~kW}$ of 
Table 28

PG\&्EE's Schedule No. A-18

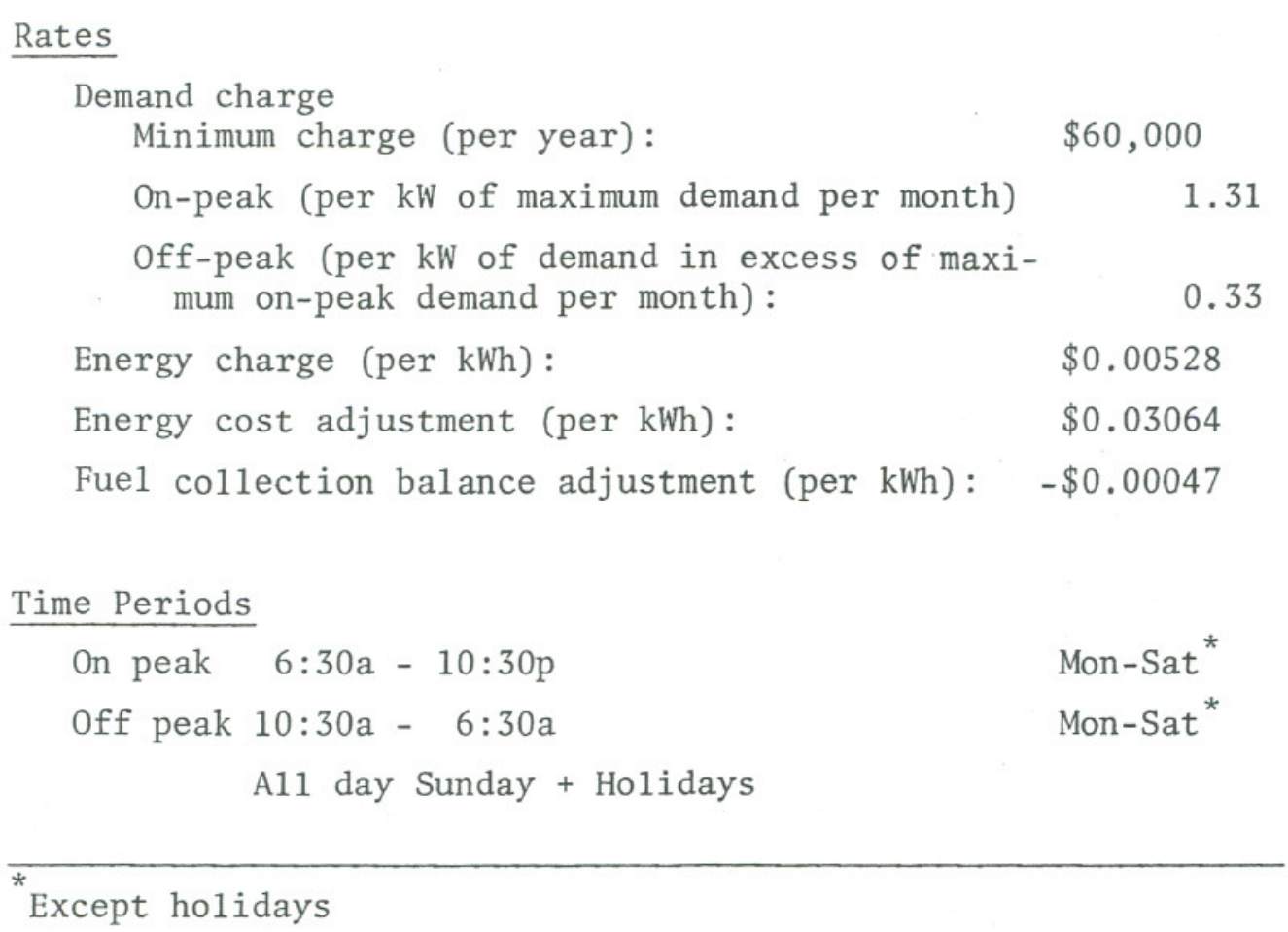


of maximum demand) who are supplied at 60,000 volts or higher. New A-18 customers must be willing to enter into an initial 10-year contract and pay for any necessary extension of transmission facilities. A-18 customers can be curtailed "when in the utilities sole judgment its reserve, energy resources or transmission margin or any combination of these is needed to meet the dmeands of its regular customers on firm rates..." In addition, A-18 customers are subject to automatic interruption by underfrequency relay whenever the frequency on the utility's system drops below 59.75 hertz (plant protection load is exempt from automatic interruption). Under the schedule shown in Tabie 28, a customer operating electricity-using equipment continusouly would pay about $\$ 26.80$ per $\mathrm{kW}$-month corresponding to an average price of 3.7 cents per kWh. This is about 10 percent less than firm A-17 summer rates and five percent less than firm A-17 winter rates. However, if the A-18 customer manages his load so that none of it occurs during the on-peak hours defined in schedule A-17, he realizes no reduction in rates - and would actua11y be paying about $\$ 1.30$ per $\mathrm{kW}-$ month more than an A-17 customer operating on this load management schedule. PGEE now has six customers on this schedule with a total maximum demand of about $130 \mathrm{MW}$. However, all of this demand is not likely to be coincident with system peaks since the largest of these customers generates its own power and uses A-18 power as standby only. In the event of a need to interrupt power because of a capacity shortage during a peak period, PGEE estimates that the interruptible power under A-18 will be closer to $90 \mathrm{MW}$.

In addition to customers covered by A-18, PGEE has contractual agreements with some research facilities (Stanford Linear Accelerator Center, Ames Laboratory and LBL) which require these customers to interrupt part of their loads as soon as possible after receiving telephone notice. For the most part, the interruptible portion of the load at these facilities is associated with occasional large experiments and, while the potential interruptible load exceeds $70 \mathrm{MW}$, PG\&E believes that these loads are unlikely to be coincident with the system peak. ${ }^{48}$

Since the benefits to the utility of interruptible power are quite substantial and the inconveniences to the customer can be considerable, the cost reductions for A-18 customers appear to be rather small. This is parti- 
cularly true for customers who are able to manage their loads to reduce peak demands. This may account for the fact that two of the six A-18 customers have given notice that they wish to change to A-17.

Both the CPUC and the CERCDC seem disposed to encourage the use of interruptible service. However, there is not at present much activity being devoted to the development of more attractive or flexible rate schedules. In the future it is likely that proposals will be considered to make interruptible service available to smaller customers and to establish a separate rate for customers who are willing to accept curtailments but do no wish to have underfrequency relays. (The former reduces the requirement for generating capacity at peak times, the latter reduces the requirement for spinning reserves at a11 times.)

The second continuing load management strategy involves the use of load controllers which interrupt the operation of energy-using equipment. In California, the type of load control equipment most likely to be used is the air-conditioner cycler for residential customers. These devices periodically interrupt the operation of an air conditioner causing it to cycle during peak periods rather than run continuously. They can be activated by a radio signal, a signal imposed on the power line (ripple contro1), or a temperature sensor. The basic effect of this equipment is to raise the temperature of the space being cooled, i.e., the strategy is equivalent to utility control of customer thermostats on peak days.

One risk in the use of cyclers is that customers can defeat their purpose by buying larger air conditioners which are sufficient to cool the space during the "on" part of the cycle. For this reason cycler programs will probably have to be voluntary and the incentive will have to be less than the cost of a larger air conditioner (i.e., it cannot be cheaper for customers to buy oversized air conditioners with cyclers than to buy properly sized equipment without cyclers).

Several of the experiments now being conducted in the Electric Utilities Demonstration Project involve the use of cyclers. Results as yet are inconclusive, but apparently customer acceptance and equipment performance have been satisfactory to date-so much so that the CERCDC staff has indicated that it is strongly considering the implementation of standards requiring air conditioner cycling programs. 
1977 Adverse Weather-year Programs

In response to the adverse weather conditions PGGE has contacted their large customers and asked them to agree to voluntarily shed load during emergencies. PGEE reports that it has found about 500 MW of 1 oad that customers will shed on request. PG\&E does not count this in its loads and resources planning since it is strictly voluntary.

In addition to its voluntary program, PGE्F has developed plans to institute rotating outages (RO's) if all other measures fail. The service area has been divided into 20 blocks each of which has about five percent of the system load. In the event of an unavoidable capacity shortage these blocks will be shed in rotation. At present these blocks do not discriminate between customers. The CPUC has asked PG\&E and the other utilities to develop RO plans that will permit certain essential customers to continue to be served. SCE has stated that for the most part it will be able to do this, but PG\&E reports that the way its circuits are arranged will make it impossible to develop Ro plans which discriminate by customer.

$\underline{\text { Possible Additional Emergency Measures }}$

The fact that PGEE is able to get a significant amount of load shedding on a purely voluntary basis suggests that a program which offered some incentives might increase the amount of interruptible load for the short term. Probably there are not many customers who would be interested in A-18 even if the limit were lowered below $5000 \mathrm{MW}$ since there is such a long period of contractual obligation and since they would be subject to interruption without notice.

If a rate could be devised which offered a short-term contract (i.e., for the duration of the drought) and provided notice to the customers, this might be more acceptable. For example, demand metered customers could receive a discount on the demand charge (say $\$ 1.00 \mathrm{~kW}$ per month) for each $\mathrm{kW}$ that they agreed to shed. Since it is usually possible to forecast the development of extreme peak demands we11 in advance, a notice of 30 minutes could be given. Shedding would be under the control of the customer, but if he failed to shed he would have to pay some fairly still penalty (say $\$ 10.00$ per $\mathrm{kW})$. 
The advantage of such a rate would be twofold. First, it would reward those customers who are now making a voluntary contribution to improve the system's reliability. Second, it would attract customers who were less public spirited to make a similar contribution.

A second measure that might be considered is a program to improve the reliability of standby electricity sources. Some customers who would suffer serious losses in the event of a power outage have standby generators. However, the reliability of these sources is often questionable; first because maintenance is frequently sporadic, and second because most of them have very limited fuel supplies.

These standby systems might be improved if the utilities offered a high reliability service to customers needing it. This service could include a routine standby equipment maintenance and testing program and an emergency fuel supply program. Because the utility maintenance crews would provide service to many customers, they would be able to devote full time to these operations. This would probably result in much better maintenance service than that which could be provided by a plant engineer who only devotes a small portion of his time to standby equipment. Pooling the emergency supply needs of all customers with standby could make it possible to develop special contracts with fuel suppliers whereby the suppliers would suspend normal deliveries during emergencies in order to service the standby systems.

In principle, the standby generators could be turned on before an RO was necessary-the reduction in load might avert outages and the utility's regular supply could back up the standby generators. 



\section{APPENDIX A \\ CAPACITY AND ENERGY SUMMARY}

Tables A-1 and A-2 summarize the energy and capacity resources, respectively, available for 1978 for the three southern California utilities. As noted in Section 3 of the report, several changes have been made in the submittals by the utilities to CERCDC (Reference 6), and these are reflected in these tables. 
Table A-1

Energy Generating Capability of Major Southern California Electric Utility Companies ${ }^{\text {a }}$

\begin{tabular}{|c|c|c|c|c|c|c|c|c|c|c|c|c|c|}
\hline \multirow[b]{3}{*}{ Resources } & \multicolumn{13}{|c|}{1978 Adverse Conditions } \\
\hline & Jan. & Feb. & Mar. & Apr. & May & June & July & Aug. & Sept. & Oct. & Nov. & Dec. & $\begin{array}{l}\text { Annual } \\
\text { Total }\end{array}$ \\
\hline & & & & & & & & & & & & & \\
\hline \multicolumn{14}{|l|}{ Hydro } \\
\hline SCE & 200 & 207 & 246 & 276 & 286 & 432 & 418 & 370 & 307 & 262 & 249 & 274 & 3527 \\
\hline LADWP & 58 & 44 & 74 & 130 & 138 & 78 & 51 & 51 & 39 & 44 & 59 & 64 & 830 \\
\hline SDG\&्ष & $\frac{1}{5050}$ & $\frac{1}{252}$ & $\frac{0}{80}$ & $\frac{1}{10}$ & $\frac{1}{10}$ & $\frac{1}{1}$ & $\frac{1}{1070}$ & $\frac{1}{10}$ & $\frac{0}{4}$ & $\frac{0}{10}$ & $\frac{0}{1}$ & $\frac{0}{1}$ & 7 \\
\hline TOTAL & 259 & $\overline{252}$ & $\overline{320}$ & $\overline{407}$ & $\overline{425}$ & $\overline{511}$ & $\overline{470}$ & $\overline{422}$ & $\overline{346}$ & $\overline{306}$ & $\overline{308}$ & $\overline{338}$ & $\overline{4364}$ \\
\hline \multicolumn{14}{|c|}{ Northwest Firm } \\
\hline SCE & 0 & 0 & 0 & 0 & 0 & 0 & 0 & 0 & 0 & 0 & 0 & 0 & 0 \\
\hline LADWP & 0 & 0 & 0 & 0 & 0 & 0 & 0 & 0 & 0 & 0 & 0 & 0 & 0 \\
\hline SDG\&E & $\frac{29}{20}$ & $\frac{27}{27}$ & 30 & 29 & $\frac{30}{20}$ & $\frac{29}{39}$ & $\frac{29}{30}$ & $\frac{29}{20}$ & $\frac{29}{20}$ & $\frac{29}{20}$ & $\frac{29}{20}$ & $\frac{30}{70}$ & $\frac{349}{310}$ \\
\hline TOTAL & $\overline{29}$ & 27 & 30 & 29 & 30 & 29 & 29 & $\overline{29}$ & 29 & $\overline{29}$ & 29 & 30 & 349 \\
\hline \multicolumn{14}{|l|}{ Coal } \\
\hline SCE & 874 & 791 & 741 & 731 & 674 & 847 & 874 & 874 & 773 & 461 & 647 & 814 & 9101 \\
\hline LADWP & 492 & 370 & 397 & 397 & 492 & 476 & 492 & 492 & 476 & 410 & 305 & 397 & 5196 \\
\hline 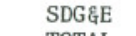 & 0 & 0 & 0 & 0 & 0 & 0 & 0 & 0 & $\frac{0}{1}$ & 0 & 0 & 0 & \\
\hline TOTAL & $\overline{1366}$ & $\overline{1161}$ & $\overline{1138}$ & $\overline{1128}$ & $\overline{1166}$ & $\overline{1323}$ & $\overline{1366}$ & $\overline{1366}$ & $\overline{1249}$ & $\overline{871}$ & $\overline{952}$ & $\overline{1211}$ & $1 \overline{4297}$ \\
\hline \multicolumn{14}{|l|}{ Nuclear } \\
\hline SCE & 223 & 201 & 223 & 216 & 223 & 216 & 223 & 223 & 216 & 0 & 92 & 223 & 22729 \\
\hline LADWP & 0 & 0 & 0 & 0 & 0 & 0 & 0 & 0 & 0 & 0 & 0 & 0 & 0 \\
\hline SDG宅E & 56 & 50 & 56 & 54 & 56 & 54 & 56 & 56 & 54 & $\underline{0}$ & 24 & 56 & 5702 \\
\hline TOTAL & 279 & $\overline{251}$ & 279 & 270 & 279 & 270 & 279 & 279 & 270 & $\frac{0}{0}$ & 116 & 279 & 2851 \\
\hline \multicolumn{14}{|c|}{ Other Receipts } \\
\hline SCE & 358 & 307 & 353 & 343 & 345 & 272 & 293 & 272 & 239 & 337 & 329 & 361 & 3809 \\
\hline LADWP & 0 & 0 & 0 & 0 & 0 & 0 & 15 & 15 & 15 & 0 & 0 & 0 & 45 \\
\hline $\begin{array}{l}\text { SDG\&्षE } \\
\text { TOTAL }\end{array}$ & $\frac{12}{370}$ & $\frac{10}{317}$ & $\frac{12}{365}$ & $\frac{10}{353}$ & $\frac{18}{363}$ & $\frac{12}{299}$ & $\frac{10}{318}$ & $\frac{9}{296}$ & $\frac{9}{248}$ & $\frac{15}{352}$ & $\frac{32}{361}$ & $\begin{array}{r}27 \\
388\end{array}$ & $\frac{176}{4030}$ \\
\hline \multicolumn{14}{|c|}{ Gas \& Oil Generation } \\
\hline SCE & 4486 & 4020 & 4454 & 4638 & 4522 & 4682 & 5245 & 5345 & 4944 & 5130 & 4746 & 4809 & 57021 \\
\hline LADWP & 1749 & 1470 & 1686 & 1637 & 1745 & 1904 & 1983 & 2188 & 2118 & 1994 & 1759 & 1891 & 22124 \\
\hline SDGE्षE & $\frac{956}{7191}$ & $\frac{846}{6336}$ & $\frac{939}{7070}$ & $\frac{865}{7110}$ & $\frac{867}{7171}$ & $\frac{889}{7175}$ & $\frac{996}{929}$ & $\frac{1017}{0.050}$ & $\frac{914}{-70076}$ & $\frac{1027}{8151}$ & $\frac{984}{7489}$ & $\frac{1065}{7765}$ & $\frac{11365}{90510}$ \\
\hline TOTAL & 7191 & 6336 & 7079 & 7140 & 7134 & $\overline{7475}$ & $\overline{8224}$ & $\overline{8550}$ & 7976 & 8151 & 7489 & 7765 & 90510 \\
\hline \multicolumn{14}{|c|}{ Total Capability } \\
\hline SCE & 6141 & 5526 & 6017 & 6204 & 6050 & 6449 & 7053 & 7084 & 6479 & 6190 & 6063 & 6481 & 75737 \\
\hline LADWP & 2299 & 1884 & 2157 & 2164 & 2375 & 2473 & 2541 & 2746 & 2633 & 2448 & 2123 & 2352 & 28195 \\
\hline SDG安E & $\frac{1054}{102}$ & $\frac{934}{9.14}$ & $\frac{1037}{127}$ & $\underline{959}$ & $\frac{972}{27}$ & 985 & $\frac{1092}{109}$ & $\underline{1112}$ & $\underline{1006}$ & 1071 & 1069 & 1178 & 12469 \\
\hline TOTAL & $\overline{9994}$ & $\overline{8344}$ & 9211 & $\overline{9327}$ & $\overline{9397}$ & $\overline{9907}$ & $\overline{10686}$ & 10942 & 10118 & 9709 & $\overline{9255}$ & $1 \overline{0011}$ & 116401 \\
\hline \multicolumn{14}{|c|}{ Energy for Load } \\
\hline $\mathrm{SCE}$ & 5445 & 4884 & 5377 & 5245 & 5455 & 5530 & 5992 & 6080 & 5635 & 5549 & 5294 & 5593 & 66079 \\
\hline LADWP & 1739 & 1581 & 1715 & 1662 & 1741 & 1794 & 1967 & 1983 & 1829 & 1811 & 1704 & 1814 & 21340 \\
\hline SDG\&్ષE & 940. & 843 & 903 & 817 & 838 & 843 & 925 & 997 & 882 & 912 & 935 & 976 & 10811 \\
\hline TOTAL & $\overline{8124}$ & $\overline{7308}$ & $\overline{7995}$ & $\overline{7724}$ & $\overline{8034}$ & $\overline{8167}$ & $\overline{8884}$ & $\overline{9060}$ & $\overline{8346}$ & $\overline{8272}$ & $\overline{7933}$ & $\overline{8383}$ & $\overline{98230}$ \\
\hline \multicolumn{14}{|c|}{ Excess Capability } \\
\hline SCE & 696 & 642 & 640 & 959 & 595 & 919 & 1061 & 1004 & 844 & 641 & 769 & 888 & 9658 \\
\hline LADWP & 560 & 303 & 442 & 502 & 634 & 679 & 524 & 763 & 804 & 637 & 419 & 538 & 6855 \\
\hline SDG安E & 114 & 91 & 134 & 142 & 134 & 142 & 167 & 115 & 124 & 159 & 134 & 202 & 1658 \\
\hline TOTAL & $\overline{1370}$ & $\overline{1036}$ & $\overline{1216}$ & $\overline{1603}$ & $\overline{1363}$ & $\overline{1740}$ & $\overline{1802}$ & $\overline{1882}$ & $\overline{1772}$ & 1437 & 1322 & $\frac{}{1628}$ & $\frac{}{18171}$ \\
\hline
\end{tabular}

${ }^{a}$ Data from Ref. 6, except as noted.

$\mathrm{b}_{\text {San }}$ Onofre refueling rescheduled from July and part of August to October and part of November. 
Table A-2

Southern California Resources Available for Summer $1978^{a}$ (MWe)

\begin{tabular}{|c|c|c|c|c|}
\hline Resource Type/Utility & June & July & August & September \\
\hline \multicolumn{5}{|l|}{ Hydro + Pumped Storage } \\
\hline SCE & 1503 & 1463 & 1451 & 1435 \\
\hline LADWP $^{\mathrm{b}}$ & 1874 & 1874 & 1874 & 1874 \\
\hline SDG६्षE & 5 & 5 & 5 & 5 \\
\hline TOTAL & 3382 & 3342 & 3330 & 3314 \\
\hline \multicolumn{5}{|l|}{ Northwest Firm Capacity } \\
\hline SCE & 650 & 650 & 650 & 650 \\
\hline LADWP $^{c}$ & 525 & 525 & 525 & 525 \\
\hline SDG\&E & 112 & 112 & 112 & 112 \\
\hline TOTAL & 1287 & 1287 & 1287 & 1287 \\
\hline \multicolumn{5}{|l|}{ Coa1 } \\
\hline SCE & 1653 & 1653 & 1653 & 1653 \\
\hline LADWP & 866 & 866 & 866 & 866 \\
\hline TOTAL & 2519 & 2519 & 2519 & 2519 \\
\hline \multicolumn{5}{|l|}{ Nuclear } \\
\hline $\mathrm{SCE}^{\mathrm{d}}$ & 349 & 349 & 349 & 349 \\
\hline SDG\&E ${ }^{d}$ & 88 & 88 & 88 & 88 \\
\hline TOTAL & 437 & 437 & 437 & 437 \\
\hline \multicolumn{5}{|l|}{ Other } \\
\hline SCE & 307 & 307 & 307 & 307 \\
\hline LADWP $^{\mathrm{e}}$ & -75 & -75 & -75 & 0 \\
\hline SDG\&E ${ }^{f}$ & -9 & -9 & -9 & -9 \\
\hline TOTAL & 223 & 223 & 223 & 298 \\
\hline \multicolumn{5}{|l|}{ Gas/Oil } \\
\hline SCE & 10049 & 10049 & 10283 & 10283 \\
\hline LADWP & 2984 & 2984 & 3268 & 3268 \\
\hline SDG\&్E & 1920 & 1914 & 1912 & 1878 \\
\hline TOTAL & 14953 & 14947 & 15463 & 15429 \\
\hline
\end{tabular}


Table A-2 (Continued)

\begin{tabular}{|c|c|c|c|c|}
\hline & June & July & August & September \\
\hline \multicolumn{5}{|l|}{ Scheduled Maintenance } \\
\hline SCE ${ }^{\mathrm{d}}$ & 892 & 0 & 0 & 1188 \\
\hline LADWP & 344 & 0 & 0 & 183 \\
\hline SDGEE ${ }^{d}$ & 20 & 0 & 0 & 0 \\
\hline TOTAL & 1256 & 0 & 0 & 1371 \\
\hline \multicolumn{5}{|l|}{ Total Capacity Available } \\
\hline SCE & 13619 & 14471 & 14693 & 13489 \\
\hline LADWP & 5830 & 6174 & 6458 & 6350 \\
\hline SDG\&્ષE & 2096 & 2110 & 2108 & 2074 \\
\hline TOTAL & 21545 & 22755 & 23259 & 21913 \\
\hline \multicolumn{5}{|l|}{ Loads } \\
\hline SCE & 10202 & 11652 & 12012 & 11272 \\
\hline LADWP & 3418 & 3967 & 4090 & 3874 \\
\hline SDGE్E & 1727 & 1823 & 1919 & 1881 \\
\hline TOTAL: So. California & 15347 & 17442 & 18021 & 17027 \\
\hline \multicolumn{5}{|c|}{ Operating Reserve Requirements: $\mathrm{g}$} \\
\hline \multicolumn{5}{|l|}{$3 \%$ of 1 oad +1 argest risk } \\
\hline SCE $\quad(7 \%$ of peak $)$ & 714 & 816 & 841 & 789 \\
\hline LADWP (1argest risk) & 560 & 560 & 560 & 560 \\
\hline SDGEE $\quad(7 \%$ of peak $)$ & 121 & 128 & 134 & 132 \\
\hline TOTAL: & 1395 & 1504 & 1535 & 1481 \\
\hline \multicolumn{5}{|l|}{ Loads + Reserves } \\
\hline SCE & 10916 & 12468 & 12853 & 12061 \\
\hline LADWP & 3978 & 4527 & 4650 & 4434 \\
\hline SDG\&్६E & 1848 & 1951 & 2053 & 2013 \\
\hline TOTAL & 16742 & 18946 & 19556 & 18508 \\
\hline \multicolumn{5}{|l|}{ Capacity Margin } \\
\hline SCE & 2703 & 2003 & 1340 & 1428 \\
\hline LADWP & 1852 & 1647 & 1808 & 1916 \\
\hline SDGE్षE & 248 & 159 & 55 & 61 \\
\hline TOTAL & 4803 & 3809 & 3703 & 3405 \\
\hline
\end{tabular}




\section{A-2 Footnotes}

Data from Reference 6, except as noted.

$\mathrm{b}_{\text {LADWP }}$ apparently does not derate either its Owens Valley and Aqueduct hydro facilities (193 MWe) or its share of Hoover (511 MWe) due to drought conditions. This figure includes full use of these facilities in addition to Castaic pumped storage (1170 MWe).

$\mathrm{c}_{\text {This }}$ is the full capacity allocation to LADWP in the $800 \mathrm{KV}-\mathrm{DC}$ intertie with the Pacific Northwest.

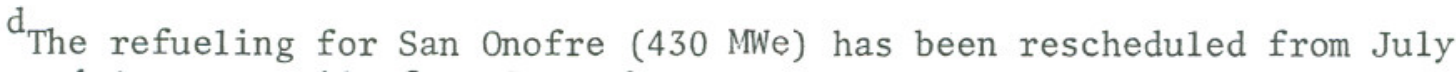
and August until after September.

Sales of peak capacity to Nevada Power Company.

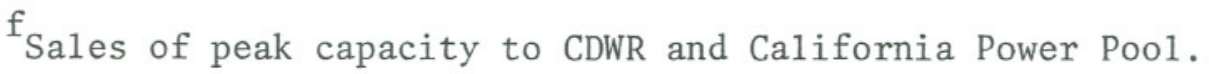

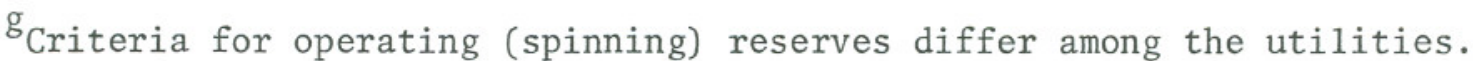
SCE and SDGEE use 7\% of the expected peak load, which is the California power pool requirement. LADWP uses the single largest contingency, which for its system is its share of the DC intertie, or 560 MWe. See Reference 37 for details. 

APPENDIX B

FORCED OUTAGE RATES

In Table B-1, we list forced outage rates for individual generation units and major interconnecting transmission lines for California. Also tabulated are partial outage states forthese plants for which these are available. While several new plants are expected to be added to the resource base in California, we have treated Diablo Canyon as a separate question. Because this plant might be available as part of PG\&E's resources for August 1978, the effects on system reliability depend upon the forced outage rate used. PG\&E uses three sets of outage rates, depending upon the relative 'maturity' of the plant. For the initial operational period up to the first refueling, the full FOR is 14 percent, and the partial (20 percent derating) is 23.3 percent. Beyond the first refueling (14-18 months after start-up) the FOR values are 12 percent (fu11) and 17 percent (partial). At plant maturity, which is expected to be about four years after start-up, the FOR's are 10 percent (ful1) and 11 percent (partial).

The forced outage rate before the first refueling is more applicable toward the end of the time period. In order to estimate the forced outage rate for August (assuming on August 1 date for commercial operation) we use the functional form of the FOR suggested in Ref. 18:

$$
\text { FOR }(t)=\text { FOR }_{M}+\left(\text { FOR }_{0}-\text { FOR }_{M}\right) e^{-0.075 t}
$$

where FOR $(t)$ is the forced outage rate at time $t$ (in months), FOR $_{M}$ is the mature FOR, FOR 0 is the initial immature forced outage rate. One can see that at time $t=0, F O R(t)=F_{0}$. In order to find $F_{0 R}$, one can rearrange the equation to give:

$$
\mathrm{FOR}_{0}=\mathrm{FOR}_{\mathrm{M}}+\left(\mathrm{FOR}(\mathrm{t})-\mathrm{FOR}_{\mathrm{M}}\right) \mathrm{e}^{0.075 \mathrm{t}}
$$

PGE्E's estimates for the forced outage rates fix $\mathrm{FOR}_{\mathrm{M}}$, and provide several values for FOR( $(t)$. These latter outage rates actually apply over a span of time, hence we pick several times, solve for $\mathrm{FOR}_{0}$, and average the results. This procedure results in $\mathrm{FOR}_{0}=19$ percent for the full forced outage rate, 
and $\mathrm{FOR}_{0}=38$ percent for the partial outage rate. These are consistent with the PG\&E estimates for the immature outage rates, as can be seen in Figure B-1. 
Table B-1

Forced Outage Rates for Individual Power P1ant Units and Major Interconnecting transmission lines for California. Generating Capacities shown are for August 1978; changes for July 1978 are noted in the footnotes.

\begin{tabular}{|c|c|c|c|c|c|}
\hline \multirow[t]{2}{*}{ Utility } & \multirow[t]{2}{*}{ Facility } & \multirow[t]{2}{*}{$\begin{array}{c}\text { Number } \\
\text { of } \\
\text { Units }\end{array}$} & \multirow[t]{2}{*}{$\begin{array}{l}\text { Unit } \\
\text { Size } \\
\text { (MWe) }\end{array}$} & \multicolumn{2}{|c|}{$\begin{array}{c}\text { Forced Outage } \\
\text { Rates } \\
\text { (in percent) }\end{array}$} \\
\hline & & & & Partial & $\mathrm{Fu} 11$ \\
\hline \multirow[t]{37}{*}{ PGE्G } & Avon, Martinez, 01eum \#2 & 3 & 46 & & 1.5 \\
\hline & 01eum \#1 & 1 & 41 & & 1.5 \\
\hline & Humboldt Bay \#1 & 1 & 52 & & 1.5 \\
\hline & Humboldt Bay \#2 & 1 & 53 & & 1.5 \\
\hline & Potrero \#1 & 1 & 56 & & 1.5 \\
\hline & Potrero \#2 & 1 & 58 & & 1.5 \\
\hline & Kern \# 1 & 1 & 74 & & 1.5 \\
\hline & Hydroelectric units-dispatched & 78 & 50 & & .8 \\
\hline & in $\sim 50$ MWe blocks & 10 & 49 & & .8 \\
\hline & Hunters Point \#2, \#3 & 2 & 107 & & 2.1 \\
\hline & Kern \#2 & 1 & 106 & & 2.1 \\
\hline & Contra Costa 1-3, Mos Ldg. 1 & 4 & 116 & & 2.1 \\
\hline & Moss Landing 2 & 1 & 115 & & 2.1 \\
\hline & Moss Landing 3 & 1 & 117 & & 2.1 \\
\hline & Hunters Point 4 , Morro Bay 1,2 & 3 & 163 & & 3.3 \\
\hline & Pittsburg $1-3$ & 3 & 153 & & 3.3 \\
\hline & Pittsburg 4 & 1 & 148 & & 3.3 \\
\hline & Contra Costa 4 , Moss Ldg. 4 & 2 & 117 & & 3.6 \\
\hline & Contra Costa 5 & 1 & 115 & & 3.6 \\
\hline & Moss Landing 5 & 1 & 100 & & 3.6 \\
\hline & Hunters Point 1 , Potrero 4-6 & 4 & 49 & & 6.0 \\
\hline & Mobile Emergency Units $1-3$ & 3 & 15 & & 6.0 \\
\hline & Geysers $5-10$ & 6 & 53 & & 6.0 \\
\hline & Geysers 11 & 1 & 106 & & 6.0 \\
\hline & Geysers 1 & 1 & 11 & & 4.0 \\
\hline & Geysers 2 & 1 & 13 & & 4.0 \\
\hline & Geysers 3,4 & 2 & 27 & & 8.0 \\
\hline & Potrero 3 & 1 & 207 & & 4.1 \\
\hline & Contra Costa 6,7 & 2 & $340^{b}$ & 24.7 & 3.0 \\
\hline & Morro Bay 3,4 & 2 & $338^{\mathrm{b}}$ & 24.7 & 3.0 \\
\hline & Pittsburg 5 & 1 & $315^{\mathrm{b}}$ & 24.7 & 3.0 \\
\hline & Pittsburg 6 & 1 & $325^{b}$ & 24.7 & 3.0 \\
\hline & Moss Landing 6,7 & 2 & $739^{c}$ & 30.8 & 4.0 \\
\hline & Pittsburg 7 & 1 & $720^{d}$ & 21.5 & 7.0 \\
\hline & Rancho Seco & 1 & $875^{\mathrm{e}}$ & 17.2 & 13.0 \\
\hline & Oakland $1-3$ & 3 & $54^{f}$ & & 6.0 \\
\hline & Diablo Canyon 1 & 1 & 1060 & - See $t$ & text- \\
\hline \multirow[t]{8}{*}{ SCE } & Ormond Beach 1,2 & 2 & 750 & & 4.0 \\
\hline & Redondo 7,8 & 2 & 480 & & 6.7 \\
\hline & Alamitos 5,6 & 2 & 480 & & 6.7 \\
\hline & Four Corners 4,5 & 2 & 384 & & 9.2 \\
\hline & E1 Segundo 3,4 & 2 & 335 & & 3.3 \\
\hline & Alamitos 3,4 & 2 & 320 & & 3.3 \\
\hline & Etiwanda 3,4 & 2 & 320 & & 3.3 \\
\hline & Huntingt on Beach 4 & 1 & 225 & & 5.0 \\
\hline
\end{tabular}


Table B-1 (Continued)

\begin{tabular}{|c|c|c|c|c|c|}
\hline \multirow[t]{9}{*}{ SCE } & Huntington Beach 1,2 & 2 & 215 & & 2.7 \\
\hline & Huntington Beach 3 & 1 & 215 & & 5.0 \\
\hline & Mandalay 1,2 & 2 & 215 & & 2.7 \\
\hline & Alamitos 1,2 & 2 & 175 & & 2.4 \\
\hline & E1 Segundo 1,2 & 2 & 175 & & 2.4 \\
\hline & Redondo 5,6 & 2 & 175 & & 2.4 \\
\hline & Etiwanda 1,2 & 2 & 132 & & 2.0 \\
\hline & Alamitos 7 & 1 & 121 & & 4.4 \\
\hline & Etiwanda 5 & 1 & 121 & & 4.4 \\
\hline & Huntington Beach 5 & 1 & 121 & & 4.4 \\
\hline & Manda1ay 3 & 1 & 121 & & 4.4 \\
\hline & Coolwater 2 & 1 & 81 & & 1.3 \\
\hline & Redondo $1,2,4$ & 3 & 74 & & 1.3 \\
\hline & Redondo 3 & 1 & 70 & & 1.3 \\
\hline & Coolwater 1 & 1 & 65 & & 1.3 \\
\hline & San Bernadino 1,2 & 2 & 63 & & 1.3 \\
\hline & E11wood 1 & 1 & 54 & & 5.0 \\
\hline & Highgrove 3,4 & 2 & 45 & & 1.3 \\
\hline & Long Beach 10,11 & 2 & 50 & & 4.0 \\
\hline & Highgrove 1,2 & 2 & 33 & & 1.3 \\
\hline & Long Beach 8 & 1 & $311^{\mathrm{k}}$ & 15.1 & 2.7 \\
\hline & Long Beach 9 & 1 & $232^{\mathrm{m}}$ & 15.1 & 2.7 \\
\hline & Coolwater $3,4 \mathrm{~g}$ & $2^{g}$ & $236^{n}$ & 8.7 & 4.9 \\
\hline & Hydroelectric units & $11^{\mathrm{h}}$ & 51 & & 1.3 \\
\hline & $\sim 50$ MWe block size & $18^{\mathrm{h}}$ & 50 & & 1.3 \\
\hline \multirow[t]{18}{*}{ LADWP } & Haynes 5,6 & 2 & 344 & & 6.0 \\
\hline & Scattergood $3^{j}$ & $1^{j}$ & 284 & & 6.0 \\
\hline & Haynes 2 & 1 & 232 & & 5.0 \\
\hline & Haynes 4 & 1 & 227 & & 5.0 \\
\hline & Haynes 1 & 1 & 222 & & 5.0 \\
\hline & Haynes 3 & 1 & 220 & & 5.0 \\
\hline & Scattergood 1,2 & 2 & 179 & & 5.0 \\
\hline & Valley 3 & 1 & 171 & & 5.0 \\
\hline & Valley 4 & 1 & 160 & & 5.0 \\
\hline & Navaho $1-3$ & 3 & 183 & & 8.0 \\
\hline & Va11ey 1,2 & 2 & 101 & & 4.0 \\
\hline & Harbor 5 & 1 & 94 & & 4.0 \\
\hline & Harbor 3,4 & 2 & 92 & & 4.0 \\
\hline & Harbor 2 & 1 & 79 & & 4.0 \\
\hline & Harbor 1 & 1 & 78 & & 4.0 \\
\hline & Harbor 6-9 & 4 & 19 & & 12.0 \\
\hline & Castaic & 5 & 225 & & 3.0 \\
\hline & Hydroelectric units & 17 & 50 & & 1.0 \\
\hline \multirow[t]{6}{*}{ SDGE्षE } & Encina 4 & 1 & 287 & & 3.0 \\
\hline & South Bay 4 & 1 & 220 & & 3.0 \\
\hline & South Bay 3 & 1 & 198 & & 4.0 \\
\hline & South Bay 2 & 1 & 142 & & 1.6 \\
\hline & South Bay 1 & 1 & 140 & & 1.6 \\
\hline & Encina 2,3 & 2 & 102 & & 1.6 \\
\hline
\end{tabular}


Table B-1 (Continued)

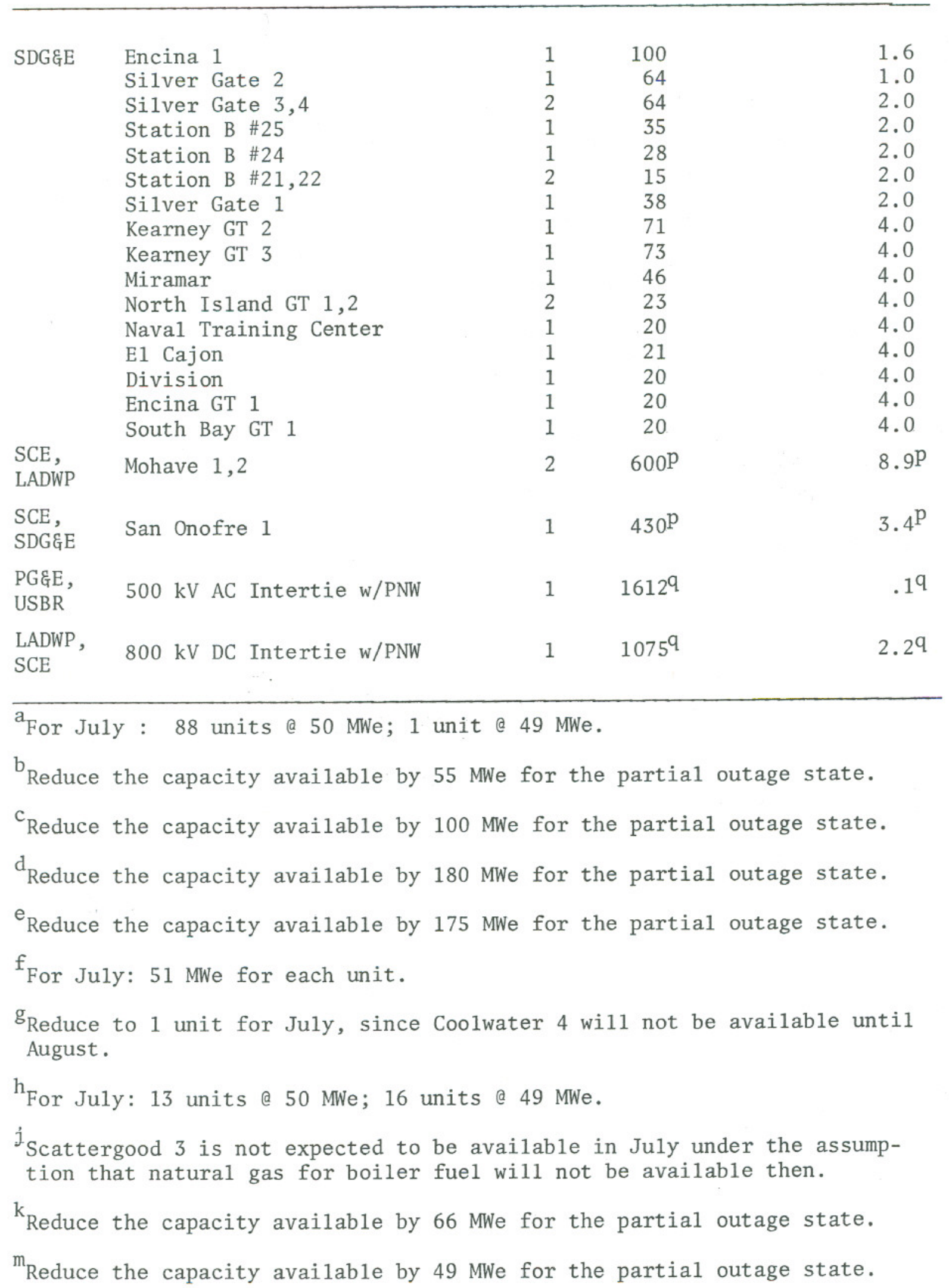


Tab1e B-1 (Continued)

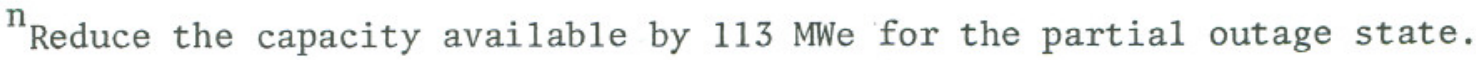

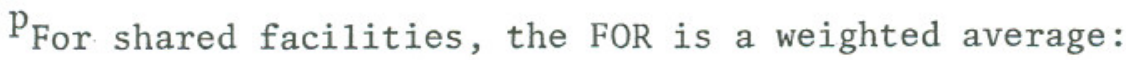

Mohave 1,2: SCE $442 \mathrm{MWe} /$ unit; FOR $=9.2$

LADWP $158 \mathrm{MWe} /$ unit; FOR - 8.0

Weighted average FOR $=8.9$

San Onofre 1: $\quad$ SCE 344 MWe FOR $=3.3$

SDG\&E: 86 MWe; FOR $=4.0$

Weighted average $\mathrm{FOR}=3.4$

$\mathrm{q}_{\text {The }} \mathrm{AC}$ and DC interties are shared. The firm power loading shown for both is typical, though some shifting of load between the AC and DC lines occurs. The FOR for the AC lines is generally agreed to be $0.1 \%$. For the DC line, SCE uses $2.2 \%$ and LADWP uses $6.0 \%$. We have used $2.2 \%$. 


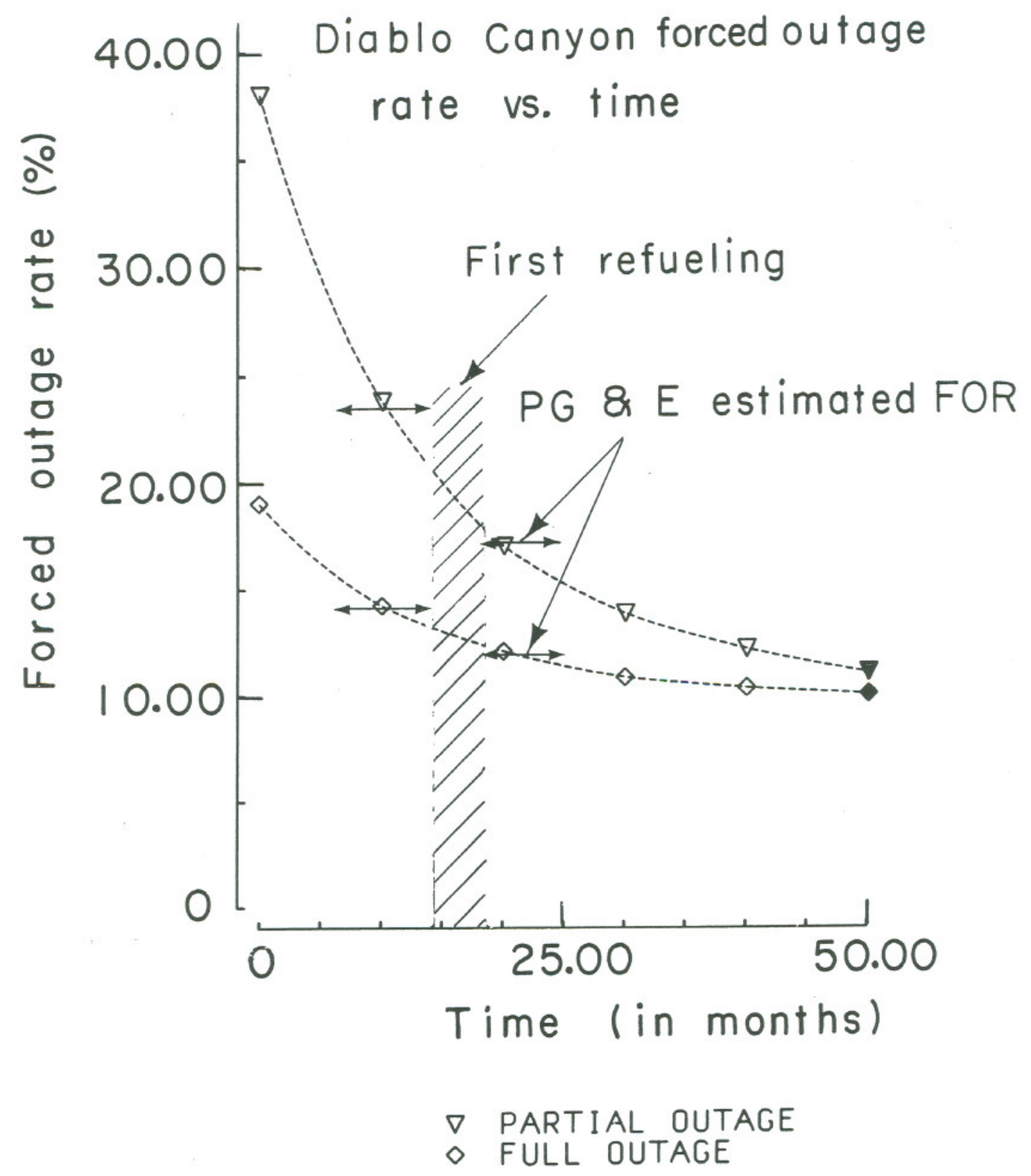

$X B L 782-224$

Figure B-1. Forced Outage Rates for Diablo Canyon as a Function of Time, With Time Zero as the Start of Commercial Operationn. The first refueling period is shown as a band, since the exact refueling data is uncertain. The shaded symbols represent PG\&्षE's assumed values for the outage rates at plant maturity. 

APPENDIX C

CALIFORNIA AGRICULTURAL ENERGY DEMAND

\section{INTRODUCTION}

California's agricultural industry has experienced a second year of drought conditions north of the Tehachapi Mountains. Water shortages during 1977 have been of only minor concern to agriculture in southern California and most central coast areas, but are particularly troublesome and costly in the Central Valley.

A map of California shown in Fig. C-1 depicts the reduced precipitation due to the drought by area. Table C-1 contains a comparison of the average precipitation in various areas of the state between a "normal" year and the 1976-77 water year. As demonstrated by the map and the corresponding table, the central coast counties and those of the coastal and desert regions of southern California received precipitation that was close to normal. Furthermore, this water was available in the past year to agriculture in the southern California area which generally relies upon surface water from the Colorado River; this eliminates any drought threat to this region. Other areas of the state, namely the north coast, San Francisco Bay, mountain, and Central Valley (Sacramento and San Joaquin Valleys) did not fare as well.

Although contributing only about three percent directly to the value of agricultural production in California, the mountain area supplies most of the surface water used by the Sacramento and San Joaquin Valleys. This water is usually stored in reservoirs located in that area. In the 197677 water year, however, these areas generally have received the lowest percentage of the State's precipitation. As of July 1977, reservoir storage in the State was about 37 percent of average.

The Sacramento and San Joaquin Valleys, which comprise the Central Valley, account for nearly 60 percent of the State's cash receipts from farm marketing of crops. Since nearly 80 percent of the estimated water use in agriculture and 75 percent of the energy requirements for pumping occur in the Central Valley, our analysis focuses on this geographic area. In addition, the major part of the Central Valley lies within Pacific Gas and Electric Company's (PG\&E) service area. 


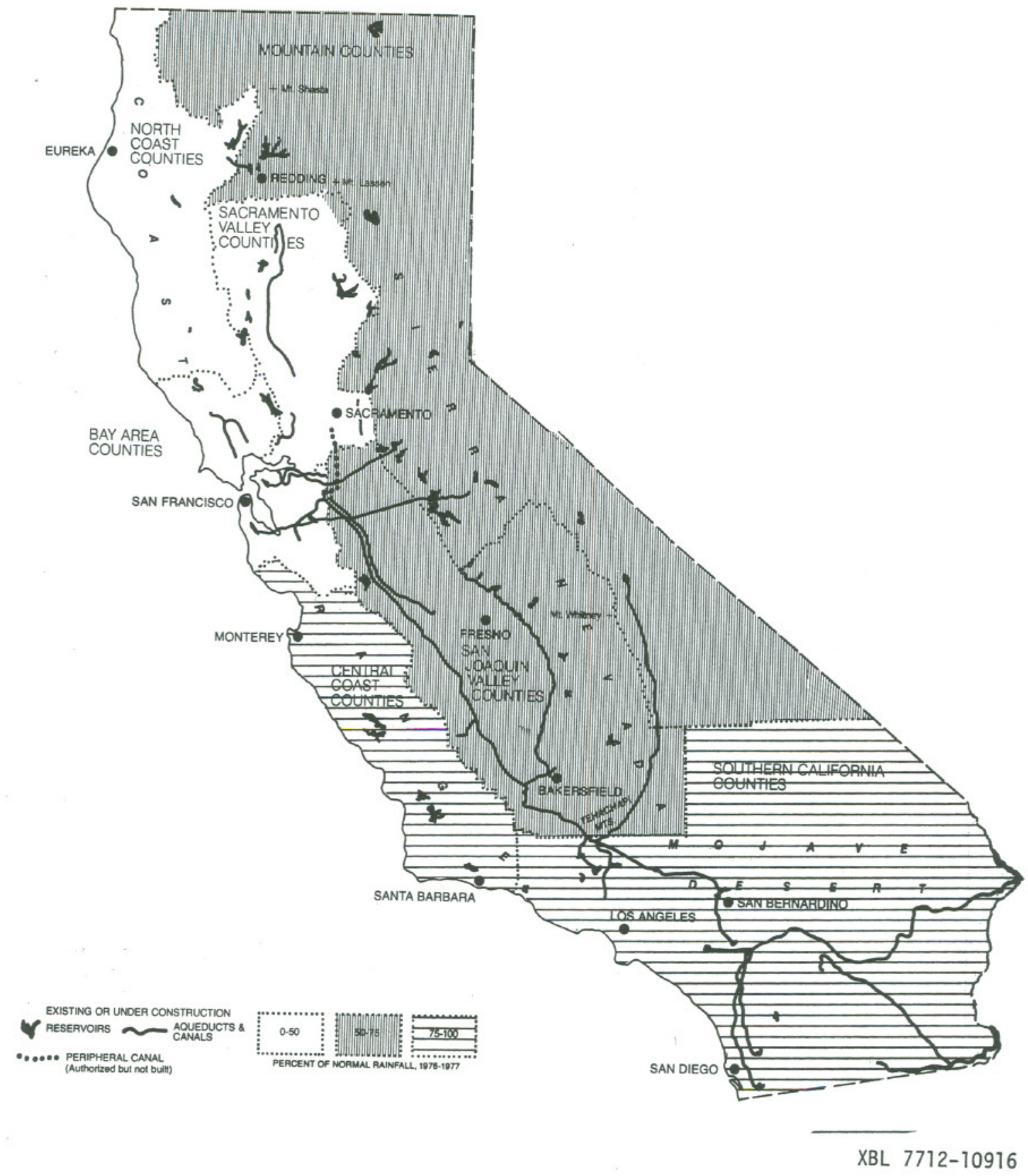

Figure C-1. Reduced Precipitation Due to the Drought by Area 
Table C-1

California Precipitation ${ }^{\mathrm{a}}$

\begin{tabular}{|c|c|c|c|}
\hline Areas & $\begin{array}{l}\text { Norma1 } \\
\text { Year } \\
\text { (inches) }\end{array}$ & $\begin{array}{c}\text { Percent of } \\
\text { Normal } \\
\text { (July 1974- } \\
\text { June 1975) } \\
\end{array}$ & $\begin{array}{c}\text { Percent of } \\
\text { Norma1 } \\
\text { (July 1976- } \\
\text { June 1977) }\end{array}$ \\
\hline North Coast & 37.6 & 105 & 42 \\
\hline San Francisco Bay & 21.6 & 96 & 47 \\
\hline Central Coast & 12.6 & 96 & 88 \\
\hline Sacramento Va11ey & 20.4 & 100 & 48 \\
\hline San Joaquin Valley & 9.5 & 91 & 68 \\
\hline Southern California ${ }^{b}$ & 7.9 & 57 & 94 \\
\hline Mountain & 32.4 & 94 & 58 \\
\hline
\end{tabular}

Average precipitation at weather stations in each area as reported by California Crop and Livestock Reporting Service, USDA (July-June weather year).

${ }^{b}$ Average of coastal and desert stations. 
ENERGY USE IN AGRICULTURE (1977)

Energy use in pumping of irrigation water varies widely across California according to the water source, the method of irrigation, and the water requirements of the various crops. In a dry year it is expected that agriculture's contribution to peak demand will increase due to decreased surface water deliveries and a consequent increase in groundwater pumping. The increased demand will occur especially in areas where the decrease in surface water supply has been the greatest (e.g., Central Val1ey).

Table C-2 contains the monthly electricity sales to agriculture in PGGE's service area for 1975-77. The data for 1975 and 1976 include sales by PGE्षE and of other utilities in PGE्षE's service area (e.g., Modesto Irrigation District, Turlock Irrigation District, Bureau of Reclamation, etc.). In addition, the total state agricultural sales are included for 1975 and 1976 as a means of comparison.

The highest monthly demand for agriculture in PG\&E's service area occurred in July during both 1975 and 1976. The growth in electrical sales to agriculture was more than 20 percent between 1975 and 1976 reflecting a response to the first year of the drought. PGEE's service area represented over 75 percent of the total statewide electricity sales to agriculture during both 1975 and 1976. PGE्G's maximum month1y sales for agriculture in 1977 took place in August and was less than 10 percent higher than the previous year. The lower rate of growth during 1977 probably corresponds to a more efficient use of water by farmers during the second year of the drought. Furthermore, not all of the surface water deficit could be made up through groundwater pumping because of certain physical limitations. The total yearly sales to agriculture in 1976 were 20 percent greater than in 1975, while they increased by only 3 percent in 1977.

A graphical representation of PG\&E's electricity sales to agriculture during 1975, 1976 and 1977 is presented in Fig. C-2. The graph shows a steady increase in electricity use from January through the peak periods in July and August followed by a steady decrease during the last quarter of the year. This pattern in total agricultural requirements corresponds 


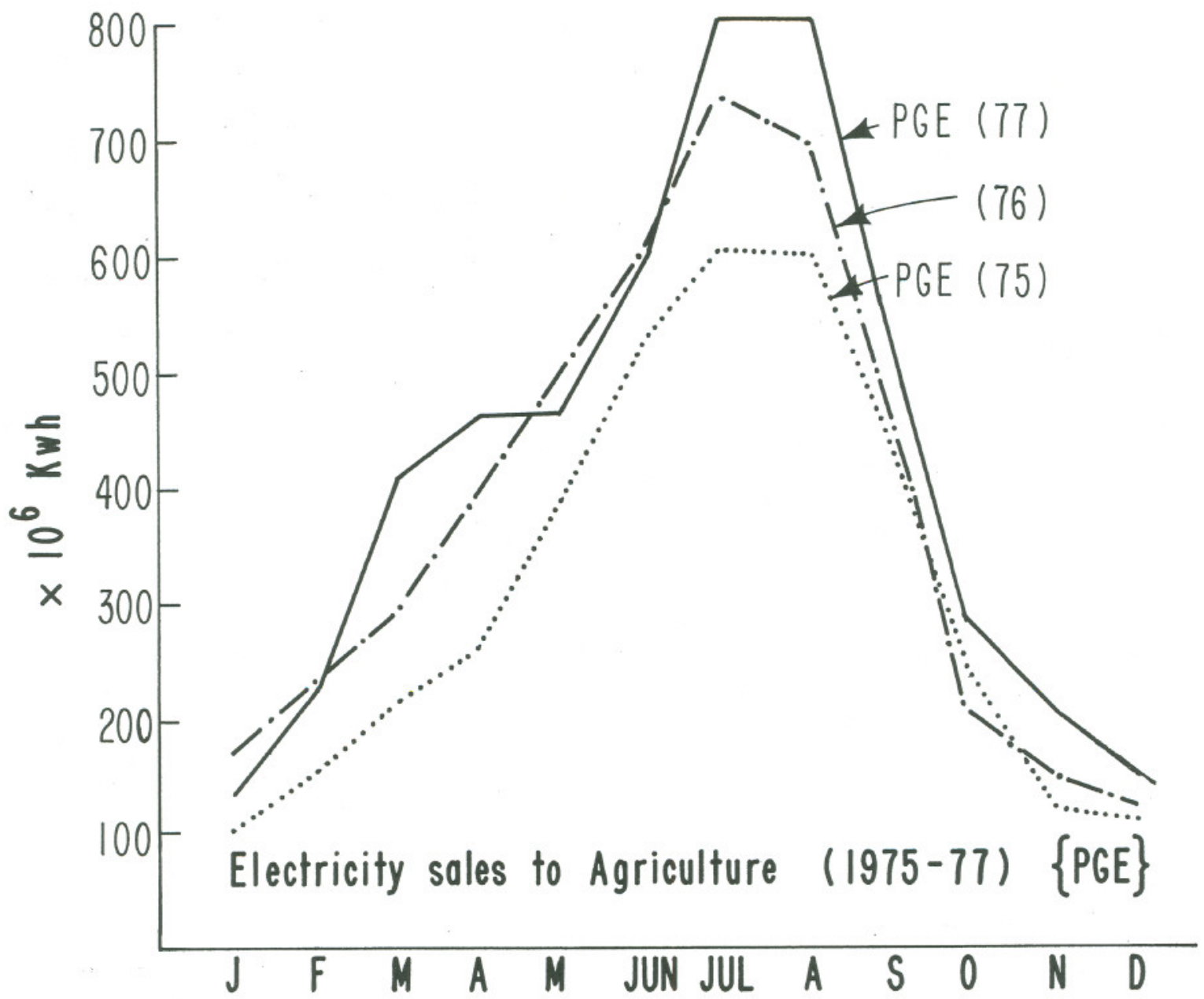

XBL77II-IIO33

Fig. C-2 
to the periods when irrigation pumping demands are the greatest. The 1977 data, although incomplete, exhibit a similar form.

Decreased water deliveries in 1977 resulted in reduced energy requirements for water pumping in both the CVP and SWP. In 1976, the CVP required 1.79 billion $\mathrm{kWh}$ for deliveries to agricultural users in the San Joaquin Valley. During 1977 the CVP used only about 800 million kWh for a savings of over 900 million $\mathrm{kWh} .{ }^{50}$ The DWR staff reported a total net energy use of about $2.95 \mathrm{billion} \mathrm{kWh}$ in 1976. This year with reductions in surface water deliveries, the estimated net energy requirement of the SWP is 1.58 billion $\mathrm{kWh}^{51}$ These combined reductions totaled over 4.5 billion kWh and were a factor in PG\&E's ability to meet peak electricity demand this past summer.

PROJECTED ENERGY DEMAND FOR AGRICULTURAL PUMPING IN THE CENTRAL VALLEY (1978)

The method for determining the estimated energy demand for agricultural pumping in the Central Valley for 1978 differs from that used in our previous report. ${ }^{16}$ In that report the energy use per acre was multiplied by the estimated planted acreage to give the total energy use for selected crops according to the water source and irrigation method. The total energy requirements for pumping in the Valley during 1977 were calculated to be 5.91 billion $\mathrm{kWh} .^{16}$ This value compares with a slightly lower estimate of 5.05 billion kWh made by the PG\&E staff. ${ }^{52}$ The calculations in our previous report, however, included energy use per acre-foot from both ground and surface sources as well as the energy required for moving the surface water within the state and federal water projects.

It is premature at this time to make estimates of cropping patterns for 1978 because there are still the uncertainties of this year's crop production, the commodity market and the future water picture. Therefore, in order to project energy demands for irrigation in 1978 we will consider an assessment of the pumping of groundwater in the Valley, as a whole, at the 1977 leve1, but from greater depths. This estimate will be compared to pumping additional water from wells to make up the projected 1978 surface water deficits. 
The total groundwater pumped in the Central Valley in 1977 is estimated to be 14.7 million acre-feet $(2.5$ million acre-feet in the Sacramento Valley and 12.2 million acre-feet in the San Joaquin Va1ley. ${ }^{44}$ In 1978, it is expected that groundwater pumped in the Valley will come from depths that are five to ten feet lower, on the average, than those of last year. This represents an additional 9 to $18.5 \mathrm{kWh}$ per acre-foot of groundwater pumped.

The average energy use during 1977 was estimated in our previous report to be $301 \mathrm{kWh}$ per acre-foot for groundwater and $158 \mathrm{kWh}$ per acrefoot for surface water sources. ${ }^{16}$ If we assume similar cropping patterns in 1978 as in 1977 and the use of the same amount of groundwater (e.g., 14.7 million acre-feet), the estimated electrical demand in agriculture for next year would be 5.83 billion $\mathrm{kWh}$. This calculation accounts for a 24 percent reduction in surface deliveries. However, if groundwater is used to make up the entire surface water deficit in 1978 (total groundwater supply equal to 17 million acre-feet), the estimated energy requirements will be 6.56 billion $\mathrm{kWh}$. This latter value represents nearly an 11 percent increase in estimated demand over 1977.

In our previous report we calculated the increase in agricultural peak load due to the dry year conditions of $1977 .{ }^{16}$ In order to predict the peak load generating capacity it is necessary to estimate the month1y increase in agricultural energy demand and combine this value with the monthly load factor as provided by PG\&E. The estimated monthly load factor used by PGGE is determined by an econometric model which compares daily, weekly and monthly load values.

Since the month1y energy requirements for agricultural pumping and the estimated monthly load factor are not available at this time, we can only make gross estimates of agriculture's contribution to the maximum peak load in 1978. If we assume that the monthly increase in agricultural electricity demands compares to the yearly percentage increase in the total energy requirements for agriculture as it has in 1975 and 1976, an increase of 89 million $\mathrm{kWh}$ is derived. Using an estimated monthly 1oad factor of 0.650 (average 1977 value for July and August), we estimate that an additional 190 MWe on peak will be required. This increased electricity requirement probably will not affect the electrical reserve capacity in a significant way. 
We have summarized in Table C-3 the recorded energy use and generation by the SWP and CVP for 1975 through 1977. The decline in water deliveries in 1977 compared with 1975 is accompanied by reduced energy requirements for pumping. For 1978, only rough estimates of the energy savings available from pumping less surface water in the federal and state projects can be made at this time. If the precipitation and runoff in 1978 are similar to that of 1977, both the SWP and CVP will deliver less water for agriculture, which will require subsequently less energy for pumping. The savings therefore will be equal to or greater than that experienced in 1977. 
Table C-3

Energy Use and Generation for

State and Federal Water Conveyance Projects

(in GWh)

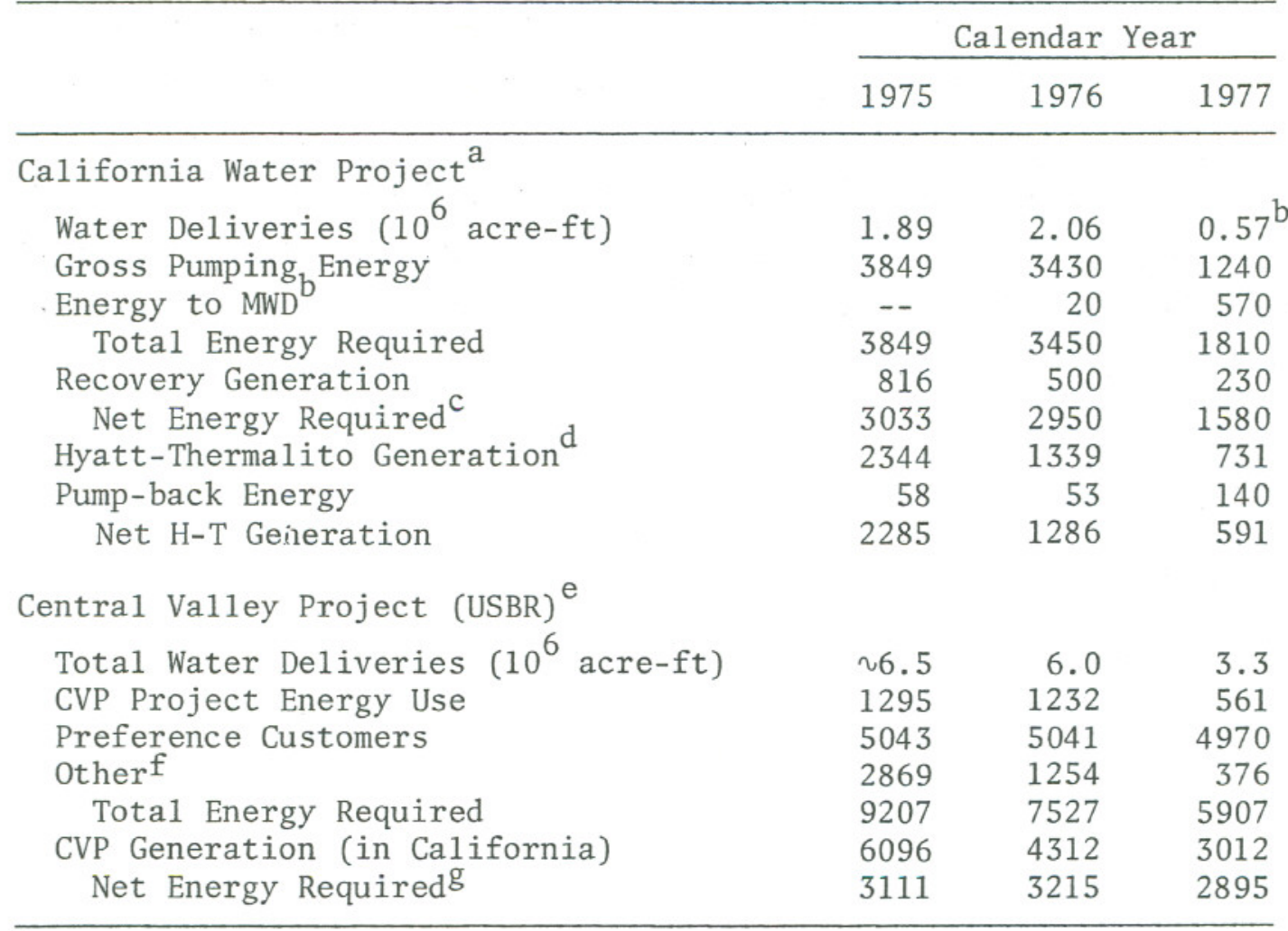

a Source: E.J. Terhaar, J. Klein, Persona1 Communication, Department of Water Resources, November 1977, February 1978.

${ }^{b}$ In 1977 DWR agreed to transfer $570 \mathrm{GWh}$ of energy available to it from the California suppliers to the Metropolitan Water District (MWD) for pumping an additional 318,000 acre-ft of water from the Colorado River for delivery to MWD customers. Normally MWD would have received this water directly via the California Aqueduct.

$\mathrm{c}_{\text {This }}$ energy is supplied via contracts with California utilities and with utilities in the Pacific Northwest (Canadian Entitlement Power).

$\mathrm{d}_{\text {This energy from the Oroville complex is sold directly to California }}$ utilities and is not used directly by the SWP for pumping energy.

esource: R. Greenhalgh, Personal Communication, USBR, February 1978.

$\mathrm{f}_{\text {Includes sales to }}$ PG\&E, interchange and transmission losses.

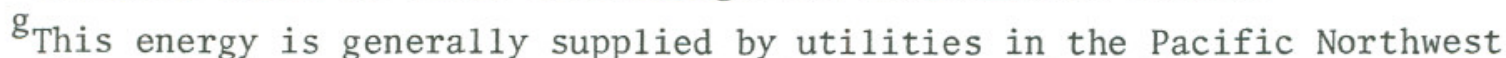
(including USBR share of the Centralia coal plant) and by PG\&EE. 
References

1. Personal communication, U.S. Bureau of Reclamation, October 1977.

2. Personal communication, California Department of Water Resources, October 1977.

3. Pacific Gas and E1ectric Company, Responses to NRC Request for Additional Information, Docket No. 50-275, September 26, 1977.

4. CERCDC, California Energy Trends and Choices, Volume 2, 1977 Biennial Report of the State Energy Commission.

5. CERCDC, Combined Response of California Electric Utilities, Docket No. 77-EA-1, May 11, 1977.

6. CERCDC, Combined Response of California Electric Utilities, Docket No. 77-EA-1, August 5, 1977.

7. Personal communication, Jack Kerler, PG\&E, October 1977.

8. Personal communication, Richard Jones, CDWR, January 1978.

9. Personal communication, Robert Griffin, BPA, September 1977.

10. USBR, Central Valley Project, Preliminary Operating Plans for 1978, September 1977, Sacramento, CA.

11. CDWR, Operational Criteria for the State Water Project, December 1, 1977 - December 31, 1978, September 1977, Sacramento, CA.

12. Personal communication, Robert Griffin, BPA, December 1977.

13. Personal communication, LADWP Staff, October 1977.

14. Personal communication, NRC Staff, December 1977.

15. NRC, Operating Units Status Report, NUREG 0020-77/9, 1977

16. Sathaye, J.A. et al., Effects of the Drought on California Electricity Supply and Demand, LBL-6356, June 1977.

17. Sullivan, Robert, Power System Planning, McGraw-Hi11, New York, 1977.

18. Pennsylvania-New Jersey-Maryland Interconnection (PJM Power Poo1), Response to Rate 'Counsel Request, New Jersey Public Utilities Commission, Docket 762-194, 1977.

19. California Air Resources Board, Emission Inventory 1973, August 1976.

20. Bartz, D.R. et a1., Control of Oxides of Nitrogen from Stationary Sources in the South Coast Air Basin (of California), KVB, Inc., Tustin, September 1974. 
References (continued)

21. Hunter, S.C. and M.L. Helgeson, Control of Oxides of Sulfur from Stationary Sources in the South Coast Air Basin of California, KVB, Inc., June 1976.

22. Cass, Glen R., "Dimensions of the Los Angeles $\mathrm{SO}_{2} /$ Sulfate Problem," Environmental Quality LAboratory Memo No. 16, Pasadena, January 1976.

23. Trijonis, John C. et a1., "Emissions and Air Quality Trends in the South Coast Air Basin," Environmental Quality Laboratory Memo No. 16, Pasadena, January 1976.

24. Southern California Air Pollution Control District, Fuel Use and Emissions from Stationary Combustion Process, July 1976.

25. CERCDC, Combined Response of California Electric Utilities, Docket No. 77-EA-1, submitted on April 20, 1977.

26. Davidson, A., Testimony before CPUC regarding Case No. 10292, South Coast Air Quality Management District, April 1977.

27. Roth, Philip M. et al., An Evaluation of Methodologies for Assessing the Impact of Oxidant Control Strategies, Systems Applications, Inc., San Rafae1, August 1976.

28. Trijonis, John C., "Economic Air Pollution Control Model for Los Angeles County in 1975," Environmental Science and Technology $\underline{8}(9), 811,1974$.

29. Dimitriades, Basi1, "Oxidant Control Strategies. Part 1. Urban Oxidant Control Strategy Derived from Existing Smog Chamber Data," Environmental Science and Technology 11 (1), 80, 1977.

30. Zeldin, Melvin D. and Donald M. Thomas, "Ozone Trends in the Eastern Los Angeles Basin Corrected for Meteorologica1 Variations," in Internationa1 Conference on Environmental Sensing and Assessment, Volume 2, Las Vegas, 1975.

31. Pacific Gas and Electric Company, Preliminary Common Stock Prospectus, November 4, 1977.

32. Kahn, Edward et al., Investment Planning in the Energy Sector, LBL-4474, March $\overline{1,} 19 \overline{76}$.

33. PGGE, Annual Report to the California PUC for 1976.

34. Personal communication, R.B. Fancher, PG\&E.

35. Personal communication, Jack Kerler, PG\&్§E, September 12, 1977

36. Personal communication, Dean Park, SMUD, January 1978.

37. CERCDC, Utility Supply P1an, Docket No. 77-EA-8, Submitted by individual California electric utilities, September 30, 1977. 
References (continued)

38. CERCDC, California Energy Trends and Choices Volume 3 Opportunities for Energy Conservation, p. 130, 1977.

39. Amaroli, G.A., Testimony before the CERCDC Regarding the Impact of an Expanded Voluntary Conservation Effort During 1977 California Drought, March 1977.

40. Cooper, J. (PG\&E Conservation Manager), Prepared Testimony Before the CPUC in the Matter of PG\&E's Rate Increase Application 55509 and 55510 ( $\operatorname{Tr}$ at 4225-4226), 1977.

41. Coffey, C.T., Presiding Officer's Proposed Report on PG\&E's Application Nos. 55509 and 55510 Before the CPUC, November 1977.

42. Acton, J.P. M.H. Graubard and D.J. Weinschrott, Electricity Conservation Measures in the Commercial Sector: The Los Angeles Experience, R-1592-FEA, The Rand Corporation, September 1974.

43. Mitche11, B.M. et al., Electricity Pricing and Load Management: Foreign Experience and California Opportunities (R-2106-CERCDC), The Rand Corporation, 1977.

44. Reynolds, S.P. Prepared Testimony in the Matter of the App1ication of PG\&E for Authority... to Implement Additional TimeVarying Rates Pursuant to Decision No. 85559 as modified by Decision No. 86543, Application No. 57666, November 1977.

45. Reynolds, S.P. (Senior Rate Engineer, PG६్E Rate Department), Personal communication, November 11, 1977.

46. Kaprillian, E., Pacific Gas and Electric Co., estimates that transmission losses between the Oregon border and the PG\&E and SCE load centers are $3 \%$ and $7-1 / 2 \%$, respectively. Assuming that losses between the Columbia River dams and the Oregon border are about 3\%, the round-trip transmission losses for banked power are $12 \%$ for PG\&E and $21 \%$ for SCE.

47. Wheatland, Gregg and John Chandley, Concurrent Brief of the Commission Staff in the Matter of Notice of Intention of PG\&E ... a Combined Cycle Power Plant ... in the San Francisco Bay Area, Docket No. 76-NOI-3, October 31, 1977.

48. Brown, Marsha11, Pacific Gas and Electric Co., personal communication, December 1977.

49. California Department of Water Resources, "The Continuing Drought," August 1977.

50. Personal Communication, U.S. Bureau of Reclamation, Central Valley Project, October 1977.

51. Personal Communication, California Department of Water Resources, October 1977.

52. Personal Communication, Pacific Gas and Electric Company, October 1977. 
This report was done with support from the Department of Energy. Any conclusions or opinions expressed in this report represent solely those of the author(s) and not necessarily those of The Regents of the University of California, the Lawrence Berkeley Laboratory or the Department of Energy. 